Utilização de objetos de aprendizagem para melhoria da qualidade do ensino de hierarquia de memória

\author{
Fernando Tiosso
}





\title{
Utilização de objetos de aprendizagem para melhoria da qualidade do ensino de hierarquia de memória
}

\section{Fernando Tiosso}

Orientadora: Profa. Dra. Sarita Mazzini Bruschi

\begin{abstract}
Dissertação apresentada ao Instituto de Ciências Matemáticas e de Computação - ICMC-USP, como parte dos requisitos para obtenção do título de Mestre em Ciências - Ciências de Computação e Matemática Computacional. VERSÃO REVISADA.
\end{abstract}

USP - São Carlos

Maio de 2015 
Ficha catalográfica elaborada pela Biblioteca Prof. Achille Bassi

e Seção Técnica de Informática, ICMC/USP, com os dados fornecidos pelo(a) autor(a)

Tiosso, Fernando
T594u Utilização de objetos de aprendizagem para melhoria da qualidade do ensino de hierarquia de memória / Fernando Tiosso; orientadora Sarita Mazzini Bruschi. -- São Carlos, 2015.

$102 \mathrm{p}$.

Dissertação (Mestrado - Programa de Pós-Graduação em Ciências de Computação e Matemática Computacional) -- Instituto de Ciências Matemáticas e de Computação, Universidade de São Paulo, 2015.

1. Educação. 2. objetos de aprendizagem. 3 . Arquitetura de computadores. 4. Simulação. 5. Memória cache. I. Bruschi, Sarita Mazzini, orient. II. Título. 


\section{AGRADECIMENTOS}

Agradeço primeiramente a Deus, pela oportunidade de concluir mais esta etapa da minha vida, tornandome mais preparado para o cumprimento de minhas funções na sociedade.

Minha eterna gratidão à minha família, minha esposa, minha mãe, meu pai e ao Nino. Minha esposa, pelo seu apoio, dedicação e suas palavras de amor e sabedoria nos momentos mais difíceis! Obrigado Fabricia! Minha mãe, pela sua atenção e dedicação constantes. Nunca mediu esforços para ajudar-me em todos os desafios, sempre com muito amor e carinho! Obrigado Dona Rosinha! Meu pai já não se encontra mais em nosso plano, mas tenho certeza absoluta que sempre estará comigo, dentro do meu coração! Obrigado Lioooo! E o Nino? Esse é o amigo de todas as horas, faça chuva ou sol, sempre está do meu lado. Um grande exemplo de vida, pois mesmo depois que perdeu toda a visão, continua alegre e disposto! Obrigado Nino!

Agradeço à minha orientadora de Mestrado, Prof. ${ }^{a}$ Sarita Mazzini Bruschi. Muito obrigado por acreditar em mim e confiar no meu trabalho! Sempre muito paciente e colaborativa, norteou criteriosamente todo o projeto com suas sábias palavras e atitudes. Como sou aluno de dedicação parcial, soube respeitar minhas limitações, principalmente de tempo, e de forma clara conduziu-me para obter o resultado final que se apresenta neste projeto.

Agradeço também ao Prof. ${ }^{\circ}$ Paulo Sérgio Lopes de Souza por toda sua excelente orientação. Junto com a Prof. ${ }^{a}$ Sarita, também acreditou e confiou em mim! Algumas palavras que ele me falou durante esses três anos juntos, levarei para o resto de minha vida. Muito obrigado!

Aos professores Ellen Francine Barbosa e Seiji Isotani, agradeço pelas colaborações realizadas ao longo de todo esse tempo. Aos demais professores e amigos do ICMC, que de alguma forma contribuíram para a conclusão deste trabalho, muito obrigado!

Aos alunos da graduação e pós-graduação que participaram dos experimentos realizados com o objeto de aprendizagem, muito obrigado por cederem uma parte preciosa de seu tempo colaborando conosco!

Não posso deixar de agradecer ao SENAC Araraquara, representado pela gerente Fernanda Maria Fornazieri Musto. Muito obrigado por atender meus pedidos de liberação em virtude dos meus compromissos com o mestrado.

Por fim, agradeço às agências de fomento FAPESP, CAPES e CNPq pelo apoio financeiro a este trabalho. 


\section{EPÍGRAFE}

Se é a crise que abre caminho para o progresso, ela deixa de ser crise.

Mokiti Okada 


\section{RESUMO}

O ensino e a aprendizagem do tema hierarquia de memória não são tarefas simples, pois muitos assuntos que são abordados em teoria podem desmotivar a aprendizagem em virtude de sua complexidade. Este projeto de mestrado apresenta a transformação do módulo de memória cache da ferramenta Amnesia em um objeto de aprendizagem, que visa facilitar a construção do conhecimento através da simulação da estrutura e da funcionalidade da hierarquia de memória na arquitetura von Neumann de uma maneira mais prática e didática. Este processo permitiu que funcionalidades existentes na ferramenta fossem readequadas e novas funcionalidades desenvolvidas. Aliado a isso, planos de aula e questionários de avaliação e usabilidade também foram concebidos, validados e implementados junto à elaboração de um tutorial para descrever o funcionamento do novo objeto. Os estudos experimentais realizados analisaram dois aspectos: o primeiro, se o objeto de aprendizagem melhorou, de fato, a aprendizagem dos alunos no assunto memória cache; o segundo, a opinião dos alunos em relação à utilização do objeto. Após a análise e avaliação dos resultados obtidos nos experimentos, foi possível demonstrar uma evolução na aprendizagem quando se fez o uso do objeto, além de se perceber que a motivação dos alunos em utilizar outros objetos de aprendizagem aumentou. 


\section{ABSTRACT}

The teaching and learning of memory hierarchy are not simple tasks, because many subjects that are covered in theory may demotivate learning because of its complexity. This Master's thesis presents the process of transformation of the cache memory module of Amnesia tool in a learning object, aiming to facilitate the construction of knowledge by simulating the structure and functionality of memory hierarchy of von Neumann architecture in a more practice and didactic way. This process allowed existing features in the tool to be adequate and new features developed. In addition, lesson plans and questionnaires of assessment and usability have also been designed, validated and implemented and a tutorial to describe the operation of the new object was developed. Experimental studies have examined two aspects: the first, if the learning object improved, in fact, the students' learning in the subject cache memory; the second, students' opinions regarding the use of the object. After the analysis and evaluation of the results obtained in the experiments, was possible show an evolution in learning when it made the use of the object, and also to perceive that students' motivation to use other learning objects increased. 


\section{SUMÁRIO}

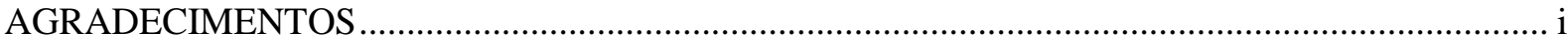

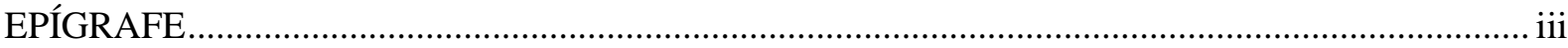

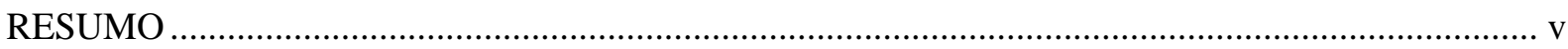

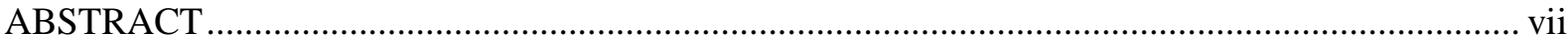

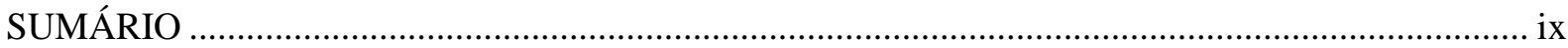

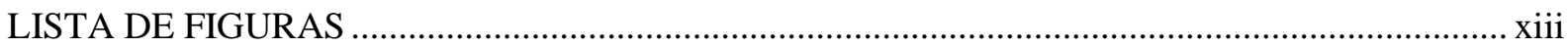

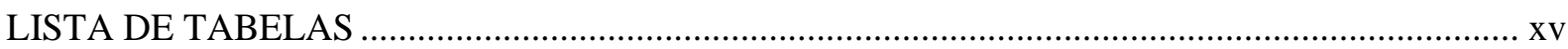

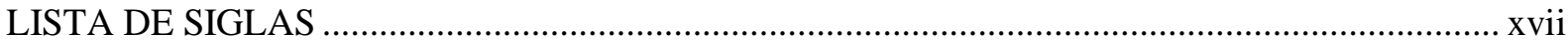

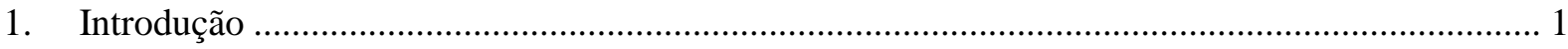

1.1. Contextualização e motivação........................................................................................... 1

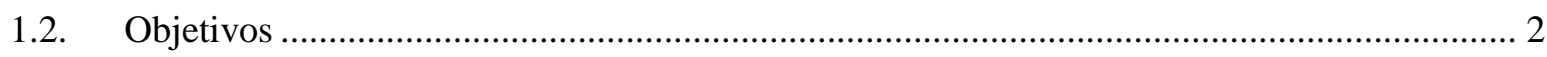

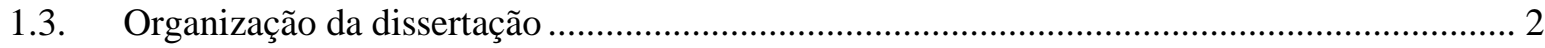

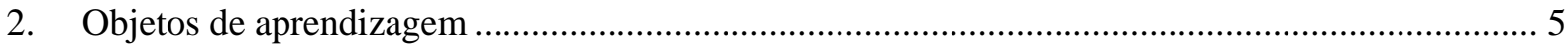

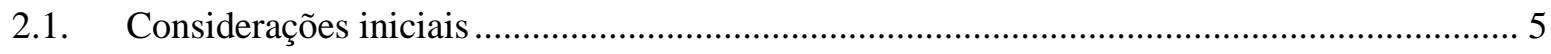

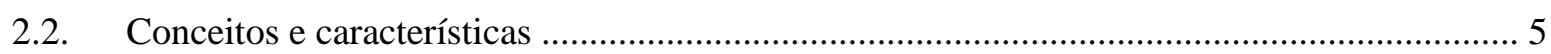

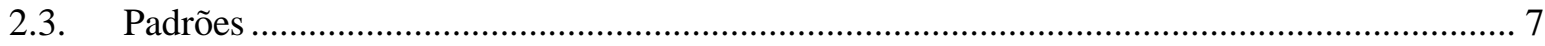

2.3.1. Learning Object Metadata (LOM) .......................................................................... 7

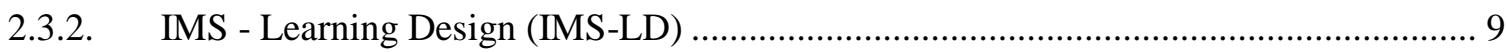

2.3.3. Sharable Content Object Reference Model (SCORM) ............................................... 11

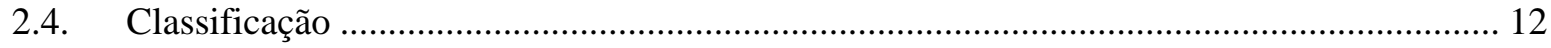

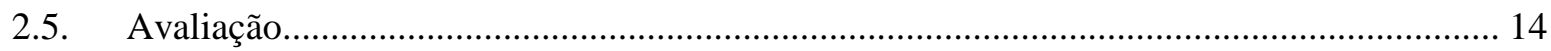

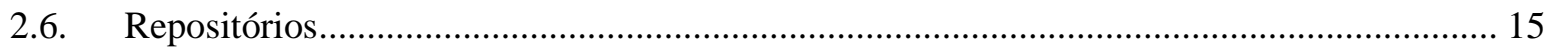

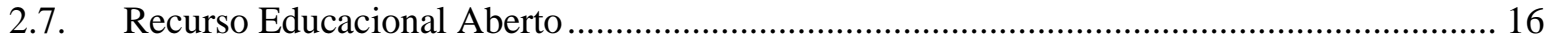

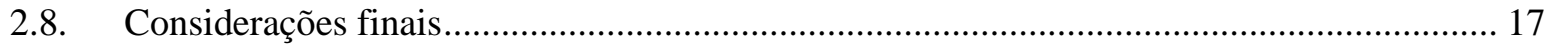

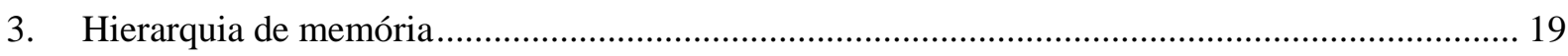

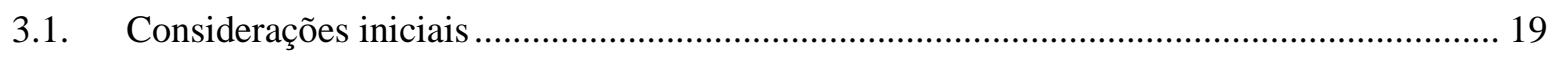

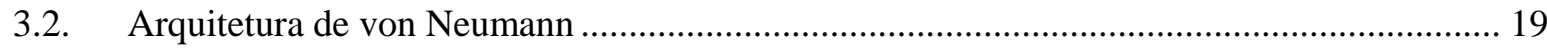

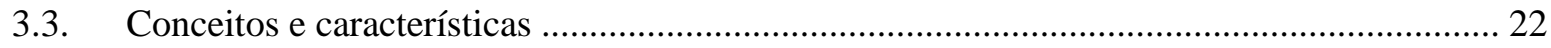

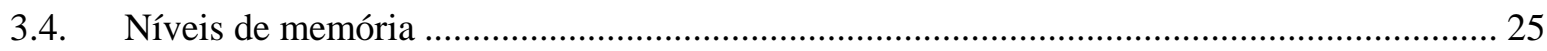

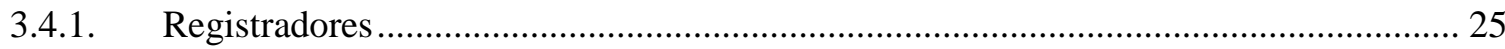




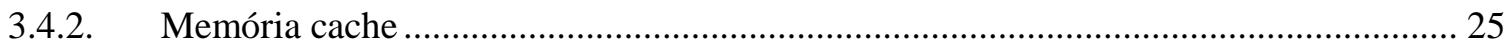

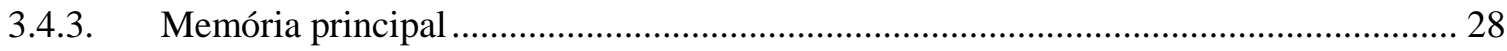

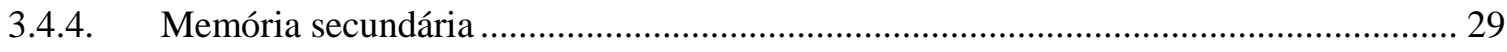

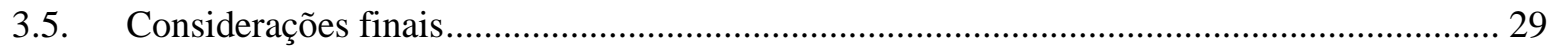

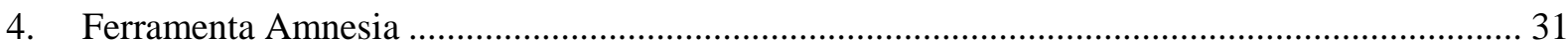

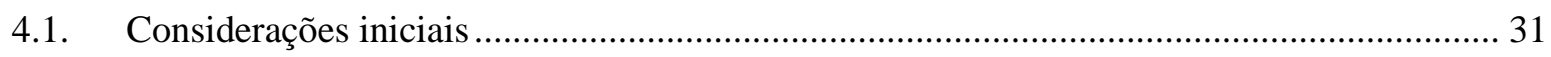

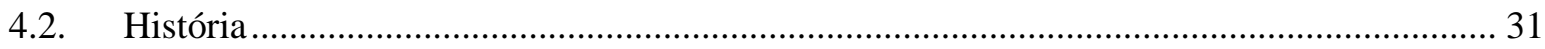

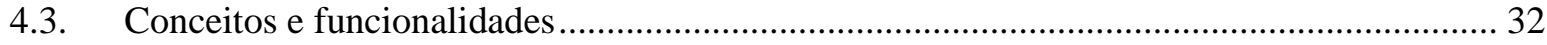

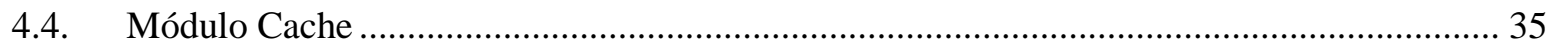

4.5. Outras ferramentas para simulação de memória .................................................................. 40

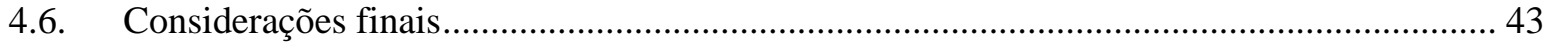

5. Transformação da ferramenta Amnesia em um objeto de aprendizagem .................................... 45

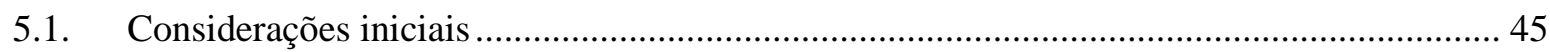

5.2. Desenvolvimento de planos de aula e questionários de avaliação e usabilidade .................. 45

5.3. Implementações e readequações de funcionalidades .............................................................. 48

5.4. Armazenamento em um repositório de objeto de aprendizagem ......................................... 51

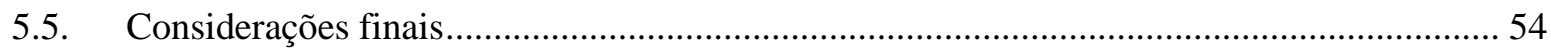

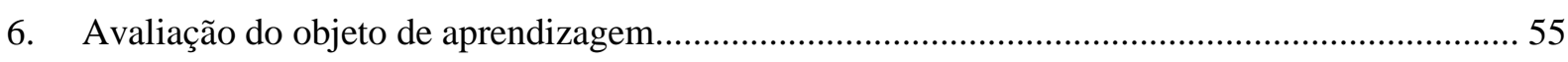

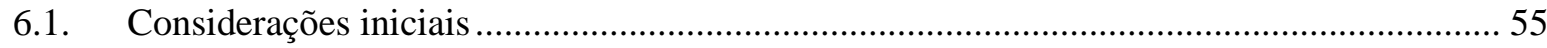

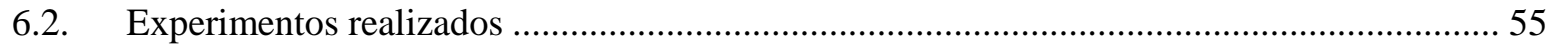

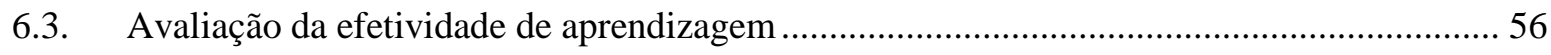

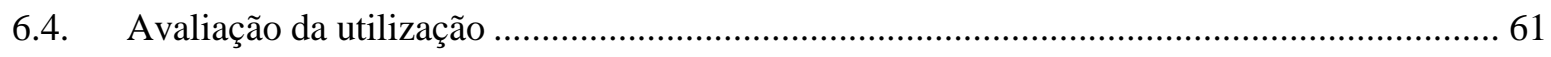

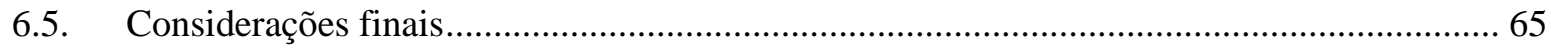

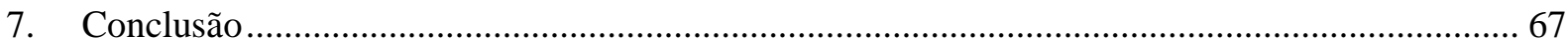

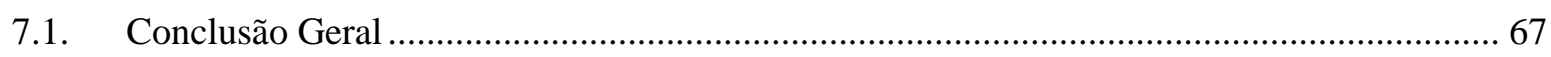

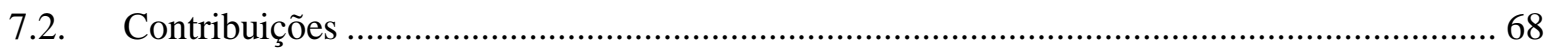

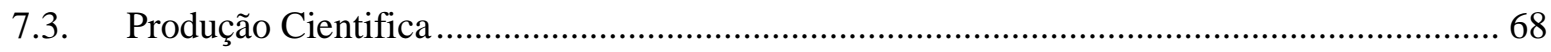

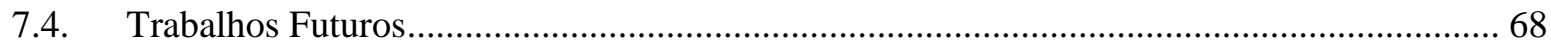

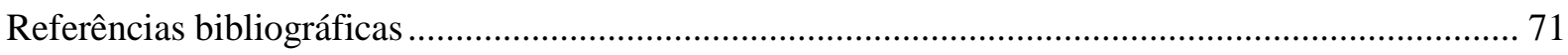

Apêndice A - Plano de aula utilizado nas aulas práticas .................................................................... 75

Apêndice B - Arquivo de arquitetura com configurações de memória cache ....................................... 87

Apêndice C - Programa representado pelo seu arquivo de rastro (trace) ……........................................ 89

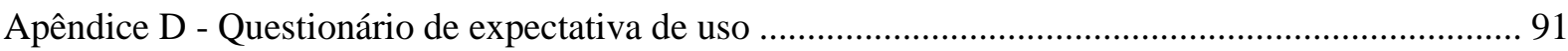




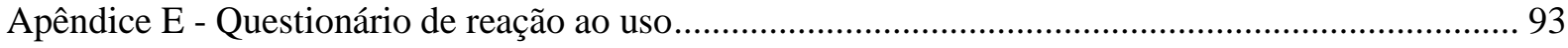

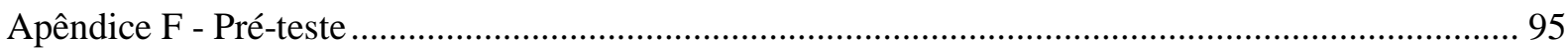

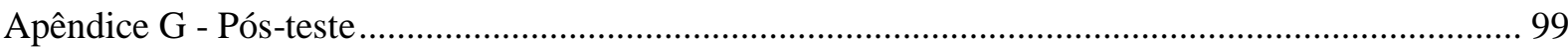




\section{LISTA DE FIGURAS}

Figura 1 - Estrutura de um objeto de aprendizagem (Singh, 2001)................................................... 6

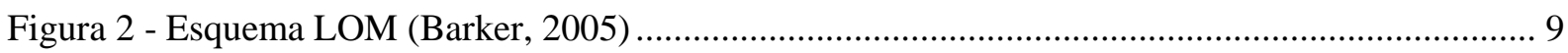

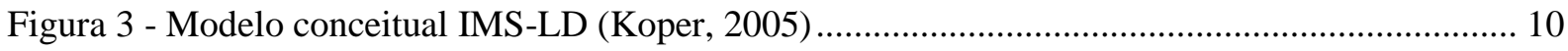

Figura 4 - Conjunto de especificações do SCORM (Fabre et al, 2013) ............................................... 12

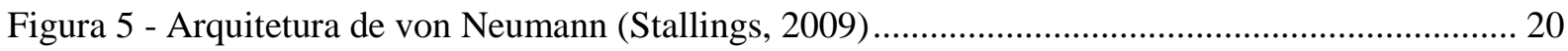

Figura 6 - Diagrama funcional da unidade central de processamento (Mano, 1998)............................ 20

Figura 7 - Diagrama de estado do ciclo de instrução (Stallings, 2009) ................................................ 21

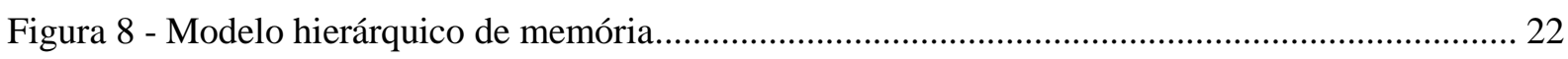

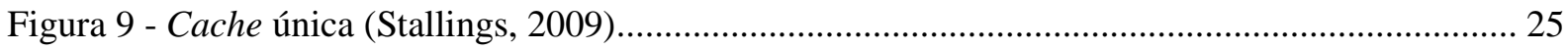

Figura 10 - Cache em três níveis: L1, L2, L3 (Stallings, 2009).......................................................... 26

Figura 11 - a) Funcionamento da ferramenta Amnesia a partir de um código binário b) Funcionamento da ferramenta Amnesia a partir de um arquivo de rastro ................................................................... 33

Figura 12 - Execução passo a passo de um arquivo de rastro .............................................................. 34

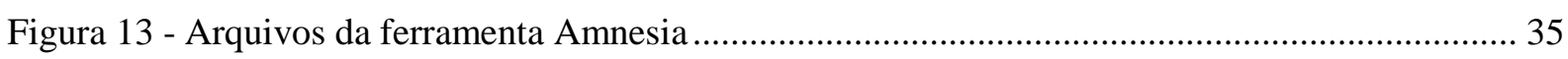

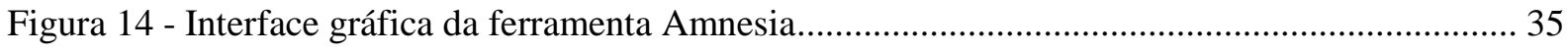

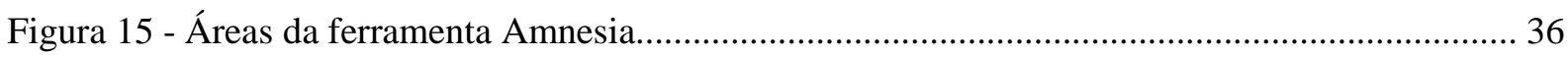

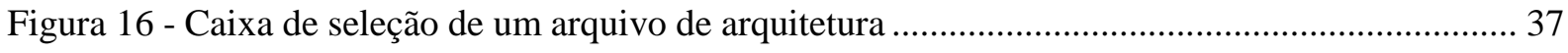

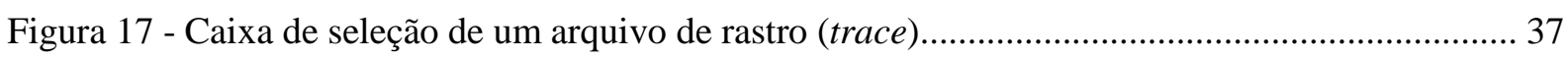

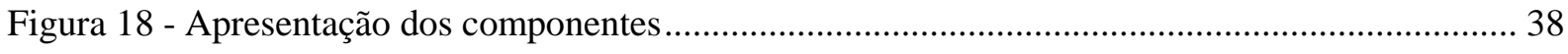

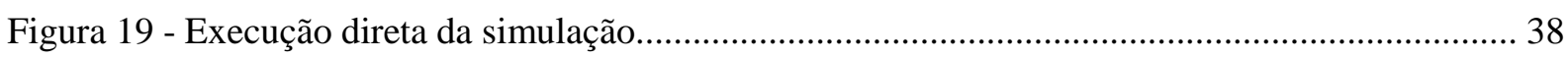

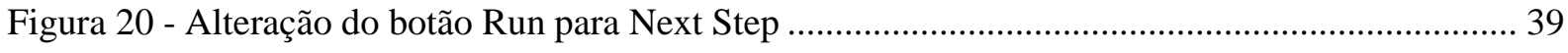

Figura 21 - Execução passo a passo de uma simulação e seu $\log$ detalhado......................................... 39

Figura 22 - Simulador de memória cache KSH (Rodrigues, 2012) .................................................... 40

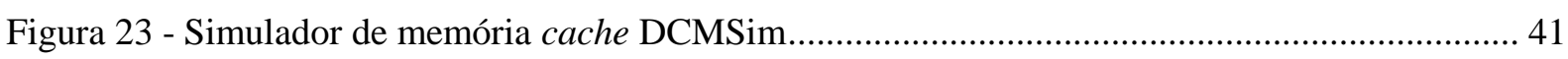

Figura 24 - Simulador de memória cache LBGCache (Netto, 2007) ................................................... 41

Figura 25 - Simulador de memória cache MSCSim (Coutinho, 2006) ................................................ 42

Figura 26 - Simulador de memória cache CacheSim (Rodrigues, 2012) ............................................ 42

Figura 27 - Ferramenta Amnesia (antes do processo de transformação) .............................................. 48

Figura 28 - Objeto de aprendizagem de memória cache (depois do processo de transformação) ........ 48

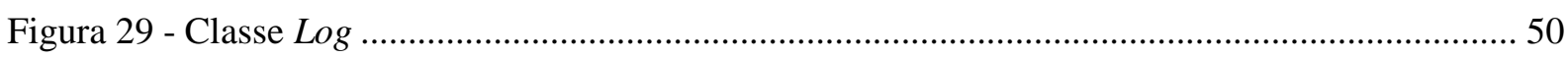

Figura 30 - Procedimento responsável pela impressão do $\log$ no terminal de saída ............................. 50

Figura 31 - Tela de cadastro do objeto de aprendizagem no MERLOT …........................................... 52

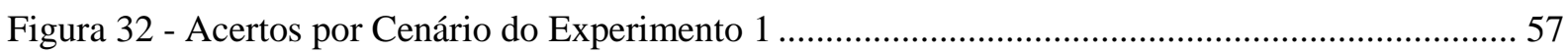

Figura 33 - a) Acertos no Cenário 1 do Experimento 1 - b) Acertos no Cenário 2 do Experimento 1. 57

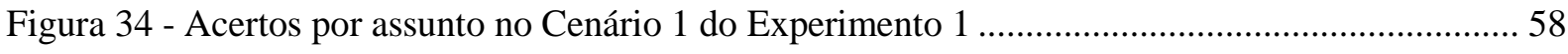

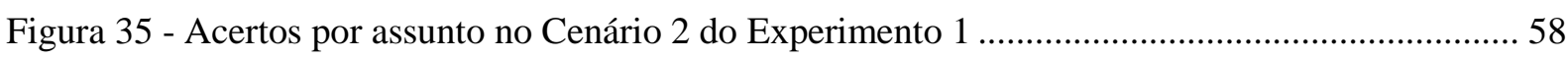

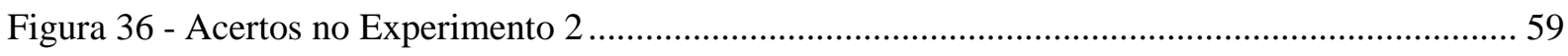

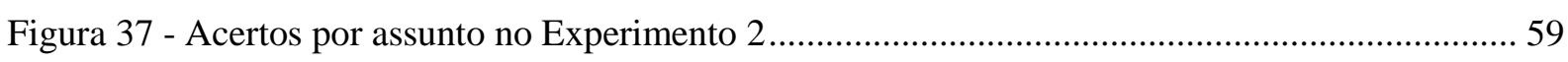




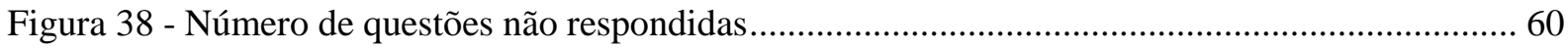

Figura 39 - Número de questões não respondidas no pré-teste e corretamente respondidas no pós-teste

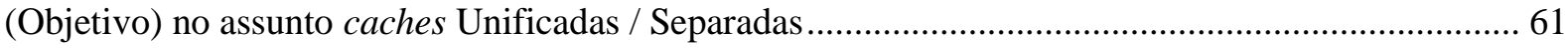




\section{LISTA DE TABELAS}

Tabela 1 - Tabela de características dos simuladores 43

Tabela 2 - Tabela de metadados cadastros no padrão LOM para o repositório MERLOT .................... 53

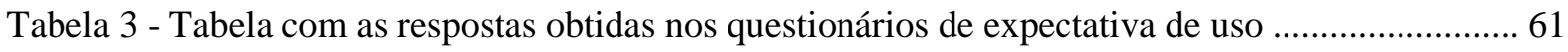

Tabela 4 - Tabela com as respostas obtidas nos questionários de reação ao uso .................................... 62 


\section{LISTA DE SIGLAS}

\begin{tabular}{|c|c|}
\hline ADL & Advanced Distributed Learning \\
\hline ALU & Arithmetical and Logical Unit \\
\hline $\mathrm{BIOE}$ & Banco Internacional de Objetos Educacionais \\
\hline BRASSCOM & $\begin{array}{l}\text { Associação Brasileira das Empresas de Tecnologia da Informação } \\
\text { Comunicação }\end{array}$ \\
\hline CEdMA & Computer Education Management Association \\
\hline CEFET-RN & Centro Federal de Educação Tecnológica do Rio Grande do Norte \\
\hline $\mathrm{CI}$ & Contador de Instruções \\
\hline $\mathrm{CP}$ & Contador de Programa \\
\hline CPU & Central Processing Unit \\
\hline $\mathrm{CU}$ & Control Unit \\
\hline DCMSim & Didactic Cache Memory Simulator \\
\hline DoD & Department of Defense \\
\hline DRAM & Dinamic Random Access Memory \\
\hline $\mathrm{E} / \mathrm{S}$ & Entrada e Saída \\
\hline EML & Educational Modelling Language \\
\hline FIFO & First In First Out \\
\hline GPL & General Public License \\
\hline GSDC & Grupo de Sistemas Digitais e Computacionais \\
\hline GUI & Graphical User Interface \\
\hline $\mathrm{HD}$ & Hard Disk \\
\hline HTML & HyperText Markup Language \\
\hline $\mathrm{I} / \mathrm{O}$ & Input e Output \\
\hline ICMC & Instituto de Ciências Matemáticas e de Computação \\
\hline IEEE & Institute of Electrical and Electronics Engineers \\
\hline IMS & Instructional Management Systems \\
\hline IMS-GLC & IMS Global Learning Consortium \\
\hline IMS-LD & IMS Learning Design \\
\hline IR & Instruction Register \\
\hline JAR & Java ARchive \\
\hline LabVirt & Laboratório Didático Virtual \\
\hline LASDPC & Laboratório de Sistemas Distribuídos e Programação Concorrente \\
\hline LCMS & Learning Content Managment Systems \\
\hline LD & Learning Design \\
\hline LFU & Least Frequently Used \\
\hline LMS & Learning Managment System \\
\hline LOM & Learning Object Metadata \\
\hline LOR & Learning Object Repository \\
\hline
\end{tabular}


Rede Latinoamericana de Portais Educacionais

RI

Registrador de Instrução

RIVED

Rede Interativa Virtual de Educação

ROA

Repositórios de Objetos de Aprendizagem

SCO's

Sharable Content Objects

SCORM

Sharable Content Object Reference Model

SEED

Secretaria de Educação a Distância

SMA

Sistemas Multiagentes

SRAM

Static Random Access Memory

STI

Sistema Tutor Inteligente

TI

Tecnologia da Informação

TLB

Translation Lookaside Buffer

$\mathrm{UC}$

Unidade de Controle

UCP

Unidade Central de Processamento

UEPG

Universidade Estadual de Ponta Grossa

ULA

Unidade Lógica e Aritmética

UML

Unified Modeling Language

USP

Universidade de São Paulo

XML 


\section{Introdução}

\subsection{Contextualização e motivação}

A profissão de professor do ensino superior é um grande desafio. Ao mesmo tempo que se deve transmitir uma grande quantidade de informação para um aluno que já se encontra no nível superior, deve-se também atentar para o modo como esse conhecimento é transmitido. Um fator de desmotivação dos alunos que ingressam na universidade é a falta de conexão entre teoria e prática. Isso pode fazer com que os alunos abandonem os cursos, provocando evasão e prejuízo para o país, dado que se sabe que o mercado está carente de profissionais bem qualificados (BRASSCOM, 2015).

No ensino de computação, a disciplina de Organização de Computadores Digitais I (SSC0112) do ICMC/USP possui um tópico extenso e complexo: hierarquia de memória. Diversos assuntos devem ser abordados em sala de aula, tais como: transferência dos dados entre os níveis de memória, princípios de localidade espacial e temporal, processador, memória cache e memória virtual. Abordar essa teoria sem a participação efetiva do aluno no processo de aprendizagem pode limitar a sua compreensão e dificultar o acompanhamento da disciplina.

Visando diminuir a distância entre teoria e prática, alguns recursos vêm sendo desenvolvidos para melhorar as formas de aprendizado nas disciplinas dos cursos de tecnologia de informação e dentre estes recursos destacam-se os "Objetos de Aprendizagem" ou Learning Objects. De acordo com Learning Objects Metadata Workgroup, objetos de aprendizagem podem ser definidos por: "Qualquer entidade, digital ou não digital, que possa ser utilizada, reutilizada ou referenciada durante o aprendizado apoiado por tecnologias." (LTSC, 2013)

Os estudos sobre objetos de aprendizagem iniciaram-se em 1996, quando o grupo denominado Learning Technology Standards Committee (LTSC) do Institute of Electrical and Electronics Engineers (IEEE) começou a desenvolver e promover padrões de tecnologia instrucional (LTSC, 2013). Com estes padrões, universidades, empresas e outras organizações ao redor do mundo encontraram uma maneira de garantir a interoperabilidade de suas tecnologias de ensino, especificamente seus objetos de aprendizagem.

Os objetos de aprendizagem caracterizam-se pelo seu reuso, facilidade de adaptação e manutenção. Devem ser bem estruturados e podem ser divididos em três partes: objetivos, conteúdo instrucional, e prática e feedback (Singh, 2001).

Com o objetivo de apoiar o ensino de hierarquia de memória de sistemas computacionais tornando o aluno mais participativo no processo de aprendizagem, desenvolveu-se a ferramenta Amnesia. No entanto, sem a preocupação de ser ou se tornar um objeto de aprendizagem.

Idealizada em 2004 e atualizada no período entre 2007 e 2008 por alunos da Universidade de São Paulo (USP) em projetos de iniciação científica, a ferramenta foi modelada utilizando a linguagem 
$\mathrm{UML}^{1}$, implementada utilizando o padrão $\mathrm{MVC}^{2}$ e organizada em três módulos: processador, memória cache e memória virtual (Oliveira et al, 2008b).

A motivação deste projeto de mestrado é transformar o módulo de memória cache da ferramenta Amnesia em um objeto de aprendizagem e introduzi-lo na área de educação, mais especificamente na disciplina de Organização de Computadores Digitais I (SSC0112) do ICMC/USP. Através da realização de experimentos e da descrição de seus resultados em forma de publicações, pretende-se comprovar e reafirmar como um objeto de aprendizagem influencia positivamente na educação, estimulando a interação dos alunos e mantendo-os inseridos no contexto do aprendizado, participativos da construção do seu próprio conhecimento.

\subsection{Objetivos}

Visando melhorar a qualidade do ensino, especificamente nas disciplinas de Organização de Computadores Digitais I (SSC0112) do ICMC/USP, este projeto de mestrado propõe-se a analisar a ferramenta Amnesia, responsável por simular uma hierarquia de memória, e validar sua utilização como um meio para facilitar o aprendizado do tema "hierarquia de memória".

Inicialmente, o funcionamento de cada módulo da ferramenta, bem como seu funcionamento global, foi minunciosamente certificado. Em seguida, analisou-se sua aplicabilidade como um objeto de aprendizagem visando melhorar a qualidade do ensino, especificamente do item memória cache.

Assim, o objetivo principal baseou-se na transformação do módulo de memória cache da ferramenta Amnesia em um objeto de aprendizagem. Para isso, funcionalidades existentes foram readequadas e novas funcionalidades desenvolvidas, testadas e implementadas. Planos de aula e questionários de avaliação e usabilidade também forma concebidos, validados e implementados junto à elaboração de um tutorial para descrever o funcionamento do objeto. Por fim, o objeto de aprendizagem foi devidamente cadastrado em um repositório de objetos de aprendizagem, melhorando sua visibilidade no meio acadêmico.

É importante ressaltar que este objeto de aprendizagem não tem o propósito de substituir o professor. Muito pelo contrário, ele será utilizado como um apoio no aprendizado, visando tornar a participação do aluno mais efetiva na disciplina e no seu próprio aprendizado.

\subsection{Organização da dissertação}

Esta dissertação está dividida em seis capítulos, conforme descrição a seguir.

No Capítulo 1 é realizada uma introdução do assunto, contextualizando-o e indicando a motivação junto com os objetivos deste projeto.

No Capítulo 2 são descritas as características dos objetos de aprendizagem, padrões de desenvolvimento, formas de classificação e avaliação, questões referentes ao seu armazenamento e a sua distribuição.

\footnotetext{
${ }^{1}$ UML - Unified Modeling Language: Linguagem utilizada para modelar a estrutura, comportamento e arquitetura dos aplicativos, além dos processos de negócios e a estrutura dos dados.

${ }^{2}$ MVC - Model View Controller: Arquitetura ou padrão de desenvolvimento que permite dividir as funcionalidades de um sistema em camadas, facilitando a resolução de um problema.
} 
No Capítulo 3 é abordado o tópico que fará parte do conteúdo do objeto de aprendizagem: hierarquia de memória. Serão descritos a arquitetura de von Neumann, conceitos, características e os níveis de memória envolvidos em uma hierarquia.

No Capítulo 4 é descrita a ferramenta Amnesia, mais especificamente o módulo de memória cache, desde sua idealização até seu estado atual: um objeto de aprendizagem. Conceitos, funcionalidades e um exemplo de simulação também são abordados, além de comparações com outras ferramentas que possuem funções similares.

No Capítulo 5 é apresentado, em detalhes, o processo de transformação da ferramenta Amnesia em um objeto de aprendizagem, proporcionando o entendimento de cada uma das ações realizadas.

No Capítulo 6 são apresentados os resultados dos experimentos realizados, através da avaliação da efetividade de aprendizagem e da avaliação da utilização do objeto de aprendizagem.

Finalmente, é apresentada a conclusão do projeto, suas contribuições e as propostas para trabalhos futuros. 


\section{Objetos de aprendizagem}

\subsection{Considerações iniciais}

Conforme citado no capítulo introdutório, um fator de desmotivação dos alunos que ingressam na universidade é a falta de conexão entre teoria e prática. Possivelmente, este aluno desmotivado acabará se desinteressando ou até mesmo desistindo de seu curso, contribuindo para a elevação da carência de profissionais bem qualificados no país (BRASSCOM, 2015).

Dentre os recursos utilizados para diminuir a distância entre teoria e prática, tornando o aprendizado mais didático, destacam-se os objetos de aprendizagem.

Com o objetivo de prover conhecimento sobre os objetos de aprendizagem, este capítulo descreve seus conceitos, características, padrões de desenvolvimento, classificação, avaliação, questões relacionadas ao armazenamento, distribuição e a abertura de seu código, tornando-o um recurso educacional aberto.

\subsection{Conceitos e características}

De acordo com o grupo Learning Technology Standards Committee (LTSC), objetos de aprendizagem podem ser definidos por: "Qualquer entidade, digital ou não digital, que possa ser utilizada, reutilizada ou referenciada durante o aprendizado suportado por tecnologias" (LTSC, 2013). Outra definição, menos abrangente, refere-se aos objetos de aprendizagem como "Quaisquer recursos digitais que possam ser (re)utilizados como apoio ao ensino" (Wiley, 2000a).

O termo objeto de aprendizagem foi popularizado em 1994 por Wayne Hodgins no projeto Computer Education Management Association $\left(\mathrm{CEdMA}^{3}\right)$. No entanto, os estudos mais aprofundados começaram em 1996 com o grupo LTSC, onde se iniciou o desenvolvimento e a promoção de padrões de tecnologia instrucional. Com estes padrões, universidades, empresas e outras organizações ao redor do mundo teriam uma maneira de garantir a interoperabilidade de suas tecnologias de ensino, especificamente seus objetos de aprendizagem (Polsani, 2003 e Friesen, 2005).

Um objeto de aprendizagem pode ser comparado a um átomo, pois um pequeno objeto pode ser combinado com outros formando um maior. É interessante que os objetos combinados sejam do mesmo contexto, possuindo conteúdos que se relacionam entre si (Wiley, 2000b). Eles também podem ser comparados com uma coleção de materiais digitais, combinados com um objetivo de aprendizado, claro e mensurável ou projetados para dar suporte ao processo de aprendizagem (Johnson, 2003).

Quanto à estrutura, um objeto de aprendizagem pode conter três partes bem definidas, conforme visualizado na Figura 1. A primeira delas são os objetivos, que possibilitam demonstrar ao aprendiz o que ele poderá aprender a partir do estudo desse objeto, ressaltando ou não uma lista de conhecimentos prévios necessários para um bom aproveitamento de todo o conteúdo disponível. A segunda refere-se ao conteúdo instrucional, responsável por apresentar todo o material didático necessário para que, após

\footnotetext{
${ }^{3}$ CEdMA: Organização de treinamento para executivos, gerentes e profissionais de TI formada por mais de 150 membros que representam mais de 60 empresas de tecnologia.
} 
o término da atividade, o aluno possa atingir os objetivos citados. Por fim, a prática e o feedback evidenciam que ao final de cada atividade com o objeto, julga-se necessário que o aprendiz verifique se o seu desempenho atingiu ou não as expectativas. Caso não tenha atingido, este aprendiz deve ter a liberdade para voltar a utilizar-se do objeto quantas vezes necessário (Singh, 2001).

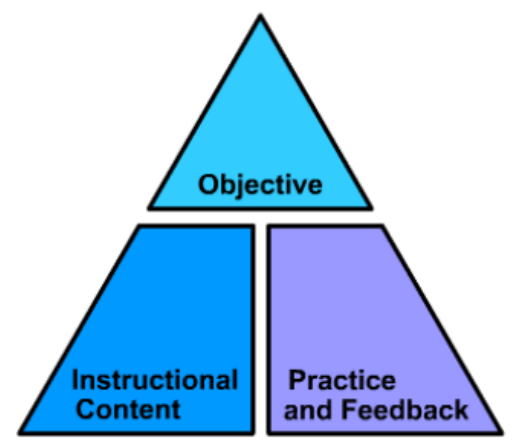

Figura 1 - Estrutura de um objeto de aprendizagem (Singh, 2001)

Os objetos de aprendizagem também se destacam pelas suas características: flexibilidade, facilidade para atualização, customização, interoperabilidade, melhora significativa da sua qualidade de ensino e usabilidade e facilidade de indexação e procura (Longmire, 2000).

A flexibilidade permite a reutilização dos objetos em vários contextos de aprendizagem, sem necessariamente depender de algum tipo de manutenção. Já a facilidade para atualização permite que os mesmos objetos sejam utilizados em diversos momentos, com atualizações em tempo real relativamente simples, desde que todos os dados relativos a estes objetos estejam em um mesmo banco de informações.

A customização propõe que os objetos de aprendizagem devem ser modulares, permitindo a recombinação de seus conteúdos de diferentes formas. Com a modularização, a ideia de utilização dos objetos em um curso, especialização ou qualquer outro tipo de qualificação torna-se real, sendo que cada entidade educacional pode utilizar-se deles e arranjá-los da maneira que mais se adequar ao seu meio.

A interoperabilidade cria um padrão para armazenagem dos objetos de aprendizagem, permitindo a reutilização dos objetos não apenas em nível de plataforma de ensino e sim em nível de mundo. A ideia de um objeto que possa ser criado e utilizado em qualquer plataforma de ensino em todo o mundo aumenta ainda mais suas vantagens de utilização.

A melhora significativa da qualidade indica que a partir do momento que um objeto é reutilizado e melhorado ao longo do tempo, sua consolidação cresce de uma maneira espontânea.

Finalmente, a indexação e procura visa facilitar a ideia de se procurar por um objeto necessário, pois quando uma pessoa necessitar de determinado objeto para completar seu conteúdo programático, a padronização dos mesmos e a utilização de assinaturas digitais tendem a criar uma maior facilidade em procurar e encontrar objetos com as mesmas características em qualquer banco de objetos que esteja disponível para eventuais consultas.

A relação entre as áreas de atuação dos profissionais que participam da construção e do desenvolvimento de um objeto de aprendizagem também deve ser ressaltada. Tomando-se como exemplo o objeto de aprendizagem que foi construído neste projeto de mestrado, destacam-se: profissionais da área de informática que são responsáveis pela programação do objeto, profissionais da área de organização e arquitetura de computadores que são responsáveis pelo conteúdo do objeto, e profissionais da área de ensino que são responsáveis pelas estratégias educacionais. A comunicação entre estes profissionais deve ser cuidadosamente controlada de forma a não gerar conflitos e equívocos 
entre as informações, preocupando-se com a interatividade do objeto de forma que o usuário final não tire conclusões inadequadas ou tenha sensações de monotonia ao utilizá-lo (Nascimento, 2007).

Mediante às definições e citações apresentadas sobre os objetos de aprendizagem, ressalta-se um consenso entre elas: o objeto de aprendizagem deve possuir um objetivo muito bem definido, sendo capaz de proporcionar a evolução do raciocínio de quem o utiliza, além de ser facilmente reutilizado em outros contextos de aprendizagem.

Assim, o modelo de objetos de aprendizagem visa facilitar e melhorar a qualidade do ensino, proporcionando aos professores, alunos e administradores diversas ferramentas facilitadoras.

\subsection{Padrões}

Com base em pesquisas realizadas sobre o processo de desenvolvimento e utilização de um objeto de aprendizagem, foram propostos alguns modelos e normas técnicas para facilitar sua condução e gerenciamento.

Nesta seção, os modelos e as normas técnicas serão referenciados como padrões, que devem prover um conjunto de atributos necessários para permitir que os objetos de aprendizagem sejam analisados, desenvolvidos, testados, aplicados, avaliados, localizados e gerenciados. Dentre esses padrões destacam-se: Learning Object Metadata (LOM), IMS-Learning Design (IMS-LD) e o Sharable Content Object Reference Model (SCORM), os quais serão detalhados a seguir.

\subsubsection{Learning Object Metadata (LOM)}

Mantido pela IEEE LTSC desde 1997, o LOM caracteriza-se por um conjunto de dados denominado metadados que visa facilitar a descoberta, localização, avaliação e aquisição dos objetos de aprendizagem por alunos, professores e processos automatizados de software. Dentre os metadados podem ser citados: tipo de objeto, autor, proprietário, termos de distribuição, formato e atributos pedagógicos (LTSC, 2013).

São características do LOM (LTSC, 2013):

- Permitir que os alunos ou instrutores pesquisem, encontrem, avaliem, adquiram e utilizem um determinado objeto de aprendizagem;

- Permitir o compartilhamento de objetos de aprendizagem através de qualquer tecnologia suportada nos sistemas de aprendizagem;

- Permitir o desenvolvimento de objetos de aprendizagem em unidades que podem ser combinadas e decompostas de maneira significativa;

- Permitir que os agentes computacionais disponibilizem de forma automática e dinâmica aulas personalizadas para um determinado aluno;

- Permitir que vários objetos de aprendizagem se comuniquem dentro de um ambiente de aprendizagem aberto e distribuído;

- Ativar a documentação do ensino existente ou objetivos de desempenho associados com objetos de aprendizagem;

- Facilitar e sustentar a distribuição dos objetos de aprendizagem permitindo economia de recursos; 
- Habilitar a aprendizagem em organizações governamentais, públicas e privadas, para expressar conteúdos educacionais e padrões de desempenho em um formato padronizado, independente do conteúdo em si;

- Fornecer aos pesquisadores normas para a seleção e compartilhamento dos dados sobre a aplicabilidade e eficácia de objetos de aprendizagem;

- Definir um padrão que é simples, mas extensível a vários domínios de modo a ser mais facilmente e amplamente adotado e aplicado;

- Apoiar a segurança necessária e autenticação para a distribuição e utilização dos objetos de aprendizagem.

A estrutura de dados que descreve o esquema LOM é formada por nove categorias, as quais são descritas a seguir e podem ser visualizadas na Figura 2 (LTSC, 2013):

1. General: contém informações gerais que descrevem o objeto de aprendizagem como um todo;

2. LifeCicle: agrupa características de evolução do objeto de aprendizagem, dos estados pelos quais passou, e sobre as pessoas ou entidades que contribuíram para essa evolução;

3. Meta-metadata: registros de metadados que armazenam informações de quem criou o objeto de aprendizagem, como, quando, e com quais referências;

4. Technical: descreve as características técnicas do objeto de aprendizagem, tais como: formato, tamanho e tecnologia;

5. Educational: descreve as características pedagógicas do objeto de aprendizagem, tais como: interatividade, tipo de recurso e papel do usuário;

6. Rights: descreve os direitos sobre a propriedade intelectual e condições de uso do objeto de aprendizagem;

7. Relations: define as relações entre o objeto de aprendizagem com outros objetos de aprendizagem;

8. Annotations: fornece informações sobre o uso educacional do objeto de aprendizagem, por quem e quando essas informações foram criadas. Aqui, destaca-se a importância do compartilhamento de avaliações e sugestões referentes ao uso;

9. Classification: descreve o objeto de aprendizagem em relação a um sistema de classificação especial.

A utilização do LOM possibilita criar descrições bem estruturadas dos objetos de aprendizagem para facilitar sua descoberta, localização, avaliação e aquisição por alunos, professores ou processos automatizados de software, bem como a adaptação das descrições de seus recursos, para atender necessidades específicas de um indivíduo ou comunidade.

Este padrão específico para metadados de objetos de aprendizagem é utilizado pela maioria dos repositórios de objetos de aprendizagem. O LOM possui 79 campos que descrevem a sintaxe e semântica de um objeto de aprendizagem, porém os repositórios utilizam em torno de 25 (Macedo, 2010). 


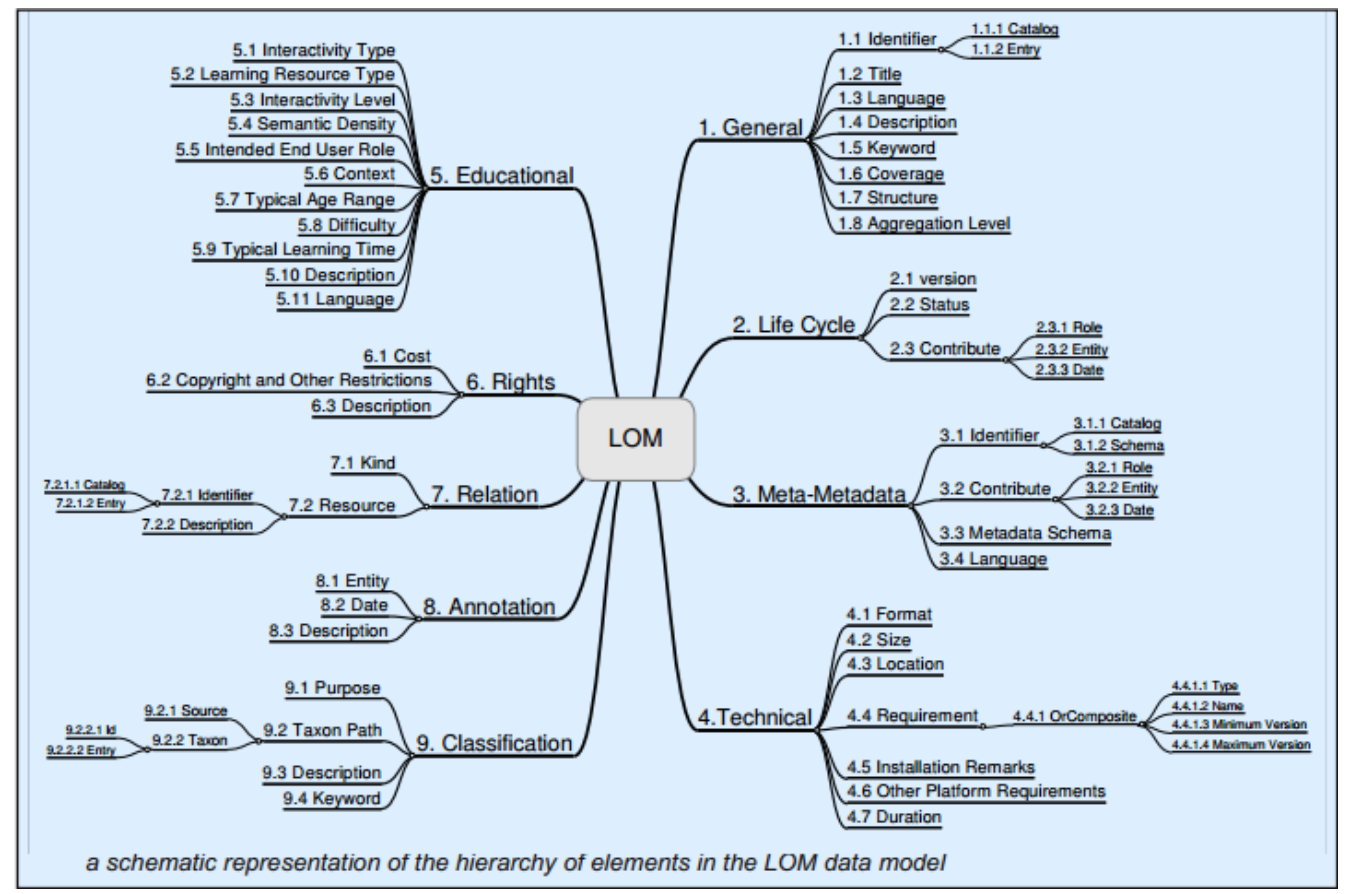

Figura 2 - Esquema LOM (Barker, 2005)

\subsubsection{IMS - Learning Design (IMS-LD)}

O Instructional Management System Learning Design (IMS-LD) foi desenvolvido com base na Educational Modelling Language (EML) (Sá et al, 2007).

A EML foi proposta para descrever, de forma integral, uma ampla variedade de processos e modelos pedagógicos existentes, não apenas o seu conteúdo, mas também as regras, as relações, as interações e as atividades que ocorrem entre os agentes do processo educacional. Além disso, ela deveria ser compreendida tanto por indivíduos quanto por máquinas (Koper e Manderveld, 2004). Embasado nesta linguagem, o IMS-LD 1.0 foi especificado oficialmente em fevereiro de 2003 pelo IMS Global Learning Consortium (IMS-GLC) como uma metalinguagem com o objetivo de permitir a modelagem de processos de aprendizagem com a utilização de tecnologia (Filatro e Piconez, 2008).

A missão do IMS GLC é manter as organizações participantes de seu consórcio trabalhando juntas para defender o uso da tecnologia no apoio à transformação da educação e aprendizagem desenvolvendo padrões de interoperabilidade abertos. Dentre as organizações participantes deste consórcio encontramse: fornecedores de hardware e software, instituições educacionais, editoras, agências governamentais, integradores de sistemas e provedores de conteúdo multimídia (IMS, 2003).

O IMS-LD é uma especificação voltada para descrever cenários de aprendizagem, permitindo que estes sejam apresentados aos alunos e compartilhados entre os sistemas. Pode, também, descrever uma variedade de modelos pedagógicos, incluindo o trabalho em grupo e aprendizagem colaborativa, em que o indivíduo conhecerá qual atividade deve realizar e qual recurso utilizar, além de toda a coordenação do processo de aprendizagem. Para esta abordagem, o IMS-LD depende de três elementos distintos: papéis que as pessoas desempenham, atividades que serão realizadas e quais ambientes serão utilizados. Esses elementos são mais conhecidos como a tríade Papel, Atividade e Ambiente (IMS, 2003).

A seguir, encontram-se listados os elementos básicos de seu modelo conceitual e na Figura 3 pode-se observar como eles se relacionam (IMS, 2003): 
a. Objetivos de aprendizagem (learning-objectives): objetivo ou meta;

b. Pré-requisitos (prerequisites): conhecimento prévio;

c. Componentes (components): possuem os papéis (roles), que podem ser o de aluno (learner) ou apoio (staff), atividades (activities), que podem ser de aprendizagem (learning-activity) ou suporte (support-activity);

d. Método (method): especifica o processo de ensino aprendizagem, quais papéis executam quais atividades e em qual ordem.

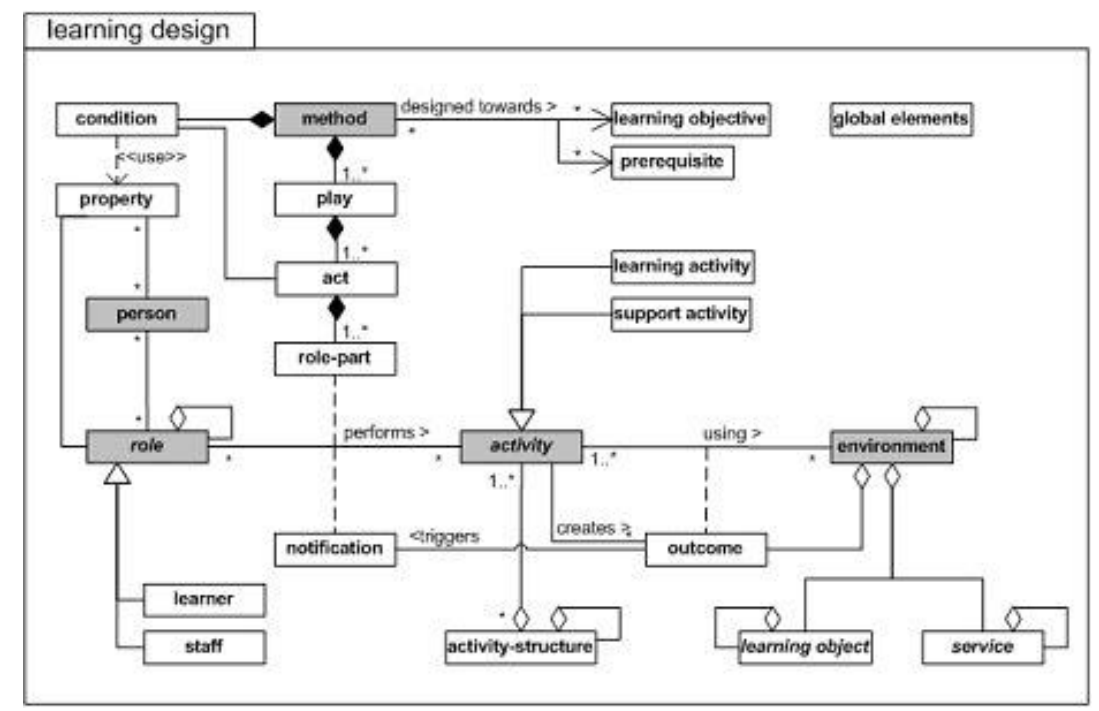

Figura 3 - Modelo conceitual IMS-LD (Koper, 2005)

Para conhecer e utilizar o padrão IMS-LD é necessário o estudo de três documentos (IMS, 2003):

1. IMS Learning Design Best Practice and Implementation Guide: guia de implementação e melhores práticas;

2. IMS Learning Design XML Binding: representação XML;

3. IMS Learning Design Information Model: modelo de informação integrado com a EML.

Já a sua implementação, pode ser dividida em três níveis:

- Nível A: contém os elementos essenciais da metalinguagem, onde os papéis, atividades, ambiente, método, objetivos e pré-requisitos são apresentados da mesma maneira para todos os usuários;

- Nível B: permite o uso de propriedades genéricas e condições com sequenciamento mais complexo das atividades; as propriedades permitem coletar informações de cada usuário, seja aluno ou professor, facilitando o rastreamento e a análise da aprendizagem. Adiciona ao Nível A, a personalização mediante o usuário;

- Nível C: acrescenta a estrutura de notificação entre componentes e papéis, permitindo que atividades sejam definidas dinamicamente e notificações possam ser enviadas aos usuários.

O IMS-LD permite outro tipo de reusabilidade além da reusabilidade de objetos, que é a reusabilidade de atividades de aprendizagem em outros contextos. O modelo especificado pelo Learning Design (LD) descreve todo o processo da unidade de aprendizagem, inclusive a abordagem pedagógica, 
por compreender o processo completo, proporcionando a construção de unidades de aprendizagem mais consistentes e coerentes (Dutra e Tarouco, 2006).

\subsubsection{Sharable Content Object Reference Model (SCORM)}

As normas técnicas contidas no padrão SCORM são de responsabilidade da Advanced Distributed Learning (ADL), resultado da Ordem Executiva Presidencial 13.111, assinada em 12 de janeiro de 1999 pelo presidente dos Estados Unidos da América, William J. Clinton.

A Ordem Executiva tinha o objetivo de garantir que Department of Defense (DoD) e outros funcionários federais dos Estados Unidos obtivessem o máximo proveito dos avanços tecnológicos, a fim de adquirir as habilidades de aprendizagem necessárias para ter sucesso em um ambiente de trabalho em constante mudança. Sua intenção era oferecer oportunidades de formações flexíveis para os trabalhadores e explorar como programas de treinamento federais, iniciativas e políticas podem melhor apoiar a aprendizagem ao longo da vida através do uso de tecnologia de aprendizagem (ADL, 2015). A

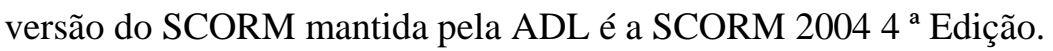

Os objetivos do SCORM são (ADL, 2015):

- Padronizar o modo como os conteúdos se relacionam com os sistemas que os suportam para permitir o rastreamento das ações do aluno dentro de um objeto de aprendizagem;

- Reutilizar os objetos de aprendizagem, permitindo ao autor do conteúdo utilizá-los em diferentes contextos;

- Flexibilizar a aprendizagem, uma vez que podem ser construídos vários percursos de aprendizagem e estes disponibilizados a diferentes alunos;

- Ser portável ao permitir que os Sharable Content Objects (SCO's) sejam independentes da plataforma ou do repositório utilizados.

As especificações do SCORM são abordadas em quatro livros, os quais podem ser visualizados na Figura 4 (ADL, 2015):

1. The SCORM Overview: visão geral das normas técnicas;

2. The SCORM Content Aggregation Model: dicionário de metadados, empacotamento, estrutura de conteúdo e o XML dos metadados dos pacotes;

3. The SCORM Runtime Environment: indica os materiais apresentados na aprendizagem e informações do progresso do curso;

4. The SCORM Sequecing \& Naviagtion: determina como deve ser seguida a sequência dos conteúdos durante o curso. 


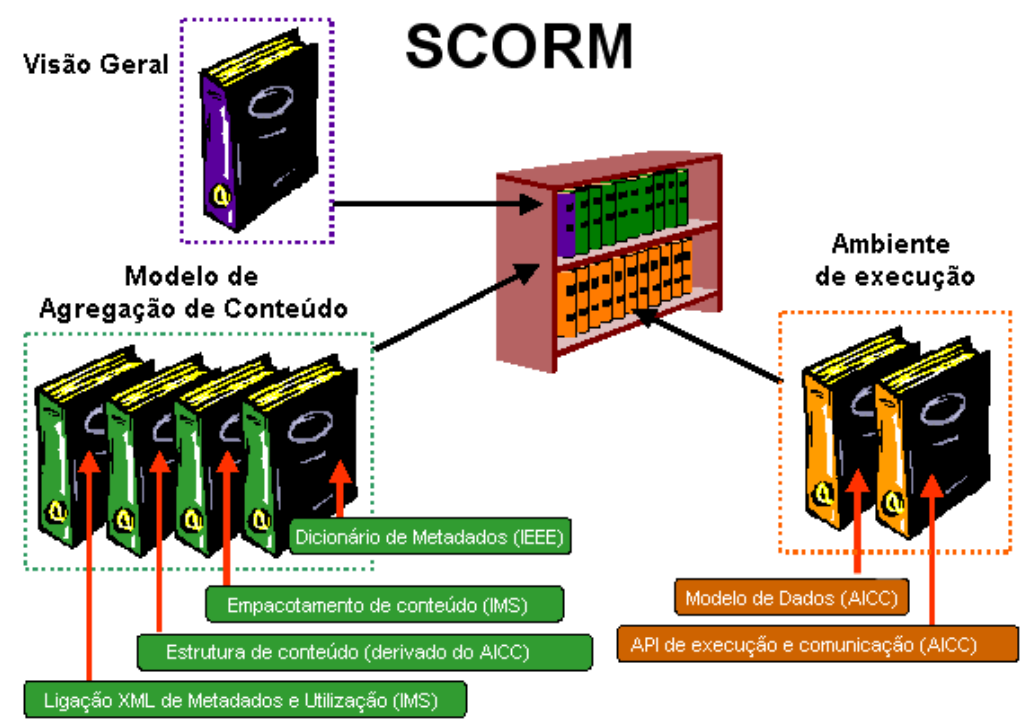

Figura 4 - Conjunto de especificações do SCORM (Fabre et al, 2013)

Salienta-se que o SCORM proporciona aos programadores como escrever seu código para que ele possa ser bem integrado com outro software ou objeto de aprendizagem, referenciando outros padrões já existentes e indicando a maneira correta de utilizá-los em conjunto. Além disso, também é importante compreender que o SCORM não faz referência ao projeto instrucional ou a qualquer outra preocupação pedagógica, ou seja, ele é puramente uma norma técnica focada em boas práticas de desenvolvimento e controle de conteúdo.

O SCORM é inadequado para documentar a interação entre as partes do ciclo de vida de um objeto de aprendizagem, pois ele não oferece a capacidade de capturar os processos de pensamento de projetistas de aprendizagem. Para resolver estas duas questões, o prolongamento do SCORM foi recomendado para apoiar a documentação mais rica de conteúdos de aprendizagem adicionando um quadro ontológico que captura informações sobre as partes interessadas e decisões pedagógicas que são feitas durante o processo de projeto (Baker, 2006).

\subsection{Classificação}

Existem várias formas de se classificar um objeto de aprendizagem e um dos motivos que a classificação se faz importante é a correta disponibilização do objeto em um repositório. Durante a realização de uma pesquisa de um objeto de aprendizagem em um repositório, a classificação poderá ser um dos fatores determinantes para que ele seja localizado e utilizado.

Os objetos de aprendizagem podem ser classificados em quatro tipos, definidos pelos seus objetivos educacionais (Longmire, 2000):

- Objetos instrucionais: lições, workshops, seminários, artigos, estudos de casos;

- Objetos de colaboração: exercícios monitorados, chats, salas de discussão;

- Objetos de prática: simulações de hardware e de software ou modelagens;

- Objetos de avaliação: certificações e testes. 
Wiley (2000b) classifica os objetos de aprendizagem em cinco tipos definidos pelo grau de qualidade das suas apresentações:

- Fundamental: Um recurso digital individual que não se combina com qualquer outro;

- Combinação fechada: Um número pequeno de recursos digitais combinados e projetados no momento da criação, pelo criador do objeto de aprendizagem, cujos objetos de aprendizagem constituintes não são individualmente acessíveis para reutilização do objeto de aprendizagem de combinação fechada propriamente;

- Combinação aberta: Um maior número de recursos digitais combinados por um computador em tempo real quando um pedido é feito para o objeto, onde os objetos de aprendizagem constituintes são diretamente acessíveis para reutilização do objeto de combinação aberta;

- Gerador de apresentação: Lógica e estrutura geradora para combinar ou gerar e combinar objetos de aprendizagem de nível mais baixo (Fundamental e tipos de Combinação Fechada). Os objetos de aprendizagem geradores de apresentação podem usar objetos acessíveis da rede e combiná-los ou gerar objetos e combiná-los para criar apresentações para uso em referência, instrução, prática e testes (os objetos de aprendizagem geradores de apresentação devem ser capazes de passar mensagens para outros objetos com lógica de avaliação quando utilizados para prática ou testes);

- Gerador de instrução: Lógica e estrutura para combinar objetos de aprendizagem (Fundamental, tipos de Combinação fechada e Gerador de apresentação) e avaliar a interação do aluno com essas combinações, criadas para sustentar a exemplificação das estratégias instrucionais abstratas.

Para Churchill (2007), a classificação dos objetos educacionais deve ser realizada com base nas seguintes categorias: objetos de apresentação, prático, simulação, modelo conceitual, informação ou representação contextual.

Outra proposta de classificação é apresentada por Battistella (2009), onde os objetos de aprendizagem podem ser separados em duas categorias:

- Não-Interativo (NI): Objetos de aprendizagem com conteúdo estático, tais como:

○ Texto: texto estático, com imagens ou não. Exemplos: documentos em geral como $p d f s$, hipertextos, etc.;

- Multimídia: conteúdo que utiliza recursos de vídeo ou som.

- Interativos (I): necessitam da interação do usuário para serem utilizados, tais como:

○ Avaliativos: fornecem um feedback sobre a aprendizagem do usuário. Exemplos: questionários;

- Exploratórios: permitem alterar o estado do objeto para obter novas saídas e informações. Exemplos: jogos, simulações, mapas conceituais;

- Colaborativos: vários usuários podem interagir com o objeto ao mesmo tempo. Exemplos: chats.

O repositório de objetos de aprendizagem Multimedia Educational Resource for Learning and Online Teaching ${ }^{4}$ (MERLOT) classifica seus objetos em vinte tipos de materiais, sendo eles: animação, apresentação, artigo de jornal aberto, atribuição, coleção, curso on-line, do repositório de objetos de

\footnotetext{
${ }^{4}$ http://www.merlot.org/merlot/index.htm.
} 
aprendizagem, ePortfolio, estudo de caso, ferramenta de avaliação, ferramenta de desenvolvimento, ferramenta de rede social, livro aberto, material de referência, material de treinamento, prática, questionário/teste, simulação, tutorial e workshop.

Já o Banco Internacional de Objetos Educacionais ${ }^{5}$ (BIOE) possui oito tipos de classificação para seus objetos: animações/simulações, áudios, experimentos práticos, hipertextos, imagens, mapas, softwares educacionais e vídeos.

De acordo com as informações fornecidas nessa seção, ressalta-se que a classificação pode conduzir a melhores indicadores de qualidade para os objetos de aprendizagem além de apoiar os recursos envolvidos em seu processo de desenvolvimento.

\subsection{Avaliação}

A avaliação de um objeto de aprendizagem, bem como do assunto por ele abordado, é a base para que o professor possa entender se as metodologias de ensino adotadas estão surtindo efeito no processo de aprendizagem.

Um objeto pode ser avaliado quanto à sua usabilidade, expectativa e reação de uso, níveis de aprendizagem, interatividade e qualidade de desenvolvimento, conforme as pesquisas de Campos e Rocha (1993), Souza et al (2007) e Romero et al (2009).

Foi constatado que não se pode avaliar um objeto de aprendizagem considerando somente sua beleza gráfica (Vieira, 1999), pois diversos problemas referentes à qualidade de conteúdo, abordagem superficial, ausência de contextualização e a falta de utilização de exemplos e analogias na utilização de objetos de aprendizagem dificultam o entendimento do aluno, bem como a fixação do conteúdo trabalhado (Almeida, 2010).

Outro ponto interessante encontra-se nos estudos de Gama e Scheer (2007), que trata do armazenamento dos objetos de aprendizagem em seus respectivos repositórios. Durante o processo de armazenamento, cada objeto passa por um processo de avaliação do próprio repositório, mas que, infelizmente, muitas vezes está restrito apenas à análise de aspectos técnicos e operacionais, como identificação de questões referentes à acessibilidade e interoperabilidade, desconsiderando sua contribuição pedagógica.

Assim, Nascimento (2007) apresenta como resultado de sua análise "distância entre a promessa e a realidade” o fato de que: “... Autores e equipes de produção muitas vezes deixam-se influenciar mais pelo potencial lúdico que pelo potencial de aprendizagem de seus produtos, resultando em atividades que entretêm o aluno, mas com os quais eles não aprendem. Outras vezes criam situações monótonas e que não aproveitam o potencial de programação do computador para obter níveis altos de interatividade, visualização e manipulação. Alguns objetos de aprendizagem mostram que não houve preocupação dos autores com o perfil do público alvo, criando contextos inadequados e sem atrativos, o que nada contribui para prender a atenção do aluno nas atividades ..."

Com o objetivo de se avaliar as diversas partes do processo de desenvolvimento e utilização de um objeto de aprendizagem com o propósito de diminuir a distância entre a promessa e a realidade, tanto em Gama (2007) quanto em Santos et al (2012) foram criados diversos questionários e dentre eles destacam-se:

${ }^{5}$ http://objetoseducacionais2.mec.gov.br 
- Em Gama (2007):

○ Avaliação da expectativa de uso;

○ Avaliação da reação de uso;

- Avaliação do objeto de aprendizagem pelo professor;

○ Avaliação do objeto pelo programador;

○ Avaliação da usabilidade;

- Avaliação da aprendizagem pedagógica.

- Em Santos et al (2012):

○ Avaliação da interatividade do objeto de aprendizagem.

Junto a essas avaliações, também é possível analisar a qualidade do desenvolvimento do objeto de aprendizagem através do método Learning Object Review Instrument (LORI) que possui dez critérios e é utilizado por diversos repositórios de objetos, dentre eles o MERLOT. Os critérios avaliados pelo método LORI são (Nesbit et al, 2004):

- Apresentação: estética;

- Apresentação: design para a aprendizagem;

- Precisão de conteúdo;

- Suporte para metas de aprendizagem;

- Motivação;

- Interação: usabilidade;

- Interação: feedback e adaptação;

- Reutilização;

- Cumprimento de metadados e interoperabilidade;

- Acessibilidade.

\subsection{Repositórios}

Os Repositórios de Objetos de Aprendizagem (ROA), que também podem ser chamados de Learning Managment System (LMS), ou Learning Content Managment Systems (LCMS) ou Learning Object Repository (LOR), caracterizam-se por fornecerem uma interface formal através da qual os objetos podem ser cadastrados, armazenados e acessados de forma segura e confiável através de uma plataforma distribuída para a manutenção e preservação do acervo digital. Assim, podem ser entendidos como um banco de dados por meio do qual é possível localizar e obter recursos educacionais para diferentes níveis de ensino e disciplinas.

Para que os objetos sejam corretamente armazenados e facilmente localizados, eles são marcados por identificadores denominados metadados (como os esquemas $\mathrm{xml}$ para troca de dados) que podem variar de acordo com a necessidade de cada repositório. Essas informações devem auxiliar e ampliar as chances de se encontrar o objeto de aprendizagem mais adequado ao conteúdo desejado e a falta de algumas delas, solicitadas pelo repositório, pode ter como consequência a dificuldade de seleção do objeto por parte do usuário.

Algumas características que devem ser encontradas nos repositórios de objetos de aprendizagem são cadastro e armazenamento eficiente, fácil recuperação da informação, disponibilização sob demanda e acervo dinâmico. 
Atualmente, existem vários repositórios de objetos de aprendizagem distribuídos pelo mundo. Dentre estes repositórios, alguns são descritos a seguir:

- MERLOT 6 : Acrônimo de Multimedia Educational Resources for Learning and Online Teaching, caracteriza-se por uma comunidade on-line para armazenamento de recursos projetados principalmente para professores, funcionários e estudantes do ensino superior de todo o mundo que desejam compartilhar seus materiais de aprendizagem e pedagogia;

- LabVirt ${ }^{7}$ : Representa o Laboratório Didático Virtual que é uma iniciativa da parceria realizada entre a Microsoft do Brasil e a Escola do Futuro da USP. Nele, encontram-se simulações, feitas pela equipe do LabVirt a partir de roteiros dos alunos de ensino médio das escolas da rede pública, links para outras simulações e sites interessantes disponibilizados na Internet;

- EduSource ${ }^{8}$ : Representa a Rede de Repositórios de Objetos de Aprendizagem do Canadá que se caracteriza por uma iniciativa de colaboração entre parceiros canadenses do setor público e privado para criar o protótipo de uma rede de trabalho de objetos de aprendizagem interoperáveis. Possui comprometimento com a implementação usando padrões internacionais e dispõe de dois idiomas para comunicação com seus usuários: inglês e francês;

- BIOE' ${ }^{9}$ : Acrônimo de Banco Internacional de Objetos Educacionais que caracteriza-se por um repositório criado pelo Ministério da Educação do Brasil, em parceria com o Ministério da Ciência e Tecnologia, Rede Latinoamericana de Portais Educacionais (RELPE), Organização dos Estados Ibero-americanos (OEI) e outros;

- RIVED ${ }^{10}$ : Representa a Rede Interativa Virtual definida por um programa da Secretaria de Educação a Distância (SEED) que tem por objetivo a produção de materiais pedagógicos digitais.

A construção de um repositório de objetos de aprendizagem possibilita a criação de comunidades virtuais ao seu redor, em que professores e alunos promovem dinâmicas de participação, estimulando trabalhos cooperativos, tornando os aprendizes coautores na produção do conhecimento e do seu próprio aprendizado (Souza, 2005).

\subsection{Recurso Educacional Aberto}

A principal diferença entre um objeto de aprendizagem e um Recurso Educacional Aberto (REA) é o conceito de "abertura". Para que um objeto de aprendizagem se torne um REA, algumas características devem ser devidamente analisadas e incorporadas ao objeto.

Os REAs são materiais de ensino, aprendizado e pesquisa em qualquer suporte ou mídia, que estão sob domínio público ou licenciados de maneira aberta, permitindo que sejam utilizados ou adaptados por terceiros. O uso de formatos técnicos abertos facilita o acesso e o reuso potencial dos recursos publicados digitalmente. REAs podem incluir cursos completos, partes de cursos, módulos,

\footnotetext{
${ }^{6} \mathrm{http} / / / \mathrm{www} . \mathrm{merlot}$. org/merlot/index.htm

${ }^{7}$ http://www.labvirt.fe.usp.br

${ }^{8} \mathrm{http}: / /$ www.edusource.ca/

${ }^{9} \mathrm{http}: / /$ objetoseducacionais2.mec.gov.br

${ }^{10} \mathrm{http} / / /$ rived.mec.gov.br/
} 
livros didáticos, artigos de pesquisa, vídeos, testes, software, e qualquer outra ferramenta, material ou técnica que possa apoiar o acesso ao conhecimento (UNESCO, 2011).

O desenvolvimento de um REA é baseado em três elementos: conteúdos de aprendizado, ferramentas técnicas e recursos para implementação. O conteúdo de aprendizado pode ser exemplificado através dos materiais utilizados em cursos, metodologia de ensino e aprendizado, exercícios, coleções, periódicos e etc. As ferramentas são representadas pelos softwares que visam auxiliar e/ou facilitar o entendimento de um determinado conteúdo. Já os recursos para implementação determinam as licenças para publicar os materiais e/ou ferramentas produzidos. Quanto às licenças, pode-se destacar a CreativeCommons ${ }^{11}$ e a GPL ${ }^{12}$ (REA, 2015).

Para um material ser classificado como um REA, deve apresentar quatro características de liberdade: uso, aprimoramento (adaptação), recombinação e distribuição. Dentre elas, destaca-se a distribuição, onde a liberdade de fazer cópias e compartilhar o material deve ser utilizada com o objetivo de aumentar o conhecimento de todos. Ressalta-se que um conteúdo gratuito não é necessariamente um REA, pois se o usuário final utilizar-se do conteúdo em sua forma original, sem poder adaptá-lo ou recombiná-lo, este conteúdo não poderá ser classificado como um REA (REA, 2015).

O REA visa facilitar o acesso de todas as pessoas ao conhecimento, garantindo a liberdade e a criatividade de produção através do incentivo de práticas de colaboração, participação e compartilhamento. Como o autor do conteúdo compartilha os direitos de utilização da sua obra, bem como os direitos de recombinação e produções de outras obras derivadas, proporciona uma melhora constante do conhecimento utilizado para a educação (REA, 2015).

\subsection{Considerações finais}

Durante o processo de desenvolvimento e utilização de um objeto de aprendizagem, diversos atores e componentes são envolvidos. É importante que este processo seja conduzido seguindo boas práticas, com o objetivo de que erros inesperados sejam minimizados e um maior número de benefícios sejam obtidos, pois uma nova forma de transmissão do conhecimento, mais colaborativa e com maior interação do aluno, poderá ser utilizada com recursos instrucionais atualizados e testados por uma comunidade crescente de usuários.

A construção e a modificação dos objetos permitem que professores e alunos se tornem autores do tema que é estudado e reutilizem componentes para atenderem a uma grande variedade de necessidades de aprendizagem em diversas disciplinas, facilitando o entendimento e adaptando-o ao ritmo de aprendizado dos alunos, objetivando uma melhoria significativa da qualidade do ensino.

No entanto, problemas referentes à qualidade de conteúdo, abordagem superficial, ausência de contextualização e a falta de utilização de exemplos e analogias na utilização dos objetos de aprendizagem, dificultam o entendimento e a fixação dos conceitos abordados.

Com o objetivo de minimizar esses problemas para o objeto de aprendizagem desenvolvido neste projeto de mestrado, o próximo capítulo descreverá a importância de se compreender a necessidade de desenvolver um sistema de memória baseado em uma hierarquia.

\footnotetext{
${ }^{11} \mathrm{http} / / /$ creativecommons.org/

12 http://www.gnu.org/licenses/licenses.html\#GPL
} 


\section{Hierarquia de memória}

\subsection{Considerações iniciais}

Basicamente, a memória de um computador caracteriza-se por todos os dispositivos que permitem o armazenamento de informações de forma temporária (volátil) ou permanente (não volátil). Seria interessante que ela possuísse um tamanho ilimitado e um tempo de acesso muito rápido, mas essas duas características são contraditórias. Quanto maior é a memória, maior é o tempo de acesso para se recuperar um dado nela contido e quanto mais rápido seu acesso, menor é o seu tamanho. No entanto, memórias menores possuem um custo elevado de produção devido ao seu alto desempenho.

Com o objetivo de se criar uma representação de uma memória rápida e ilimitada, com um custo acessível e ágil na manipulação das informações trocadas entre os programas executados em um computador, surgiu a necessidade de se ter ao mesmo tempo diferentes tipos de memória, pois existem momentos em que é necessário manipular rapidamente as informações e em outros momentos, armazenar grandes quantidades de informações.

Implementando-se o sistema de memória em forma de uma hierarquia composta pelos níveis conhecidos como registradores, memória cache, memória principal e secundária, foi possível estabelecer um sistema de memória capaz de armazenar grandes quantidades de informações e ainda manipulá-las rapidamente.

Assim, este capítulo proporcionará o entendimento da necessidade da criação de uma hierarquia de memória, bem como os múltiplos níveis nela existentes e seu processo de comunicação

\subsection{Arquitetura de von Neumann}

Para compreender a necessidade de se desenvolver um sistema de memória baseado em uma hierarquia, primeiramente é necessário conhecer a arquitetura de von Neumann, a qual foi a precursora dos sistemas armazenados, ou seja, sistemas cujas operações realizadas pelo computador são definidas pelos dados e instruções dos programas carregados na memória.

John von Neumann foi um matemático húngaro de origem judaica que teve diversas contribuições importantes nas áreas de arquitetura de computadores, princípios de programação, análise de algoritmos, análise numérica, computação científica, teoria dos autômatos, redes neurais e tolerância às falhas. No entanto, o nome de von Neumann geralmente está associado à ideia da arquitetura de von Neumann, hoje considerada clássica, proposta em 1946 e fundamentada sobre o conceito de programa armazenado, onde o computador foi concebido com uma memória geral que permitiu programas e dados serem armazenados juntos, facilitando o processo de programação (MacRae, 1992).

A arquitetura de von Neumann formalizou o conceito de que um computador é constituído essencialmente de três elementos, conforme descrito a seguir e melhor visualizado na Figura 5 (Stallings, 2009):

- Unidade Central de Processamento (UCP) ou Central Processing Unit (CPU): responsável pela execução das instruções de um determinado programa;

- Memória: responsável pelo armazenamento das instruções e dos dados de um programa; 
- Dispositivos de Entrada e Saída (E/S) ou dispositivos de Input e Output (I/O): responsáveis por traduzir os dados de algum meio externo para o formato interno de armazenamento na memória e vice-versa ou para um formato externo legível para seres humanos.

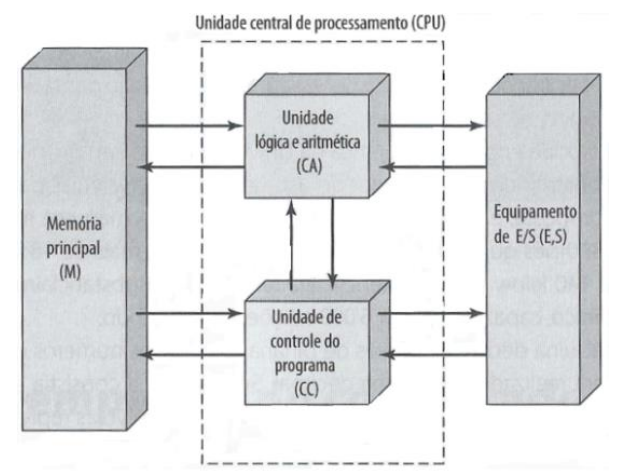

Figura 5 - Arquitetura de von Neumann (Stallings, 2009)

Dentre estes elementos, destaca-se a Unidade Central de Processamento, conforme a Figura 6, que é formada pelos seguintes componentes (Stallings, 2009):

- Unidade de Controle (UC) ou Control Unit (CU): responsável pela interpretação das instruções de um programa e pelo sequenciamento das atividades necessárias para a sua execução;

- Unidade Lógica e Aritmética (ULA) ou Arithmetical and Logical Unit (ALU): responsável pela execução das operações unitárias aritméticas e lógicas;

- Registradores: pequenas áreas de memória interna do processador, utilizados para armazenamento temporário de operandos e resultados de instruções bem como dados sobre o estado interno do processador em relação ao programa em execução;

- Contador de Programa (CP), Contador de Instruções (CI) ou Programm Counter (PC): caracterizado pelo registrador mais importante do processador, pois detém a função de indicar a próxima instrução a ser executada;

- Registrador de Instrução (RI) ou Instruction Register (IR): registrador que contém a instrução que é executada no momento.

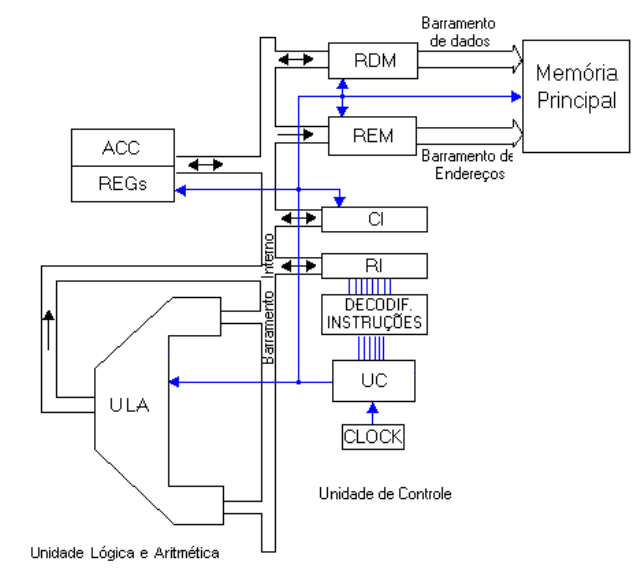

Figura 6 - Diagrama funcional da unidade central de processamento (Mano, 1998) 
Esses componentes comunicam-se através de dispositivos denominados barramentos e a execução de uma determinada instrução, conforme pode ser observado na Figura 7, realiza-se através dos seguintes passos (Stallings, 2009):

1. A unidade de controle obtém a próxima instrução do programa na memória principal; o contador de programa é utilizado para determinar onde a instrução está localizada;

2. A instrução é decodificada para uma linguagem que a unidade lógica e aritmética possa entender;

3. Os operandos de dados requeridos para executar a instrução são carregados da memória e inseridos em registradores;

4. A unidade lógica e aritmética executa a instrução e coloca os resultados em registradores ou na memória.

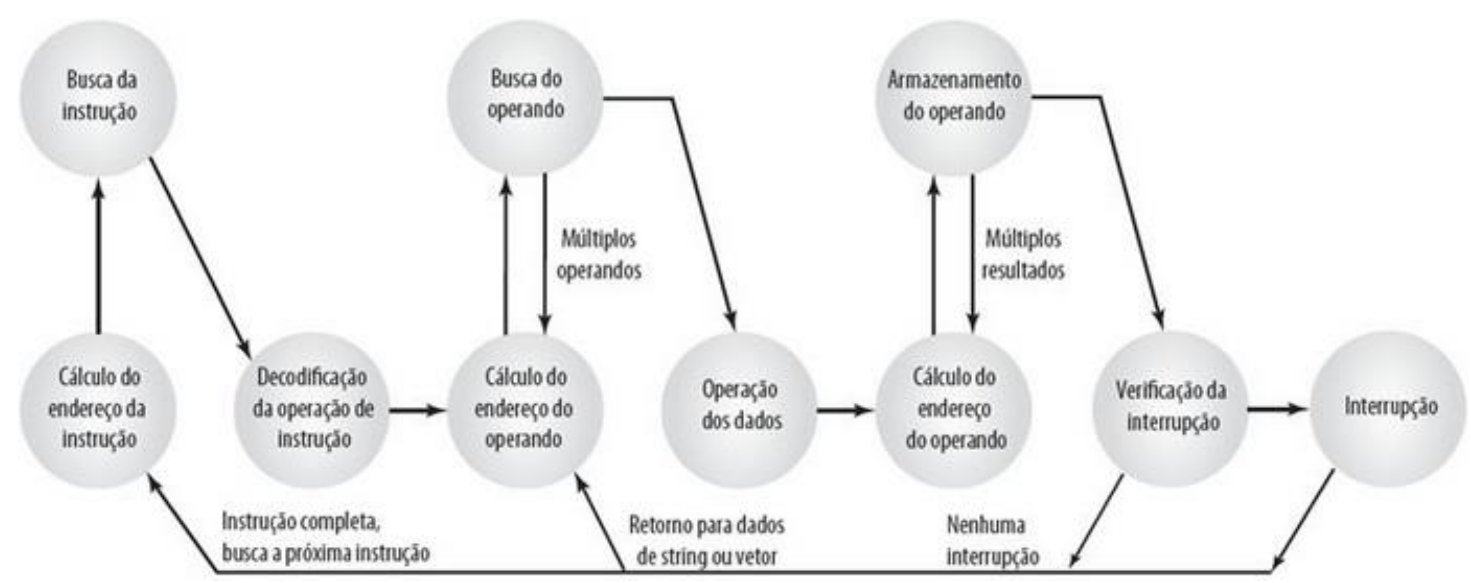

Figura 7 - Diagrama de estado do ciclo de instrução (Stallings, 2009)

Assim, a arquitetura de von Neumann foi e será continuamente influenciada pela evolução tecnológica, cuja implementação tem variado ao longo do tempo devido às evoluções das tecnologias de fabricação dos componentes eletroeletrônicos existentes em um computador.

Uma outra arquitetura que deve ser destacada é a Arquitetura de Harvard, a qual tem como principal característica o sistema de memória armazenar separadamente instruções e dados e com espaços de endereçamento distintos. Isso faz com que os ciclos de busca e execução da instrução possam ser executados em paralelo e independentes. O objetivo da Arquitetura de Harvard é fornecer um melhor desempenho pois o acesso à memória é um dos gargalos. Uma variação da Arquitetura de Harvard é a Arquitetura de Harvard Modificada, a qual relaxa a principal característica de ter memórias distintas para dados e instruções.

A arquitetura considerada neste trabalho é a Arquitetura de von Neumann, que considera instruções e dados sendo armazenados na mesma memória e utilizando o mesmo espaço de endereçamento. 


\subsection{Conceitos e características}

A hierarquia de memória é construída baseando-se em algumas tecnologias, as quais possibilitam a implementação das suas principais características. Nesta subseção serão detalhadas as tecnologias e as implicações nas características.

Existem três tecnologias principais utilizadas na construção de memória (Patterson e Hennessy, 2010):

- Static Random Access Memory (SRAM): utilizada pelos níveis de memória mais próximos ao processador. Caracteriza-se por uma memória de rápido acesso, pouca capacidade de armazenamento e um alto custo de produção;

- Dinamic Random Access Memory (DRAM): localizada um pouco mais afastada do processador do que a SRAM, também é conhecida como memória principal, memória de acesso randômico ou memória RAM. Quando comparada à memória SRAM, possui um custo de produção mais barato, acesso mais lento e capacidade de armazenamento maior, na escala de gigabytes;

- Disco magnético: é o nível da hierarquia de memória mais afastado do processador, caracterizado pelo componente Hard Disk (HD). Quando comparado à DRAM, possui um custo de produção mais barato, acesso mais lento e capacidade de armazenamento maior.

Através da Figura 8 é possível notar que as unidades mais próximas do processador possuem menor capacidade de armazenamento, são mais rápidas na manipulação das informações e devido a sua performance possuem custo elevado de aquisição. Já as unidades que se localizam mais distantes do processador, armazenam maiores quantidades de informações e são mais lentas para manipular os dados, o que justifica seu valor de aquisição mais acessível.

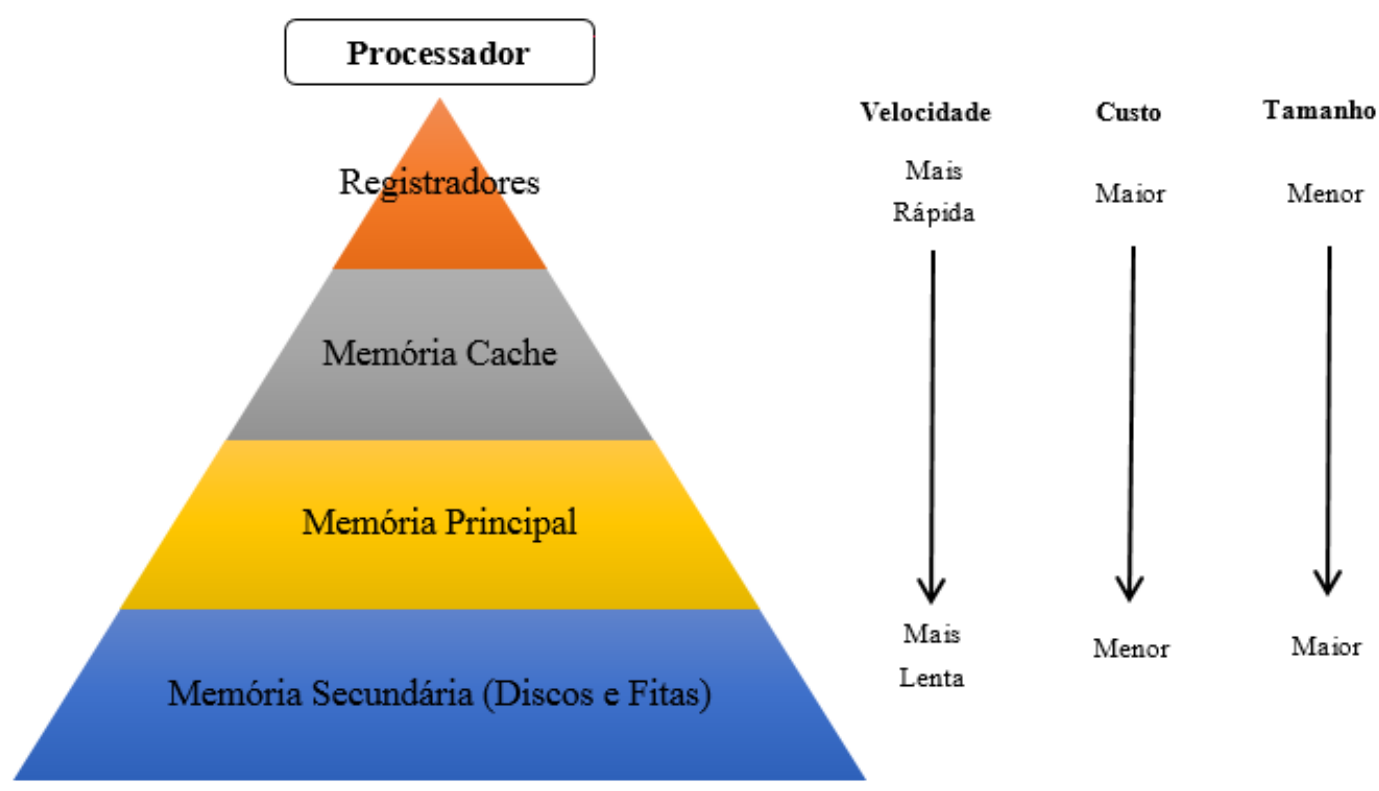

Figura 8 - Modelo hierárquico de memória

Ainda observando-se a Figura 8, nota-se um modelo hierárquico de memória composto por níveis denominados registradores, memória cache, memória principal e memória secundária, os quais são estruturados tendo como base os princípios de localidade temporal e espacial. 
A localidade temporal enfatiza que se um dado ou instrução é referenciado, eles tendem a ser referenciados novamente dentro de um curto espaço de tempo. Já a localidade espacial, enfatiza que se um dado ou instrução é referenciado, outros dados e instruções cujos endereços sejam próximos a eles tendem a ser referenciados também (Patterson e Hennessy, 2010).

Assim, pequenas partes de um programa podem ser carregadas e armazenadas sob demanda em pequenos locais, tornando o processamento mais rápido e menos ocioso, explorando o melhor custo/benefício de cada tecnologia.

A organização do sistema de memória como uma hierarquia faz com que o nível mais próximo do processador seja um subconjunto de qualquer nível mais distante, mas para armazenamento permanente dos dados são utilizados os níveis mais distantes ou mais baixos, localizados na base da pirâmide visualizada na Figura 8.

É importante ressaltar que a manipulação dos dados sempre ocorre entre apenas dois níveis adjacentes ao mesmo tempo e se realiza através da unidade de transferência e dos métodos de acesso (Patterson e Hennessy, 2010).

Para entender a unidade de transferência de uma hierarquia de memória, dois conceitos importantes devem ser descritos (Stallings, 2009):

- Palavra: caracteriza-se pela unidade "natural" de organização da memória. Seu tamanho normalmente é igual ao número de bits utilizados para representar um inteiro e ao tamanho da instrução;

- Unidades endereçáveis: em alguns sistemas a unidade é a palavra. No entanto, muitos sistemas permitem o endereçamento no nível de byte. Contudo, o relacionamento entre o tamanho em bits $\mathrm{A}$ de um endereço e o número $\mathrm{N}$ de unidades endereçáveis é $2^{\mathrm{A}}=\mathrm{N}$.

Desta forma, a unidade de transferência é, para a memória principal, o número de bits lidos ou escritos de uma só vez e não precisa ser igual a uma palavra ou uma unidade endereçável. Já para a memória secundária, os dados são transferidos em uma unidade muito maior que a palavra, denominada blocos, pois o custo relativo para se transferir um grupo de dados (bloco) é menor do que para uma única palavra, além de já antecipar acessos (Stallings, 2009).

Ao tentar acessar um bloco pode-se obter um sucesso, mais conhecido como acerto, ou uma falha. O acerto ocorre quando a informação desejada é encontrada em um nível de memória e a falha ocorre quando esta informação não é encontrada. No caso de uma falha, o nível inferior ao nível que ocorreu a falha é acessado para recuperar a informação desejada e esta operação é repetida até que a informação seja encontrada. Mediante este processo de busca de informações, surgem algumas características que destacam-se por avaliar a performance obtida com a estrutura de hierarquia de memória, tais como (Stallings, 2009):

- Tempo de acesso (latência): para memórias de acesso aleatório, é o tempo decorrido desde o instante em que um endereço é apresentado à memória até o momento em que os dados são armazenados ou se tornam disponíveis para utilização. Já em memórias de acesso não aleatório é o tempo necessário para posicionar o mecanismo de leitura e escrita na posição desejada;

- Tempo de ciclo de memória: aplicável principalmente às memórias de acesso aleatório, caracteriza-se pelo tempo de acesso mais qualquer tempo adicional requerido antes que um segundo acesso seja iniciado. O tempo adicional pode ser necessário para o desaparecimento 
de transientes nas linhas de sinal ou para regeneração de dados. É importante ressaltar que esse tempo refere-se ao barramento do sistema e não ao processador;

- Taxa de transferência: taxa na qual os dados podem ser transferidos para dentro ou para fora de uma unidade de memória;

- Taxa de acertos: proporção dos acessos encontrados em um nível de hierarquia de memória;

- Taxa de falhas: proporção dos acessos não encontrados em um nível de hierarquia de memória;

- Tempo de acerto: tempo para se acessar um nível da hierarquia de memória, incluindo o tempo necessário para determinar se o acesso é um acerto ou uma falha;

- Penalidade de falha: tempo para se trazer um bloco de nível inferior para um nível superior da hierarquia de memória, incluindo o tempo para acessar o bloco, transmiti-lo de um nível para outro e inseri-lo no nível que obteve a falha.Os métodos de acesso definem como os dados são acessados nos diferentes níveis de uma hierarquia de memória e podem ser categorizados da seguinte forma (Stallings, 2009):

- Acesso sequencial: a organização dos dados realiza-se em registros sequenciais, em que o acesso é feito através de uma sequência linear específica. Possui um tempo de acesso altamente variável, pois seu mecanismo de leitura e escrita precisa ser movido do local atual para o desejado e os registros intermediários a estes dois pontos precisam ser rejeitados. Fitas magnéticas utilizam-se deste tipo de acesso;

- Acesso direto: cada bloco de dados possui um endereço único, baseado na localização física. O acesso é realizado de forma direta a uma vizinhança genérica do registro seguido por uma busca sequencial, contagem ou espera até localizar o destino. Em virtude deste processo, o tempo de acesso torna-se variável. Unidades de disco utilizam-se deste tipo de acesso;

- Acesso aleatório: cada posição de memória possui um endereço único e o tempo de acesso a uma posição é constante, sendo independente da sequência de acessos anteriores. A memória principal e alguns sistemas de memória cache utilizam-se deste tipo de acesso;

- Associativo: tipo de acesso aleatório que compara simultaneamente certo número de bits de uma palavra com todas as palavras da memória, determinando quais delas contêm o mesmo padrão de bits, ou seja, uma palavra é recuperada com base em uma parte do seu conteúdo em vez do seu endereço. O tempo de acesso é constante, pois cada local tem seu próprio mecanismo de endereçamento independentemente do local ou padrões de acesso anteriores. As memórias cache utilizam-se deste tipo de acesso.

Como os sistemas de memória são essenciais para o desempenho de sistemas computacionais, os projetistas vêm se dedicando no desenvolvimento de novos e eficientes mecanismos que visam melhorar o desempenho do sistema hierárquico de memória, visto que os acessos de acerto no nível mais alto, perto do processador, podem ser processados rapidamente. Já os acessos de falha se estendem para os níveis mais baixos da hierarquia, que são maiores e mais lentos. Assim, se a taxa de acertos for alta, o tempo de localização de informação será pequeno, promovendo maior agilidade ao sistema de hierarquia de memória (Patterson e Hennessy, 2010). 


\subsection{Níveis de memória}

Conforme observado na Seção 3.3, a hierarquia de memória consiste em diferentes níveis de memória, tais como: registradores, memória cache, memória principal e secundária. Estes níveis são associados a diferentes velocidades de acesso, tamanhos e objetivos. Para melhor entendê-los, eles são detalhados a seguir.

\subsubsection{Registradores}

O objetivo final de um sistema de memória é armazenar informações destinadas a serem, em algum momento, utilizadas pelo processador que é o responsável pela execução das instruções, manipulação dos dados e produção dos resultados das operações.

A unidade lógica e aritmética e a unidade de ponto flutuante são as unidades funcionais responsáveis por realizar as ações operativas do processador. No entanto, o processador necessita buscar a instrução onde ela estiver armazenada, podendo ser na memória cache ou principal, e transferi-la para seu interior em pequenas unidades de memória transitórias, denominadas registradores de instrução ou apenas registradores.

Os registradores pertencem ao nível superior da pirâmide de hierarquia de memória, conforme visualizado na Figura 8, por possuir a maior velocidade de transferência do sistema de memória proporcionando um menor tempo de acesso na escala de ciclos de processamento, mas por outro lado, possui a menor capacidade, entre 32 e 64 bits de armazenamento cada registrador, e um maior custo.

\subsubsection{Memória cache}

Considerando que o período de tempo gasto por um ciclo da memória principal é bem maior que o período de tempo que o processador gasta para realizar uma operação na unidade lógica e aritmética, pode-se observar a existência de um gargalo na memória principal, resultando em um ponto frágil no que se refere à performance do sistema.

$\mathrm{Na}$ tentativa de solucionar este gargalo, foi proposta uma técnica que consiste na inclusão de um ou mais dispositivos de memória entre o processador e a memória principal denominados "Caches", como pode ser visualizado nas Figuras 9 e 10.

A memória cache é caracterizada por uma memória temporária que possui a função de armazenar os dados e/ou instruções mais frequentemente utilizados pelo processador com o objetivo de acelerar a velocidade de transferência das informações entre ele e a memória principal, aumentando consideravelmente o desempenho dos sistemas de computação.

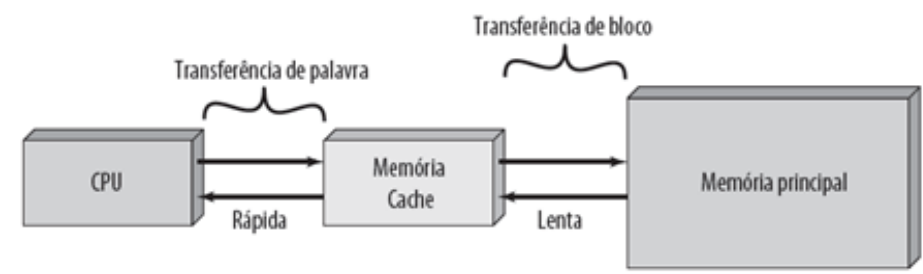

Figura 9 - Cache única (Stallings, 2009) 


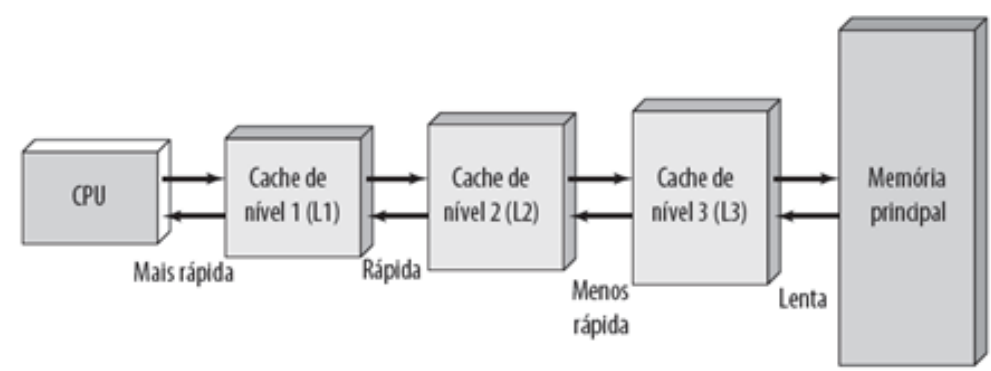

Figura 10 - Cache em três níveis: L1, L2, L3 (Stallings, 2009)

Como a memória cache só pode conter algumas partes dos dados devido ao seu tamanho, surgiu a necessidade de se desenvolver algoritmos para mapear blocos de memória principal na memória cache, sendo possível identificar se bloco procurado encontra-se ou não na memória cache. Caso esteja presente, ocorre um acerto. Caso contrário, ocorre uma falha que pode ser compulsória, de capacidade ou de conflito (Patterson e Hennessy, 2010).

A falha do tipo compulsória ocorre no primeiro acesso a uma parte da memória que nunca esteve na cache.

A falha do tipo capacidade é causada pela ausência de blocos que já estiveram na memória cache, mas foram descartados por falta de espaço.

A falha do tipo conflito ocorre quando um bloco deve ser carregado para um local de memória cache que já possui outro bloco, originando uma colisão ou conflito. O conteúdo atual do local da memória cache deverá ser retirado para que o novo bloco seja armazenado.

Ressalta-se que a falha do tipo compulsória é esperada e não compromete o desempenho do sistema. No entanto, os dois outros tipos, capacidade e conflito, devem ser devidamente analisados para que não prejudiquem a performance do sistema.

Políticas de substituição devem ser utilizadas para substituir ou não os blocos presentes na cache por novos que foram solicitados. Aliado a isso, caso os blocos da cache sejam atualizados, os blocos correspondentes dos níveis inferiores também devem ser atualizados através das políticas de escrita.

Para identificar o resultado da busca por um bloco na memória cache, foram criadas algumas variáveis que reportam importantes informações sobre este processo (Patterson e Hennessy, 2010):

- Hit (acerto): dado encontrado no nível procurado;

- Miss (falha): dado não encontrado no nível procurado;

- Hit rate (taxa de acerto): percentual de hits no nível;

- Miss rate (taxa de falha): percentual de misses no nível. É complementar ao hit rate;

- Hit time: tempo de acesso ao nível, incluindo o tempo de identificar se é hit ou miss;

- Miss-penalty: tempo médio gasto para que o dado não encontrado no nível desejado seja transferido dos níveis mais baixos.

Essas variáveis são constantemente utilizadas e atualizadas durante a manipulação dos blocos entre os níveis de memória envolvendo a memória cache, através dos algoritmos de mapeamento responsáveis pela sua organização conhecidos como mapeamento direto, associativo e associativo por conjunto.

O mapeamento direto é a forma mais simples de mapeamento, pois cada bloco na memória principal é mapeado sempre no mesmo local da cache, em que rótulos (tags) são utilizados para 
identificar se o bloco requisitado está ou não na cache e um bit de validade é utilizado para indicar se uma entrada contém ou não um endereço válido (Patterson e Hennessy, 2010).

As vantagens de se utilizar este tipo de mapeamento são a técnica simples e o baixo custo de implementação. No entanto, ele também possui desvantagens, pois cada bloco é mapeado em uma posição fixa na memória cache e se houver referência a blocos distintos mapeados na mesma posição, os blocos são trocados continuamente levando a uma baixa taxa de acertos.

O mapeamento associativo evita as desvantagens do mapeamento direto, pois permite que um bloco da memória principal possa ser carregado em qualquer posição da memória cache, aproveitandoa completamente. $\mathrm{O}$ endereço de memória é interpretado como um campo de rótulo (tag) e um campo de palavra e para determinar se um bloco está na memória cache, a lógica de controle da memória cache compara simultaneamente o campo de rótulo do endereço do bloco acessado com o rótulo de todas as linhas (Patterson e Hennessy, 2010).

No mapeamento associativo, para se localizar um determinado bloco é necessário pesquisar todas as entradas da memória cache, visto que ele pode estar em qualquer lugar. Para tornar essa busca mais rápida, pode-se realizá-la em paralelo com um comparador associado a cada uma das entradas da memória cache, mas este processo aumenta consideravelmente o custo do hardware tornando-se viável para memórias caches com pequenos números de blocos.

As vantagens de se utilizar este tipo de mapeamento são permitir maior flexibilidade para a escolha do bloco a ser substituído quando um novo bloco for incluído na memória cache e um melhor aproveitamento de suas posições. Por outro lado, existem desvantagens como a complexidade do conjunto de circuitos necessários para a comparação dos rótulos contidos na memória cache elevando seu custo e a necessidade de uma política de substituição de dados.

O mapeamento associativo por conjunto caracteriza-se por ser um meio termo entre mapeamento direto e associativo, pois a memória cache associativa conjuntiva é dividida em $\mathrm{S}$ conjuntos de $\mathrm{N}$ blocos. Quando o valor de S é igual a 1, realiza-se o mapeamento associativo, caso contrário, se $\mathrm{S}$ for igual a $\mathrm{N}$, realiza-se o mapeamento direto (Patterson e Hennessy, 2010).

No mapeamento associativo, o endereço é constituído pelos campos rótulo, conjunto e palavra. A busca por algum bloco só é realizada comparando rótulos de um mesmo conjunto, proporcionando vantagens como flexibilidade e a utilização total da memória cache. No entanto, ele também possui algumas desvantagens como seu custo e a necessidade de uma política de substituição de dados.

Quando uma falha ocorre em uma memória cache que possui seu conteúdo totalmente preenchido, surge a necessidade de se retirar um de seus blocos para que esta posição seja liberada para a alocação do novo bloco que não foi encontrado.

Caso a memória cache seja diretamente mapeada, a substituição torna-se fácil, visto que existe apenas um candidato para a substituição. Já para memórias caches com mapeamento associativo ou associativo por conjunto, é necessário selecionar um bloco a ser substituído, pois no primeiro caso, todos os blocos são candidatos à substituição e no segundo caso, os candidatos à substituição são os blocos do conjunto. Desta maneira, foram criadas políticas de substituição de blocos e dentre elas destacam-se (Patterson e Hennessy, 2010):

- Substituição aleatória ou Random: caracterizado por selecionar aleatoriamente o bloco que será retirado da memória; 
- FIFO (First In - First Out): caracterizado por manter uma lista dos blocos correntes na memória, onde o bloco do início da lista é o mais antigo e o bloco do final da lista é o mais novo. O bloco que esteve na memória cache por mais tempo será substituído. Possui uma desvantagem, pois um bloco que está em constante uso pode ser retirado;

- LFU (Least Frequently Used): caracterizado por retirar da memória cache o bloco que foi menos acessado. Utiliza-se um contador de acessos associado a cada bloco (hit) que é zerado quando este deixa a memória. Não favorece os blocos recém carregados que possuem o contador de acessos zerado, tornando-os fortes candidatos para substituição;

- LRU (Least Recently Used): caracterizado por retirar da memória os blocos que possuem mais tempo sem utilização. Seu funcionamento baseia-se na ideia de que os blocos que foram muito utilizados nas últimas instruções, provavelmente serão utilizados nas próximas. Contém uma lista com os blocos contidos na memória que deve ser atualizada a cada referência, tornando seu processo de implementação oneroso. Pode ser implementado tanto por hardware quanto em software.

Ainda com relação à manipulação dos dados na memória cache, deve-se ressaltar o fator da integridade dos dados que são manipulados, pois uma informação pode sofrer atualização somente na memória cache e não ser alterada no seu local de origem e em algum momento pode ser selecionada por um algoritmo de substituição para ser retirada. Neste caso, esta informação não pode ser descartada, já que não foi corretamente atualizada. Para evitar esse problema e manter a integridade dos dados na memória cache, existem as políticas de escrita (Patterson e Hennessy, 2010):

- Write-Through: mais antiga, em que as modificações ocorridas na memória cache são sempre propagadas para o nível inferior de memória. Assim, os dados sempre ficarão atualizados, mas este processo causará um uso maior do barramento, pois cada escrita na memória cache necessitará de um outro acesso à memória principal;

- Write-Back: mais recente, em que as modificações são propagadas somente quando existe a necessidade de atualização. Este processo utiliza a ajuda de um bit de estado chamado "Dirtybit”. Desta forma, escritas múltiplas de um endereço requerem apenas uma escrita na memória e consequentemente consomem menos largura de banda. No entanto, é mais complicado de se implementar do que a política anterior.

Por fim, as memórias caches podem ser unificadas ou separadas. A primeira armazena as referências aos dados e instruções em um único local e a segunda possui um local dedicado para dados e outro para instruções. Para uma memória cache unificada, as políticas de substituição e de escrita afetam dados e instruções. Já nas memórias caches separadas, as políticas de substituição e de escrita podem ser aplicadas de forma distintas para dados e instruções.

\subsubsection{Memória principal}

A memória principal também é chamada de Memória de Acesso Randômico ou Random Access Memory (RAM). Caracteriza-se por um espaço de armazenamento temporário onde instruções e dados são armazenados diretamente pelo processador durante o processamento, através do endereçamento efetivo das instruções (Patterson e Hennessy, 2010). 
Dentre as características da RAM, destacam-se o armazenamento temporário, pois seu conteúdo é perdido quando o computador é desligado, o acesso aleatório aos dados e o suporte à leitura e gravação dos mesmos.

Quando comparada às memórias caches, apresentam uma maior capacidade de armazenamento mas com uma velocidade menor e quando comparadas à memória secundária, oferecem tempos de acesso mais baixos e taxas de transferências mais altas.

A alocação de dados e processos na memória principal podem acarretar a sua fragmentação. Dependendo do tipo de gerenciamento selecionado pode-se ter fragmentação interna e/ou externa. Na interna, os processos ocupam apenas uma parte de uma partição deixando a outra parte como um espaço sem utilização. Na externa, os processos alocam partições de vários tamanhos originando lacunas entre esses processos, que em muitas vezes, por serem tão pequenas, acabam por se tornarem inutilizáveis (Patterson e Hennessy, 2010).

Para minimizar o problema de fragmentação e também para aumentar a capacidade de memória disponível para os processos, pode-se utilizar o recurso denominado memória virtual, onde uma parte do disco pode ser destinada à extensão da memória principal.

\subsubsection{Memória secundária}

Devido às características específicas da memória principal como a volatilidade e o alto custo, surgiu a necessidade de implementação de outro tipo de memória, chamado memória secundária. Este tipo de memória caracteriza-se por não ser volátil, ter maior capacidade de armazenamento e um custo mais barato quando comparado a memória principal. No entanto, o tempo de acesso as suas informações é consideravelmente maior (Patterson e Hennessy, 2010).

As memórias secundárias podem ser removíveis ou não, ou seja, podem ser retiradas do computador e facilmente transportadas para outro. Como exemplo deste tipo de memória podem ser citados: fitas magnéticas, discos rígidos (HDs) e flexíveis (disquetes), CD-ROM, DVD-ROM entre outros.

\subsection{Considerações finais}

O sucesso do sistema de hierarquia de memória baseia-se na diminuição dos acessos à memória mais lenta, acelerando a transferência das informações para o processador.

Assim, explorando o melhor custo/benefício de cada tecnologia empregada na construção das memórias utilizadas no sistema de hierarquia e também o princípio da localidade temporal e espacial, é possível representar uma memória rápida, ilimitada, com um custo acessível e ágil na manipulação das informações trocadas entre os programas executados em um computador.

Como o principal objetivo deste projeto de mestrado consiste na transformação do módulo de memória cache da ferramenta Amnesia em um objeto de aprendizagem, o próximo capítulo descreverá essa ferramenta que se caracteriza por ser um simulador de hierarquia de memória na máquina de von Neumann, além de prover conhecimentos e comparações com outras ferramentas. 


\section{Ferramenta Amnesia}

\subsection{Considerações iniciais}

Conforme citado no capítulo introdutório, o tópico de hierarquia de memória da disciplina de Organização de Computadores Digitais I (SSC0112) do ICMC/USP é extenso e complexo. Diversos assuntos devem ser abordados em sala de aula, tais como: transferência dos dados entre os níveis de memória, princípios de localidade espacial e temporal, processador, memória cache e memória virtual. Abordar essas teorias sem a participação efetiva do aluno no processo de aprendizagem pode limitar a sua compreensão e dificultar o acompanhamento da disciplina.

Com o objetivo de diminuir a distância entre a teoria e a prática e tornar o aluno mais participativo no processo de aprendizagem, a ferramenta Amnesia, desenvolvida desde 2004, caracteriza-se por ser um simulador de hierarquia de memória na máquina de von Neumann. Sua função é demonstrar o funcionamento dos registradores de um processador, memórias caches, principal e virtual de forma didática, com o objetivo de facilitar e melhorar o aprendizado na disciplina de Organização e Arquitetura de Computadores.

Os principais conceitos abordados por ela referem-se ao assunto hierarquia de memória, tais como: palavra, bloco, página, princípios de localidade temporal e espacial, caches multiníveis, acertos e falhas de cache, bem como algoritmos para tratamento das falhas, algoritmos de mapeamento direto e associativo (totalmente associativo ou por conjunto), transferência dos dados entre os níveis de memória, memória virtual, tabela de páginas e Translation Lookaside Buffer (TLB).

A base para a construção da ferramenta Amnesia foram os módulos processador, memória cache e memória virtual, juntos a um conversor de código binário para código Assembly MIPS e vice-versa e a um leitor de arquivos de rastro no padrão DIN, proposto por Mark Hill (Hill, 2015).

Com o objetivo de conhecer o ciclo de vida e o funcionamento da ferramenta Amnesia, este capítulo abordará a história referente ao seu desenvolvimento, bem como a explicação de cada um dos módulos que compõe a sua estrutura e permite o seu funcionamento. No entanto, como este projeto de mestrado foi fundamentado no módulo de memória cache, este será mais detalhado.

Ressalta-se que apesar deste capítulo descrever a ferramenta Amnesia, todas as telas e funcionamentos do módulo de memória cache já incorporam as modificações realizadas no processo da sua transformação em um objeto de aprendizagem.

\subsection{História}

Utilizando-se da experiência adquirida em sala de aula pelo Prof. Dr. Paulo Sérgio Lopes de Souza, surgiu em 2004, na Universidade Estadual de Ponta Grossa (UEPG) no Paraná, o modelo da ferramenta Amnesia. Dentre seus objetivos, destacava-se a proposta de uma nova forma de transmissão de conhecimento para os alunos que cursavam a disciplina de Organização e Arquitetura de Computadores.

No ano de 2007, na USP, os modelos propostos para a ferramenta Amnesia foram revistos e adequados no projeto denominado Amnesia. O desenvolvimento da ferramenta foi continuado no Laboratório de Sistemas Distribuídos e Programação Concorrente (LASDPC) do ICMC/USP utilizando- 
se a linguagem JAVA a partir do modelo de software MVC, que isola a lógica da aplicação da interface com o usuário e permite desenvolver, editar e testar separadamente cada parte da ferramenta (Oliveira, 2008).

Durante o período de 2007 a 2008 o projeto Amnesia obteve o auxílio de três bolsas de iniciação científica do projeto Ensinar com Pesquisa da Pró-Reitoria de Graduação da USP, com a orientação e supervisão de três docentes: Prof. Dr. Paulo Sérgio Lopes de Souza, Profa. Dra. Sarita Mazzini Bruschi e Profa. Dra. Simone do Rocio Senger de Souza. Neste período, foram desenvolvidos e aperfeiçoados os módulos de processador multiciclo, memória cache, memória virtual e a elaboração e execução dos planos de testes dos módulos e suas integrações.

Atualmente, após a transformação do módulo de memória cache em um objeto de aprendizagem realizada no decorrer deste projeto de mestrado, os módulos continuam dispostos da mesma forma: processador, memória cache e memória virtual juntos a um conversor de código binário para código Assembly MIPS e vice-versa e a um leitor de arquivos de rastro. No entanto, o módulo de memória cache foi totalmente revisado e validado junto com o desenvolvimento de novas funcionalidades que foram incorporadas para facilitar e melhorar seu funcionamento, além de transformá-lo em um objeto de aprendizagem.

\subsection{Conceitos e funcionalidades}

Os principais conceitos abordados pela ferramenta Amnesia referem-se à disciplina de Organização e Arquitetura de Computadores, mais especificamente ao assunto hierarquia de memória: palavra, bloco, página, princípios de localidade espacial e temporal, caches multiníveis, acertos e falhas de cache bem como algoritmos para tratamento das falhas, algoritmos de mapeamento direto e associativo, transferência dos dados entre os níveis de memória, memória virtual, tabela de páginas e Translation Lookaside Buffer (TLB).

Esses conceitos são abordados pela ferramenta durante a utilização de suas funcionalidades tanto por uma interface textual quanto por uma interface gráfica, proporcionando mais interatividade com o usuário. As funcionalidades encontram-se distribuídas nos módulos já citados e aqui detalhados:

- Módulo Processador: implementa uma arquitetura MIPS (Microprocessor without Interlocked Pipeline Stages), a qual foi proposta por Patterson e Henessy com o objetivo de simular o funcionamento de um processador RISC multiciclo de 32 bits bem como de seus registradores (Patterson e Hennessy, 2010);

- Módulo Cache: responsável por simular memórias caches multiníveis (L1, L2, L3, etc.) bem como memórias caches do tipo Splited (dados e instruções em caches separadas) ou Unified (dados e instruções em uma única cache);

- Módulo Memória Virtual: responsável por simular endereços virtuais, memória associativa TLB e os acessos a disco em virtude de uma possível paginação;

Junto a esses três módulos, a ferramenta possui um conversor de código binário para código Assembly MIPS e também manipula e gera arquivos de rastro no padrão DIN, mais conhecidos como trace files. O conversor de código é responsável por converter um código binário desenvolvido por um aluno para um código em Assembly MIPS e vice-versa. Os arquivos de rastro são responsáveis por demonstrar ao aluno, de forma prática, o impacto de uma sequência de instruções na memória principal. 
Assim, para gerar arquivos com o log de todas as operações executadas na memória, utiliza-se do padrão DIN (Hill, 2015). Neste log, existe um rótulo no início de cada linha, composto por um único número, que indica a operação executada na memória principal. O rótulo " 0 " indica leitura de dados, "1" gravação de dados, "2" busca de instrução, "3" acesso desconhecido e "4" a operação de cache flush.

Analisando as Figuras 11a e 11b, é possível visualizar o funcionamento da ferramenta Amnesia de forma global. Para iniciar uma simulação é necessária a indicação de uma arquitetura mantida em um arquivo formatado no padrão $\mathrm{xml}$. Nesse arquivo, atributos de processador, memória cache, principal e virtual podem ser configurados. Para realizar uma simulação com o objetivo de analisar o funcionamento da memória cache, por exemplo, os atributos do processador, da memória cache e principal devem ser obrigatoriamente especificados. Para o processador deve-se configurar o tamanho da palavra em bytes. Para cada nível da memória cache deve-se configurar o seu tipo (unificada ou separada), seu tamanho em palavras, o número de palavras por bloco, o número de blocos por conjunto (i.e. a associatividade), o número de ciclos para cada acesso de leitura, o número de ciclos para cada acesso de escrita, o tempo de cada ciclo, a política de substituição (FIFO ou LRU) e a política de atualização (write-through ou write-back). Para a memória principal deve-se configurar seu tamanho em palavras, o número de palavras por bloco, o número de ciclos para cada acesso de leitura, o número de ciclos para cada acesso de escrita e o tempo de cada ciclo.
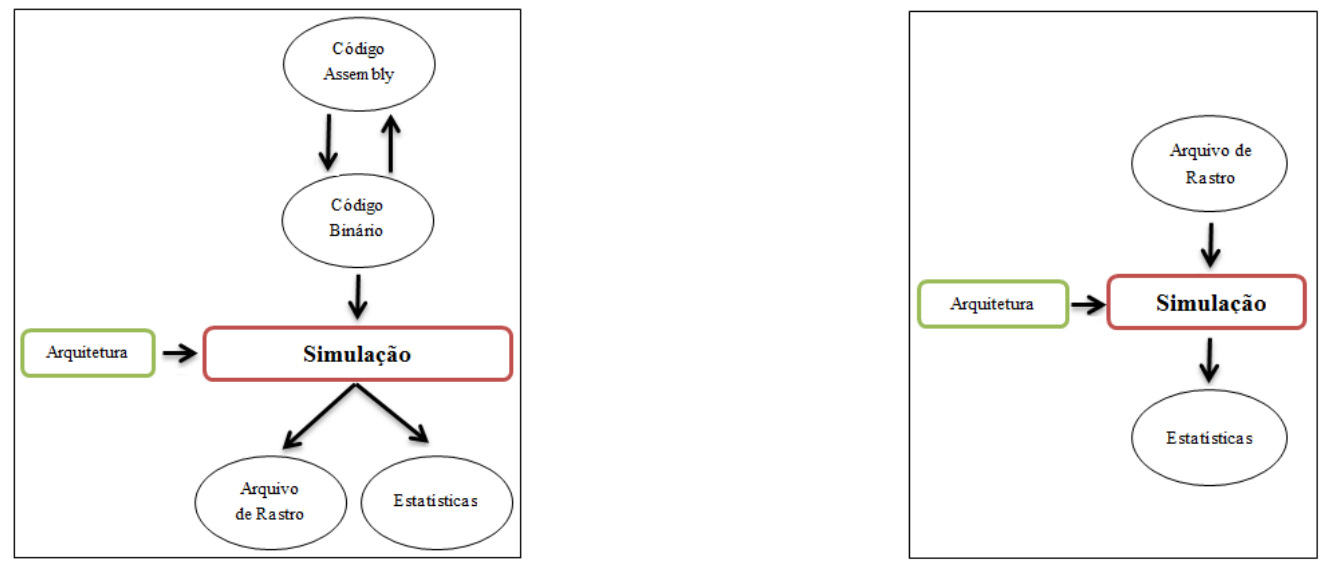

Figura 11 - a) Funcionamento da ferramenta Amnesia a partir de um código binário b) Funcionamento da ferramenta Amnesia a partir de um arquivo de rastro

Observando-se a Figura 11a, nota-se que a simulação pode ser conduzida a partir de uma sequência de códigos binários originados pela conversão de um código assembly MIPS, gerando estatísticas e um arquivo de rastro (trace) no padrão DIN contendo os acessos realizados na memória principal. Já a Figura 11b, mostra que uma simulação pode ser conduzida a partir de um arquivo de rastro (trace) no padrão DIN, gerando estatísticas.

Seja por código binário ou arquivo de rastro, a simulação pode ser executada de forma direta ou passo a passo. A Figura 12, que simula a execução passo a passo de um programa a partir de um arquivo de rastro, mostra que este tipo de execução provê um $\log$ detalhado e em tempo real da alocação das informações da memória principal na memória cache, possibilitando visualizar o espalhamento dos bits de um endereço requisitado e a determinação do byte-offset, word-offset, set e tag a cada instrução executada. 


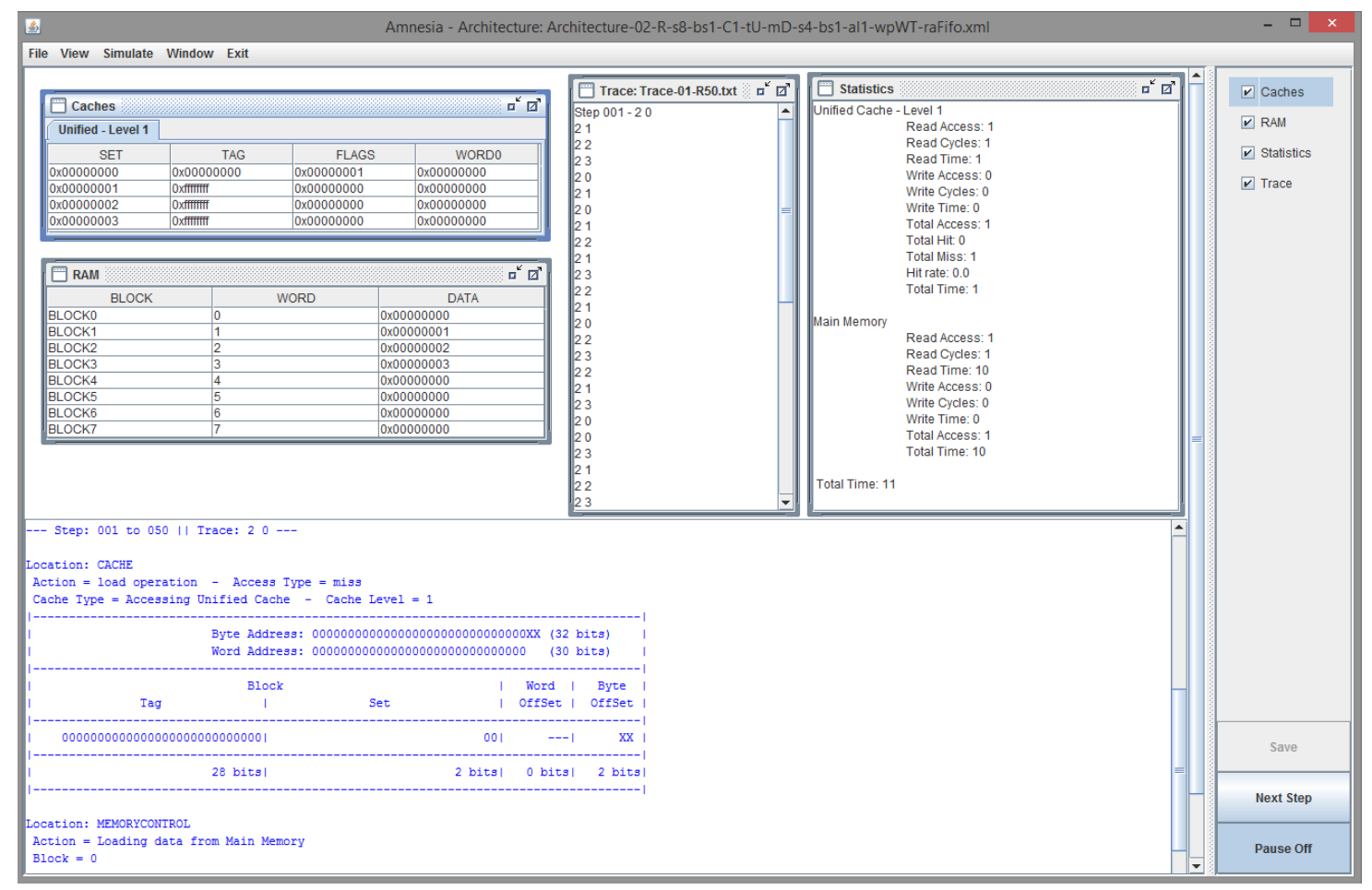

Figura 12 - Execução passo a passo de um arquivo de rastro

Continuando a análise da Figura 12, também é possível visualizar o arquivo de rastro (trace) que é executado e o passo exato de execução, os dados contidos na memória cache e principal bem como suas estatísticas de acesso. Para cada nível de memória cache, pode-se analisar seus aspectos de desempenho a partir do número de acessos, número de ciclos e tempo de leitura, número de acessos, número de ciclos e tempo de escrita, número total de acessos, número total de acertos (hit) e de falhas (miss), percentual de acerto (hit rate) e o tempo total de execução. Já para a memória principal, pode-se analisar o número de acessos, número de ciclos e tempo de leitura, número de acessos, número de ciclos e tempo de escrita, número total de acessos e o tempo total de execução. Desta forma, é possível que o aluno verifique, de maneira clara, os aspectos de desempenho envolvendo a execução de um programa em um determinado ambiente.

Ressalta-se que um mesmo código binário ou arquivo de rastro pode ser executado em diferentes arquiteturas com configurações distintas de processador, memória cache, principal ou virtual. Essa característica é importante para que o aluno possa executar a mesma sequência de instruções em diferentes ambientes e comparar os resultados obtidos.

Após o término da simulação, um log pode ser gravado contendo as informações da arquitetura utilizada, código binário ou arquivo de rastro executado, espalhamento dos bits de cada endereço de memória requisitado e as estatísticas de acesso às memórias cache, principal e virtual.

Com o objetivo de se compreender a estrutura e o funcionamento detalhado do módulo de memória cache, foco principal deste projeto de mestrado, todo o processo de simulação será minunciosamente descrito a seguir. 


\subsection{Módulo Cache}

A execução do simulador é iniciada através do arquivo JAR ${ }^{13}$, conforme mostra a Figura 13. Logo após a inicialização, pode ser visualizada a interface gráfica da ferramenta, apresentada na Figura 14. Os demais arquivos exibidos na Figura 13, junto com o arquivo JAR, referem-se às arquiteturas e arquivos de rastro que podem ser utilizados em diversas simulações.

\begin{tabular}{|c|c|c|c|}
\hline Name & Date modified & Type & Size \\
\hline & 6/2/2014 10:47 PM & File folder & \\
\hline प्राज & 6/10/2014 1:32 PM & Executable Jar File & $1,011 \mathrm{~KB}$ \\
\hline 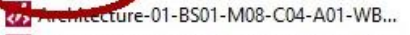 & 6/10/2014 2:13 AM & XML File & $1 \mathrm{~KB}$ \\
\hline Architecture-02-BS01-M08-C04-A01-WF-... & 6/10/2014 1:42 AM & XML File & $1 \mathrm{~KB}$ \\
\hline Architecture-03-BS02-M08-CO4-A01-WF-... & 6/10/2014 2:35 AM & XML File & $1 \mathrm{~KB}$ \\
\hline As. Architecture-04-BSO4-M08-CO4-A01-WF-... & 6/10/2014 2:44 AM & XML File & $1 \mathrm{~KB}$ \\
\hline Architecture-05-BS01-M08-CO4-A02-WF-... & 6/10/2014 2:50 AM & XML File & $1 \mathrm{~KB}$ \\
\hline Architecture-06-BSO2-M08-CO4-A02-WF-... & 6/10/2014 2:58 AM & XML File & $1 \mathrm{~KB}$ \\
\hline Architecture-07-BS01-M08-CO4-A04-WF-... & 6/10/2014 2:55 AM & XML File & $1 \mathrm{~KB}$ \\
\hline Architecture-08-BSO1-M08-C02-CO4 & 6/10/2014 3:33 AM & XML File & $2 \mathrm{~KB}$ \\
\hline Architecture-09-BS01-M08-C04-A01-WF-... & $6 / 10 / 20144: 00$ AM & XML File & $2 \mathrm{~KB}$ \\
\hline Architecture-10-BS01-M256-C64-A01-W... & 6/10/2014 4:11 AM & XML File & $1 \mathrm{~KB}$ \\
\hline Trace01-WR & 6/10/2014 8:09 AM & Text Document & $1 \mathrm{~KB}$ \\
\hline Trace02-WRI & 6/10/2014 2:20 AM & Text Document & $1 \mathrm{~KB}$ \\
\hline Trace $03-$ WRI-R & 6/10/2014 2:24 AM & Text Document & $1 \mathrm{~KB}$ \\
\hline Trace04-WRI-NR & 6/10/2014 2:29 AM & Text Document & $1 \mathrm{~KB}$ \\
\hline Trace05-RSameBlock & 6/10/2014 3:48 AM & Text Document & $1 \mathrm{~KB}$ \\
\hline Trace06-WRI-A10 & 6/10/2014 8:06 AM & Text Document & $1 \mathrm{~KB}$ \\
\hline
\end{tabular}

Figura 13 - Arquivos da ferramenta Amnesia

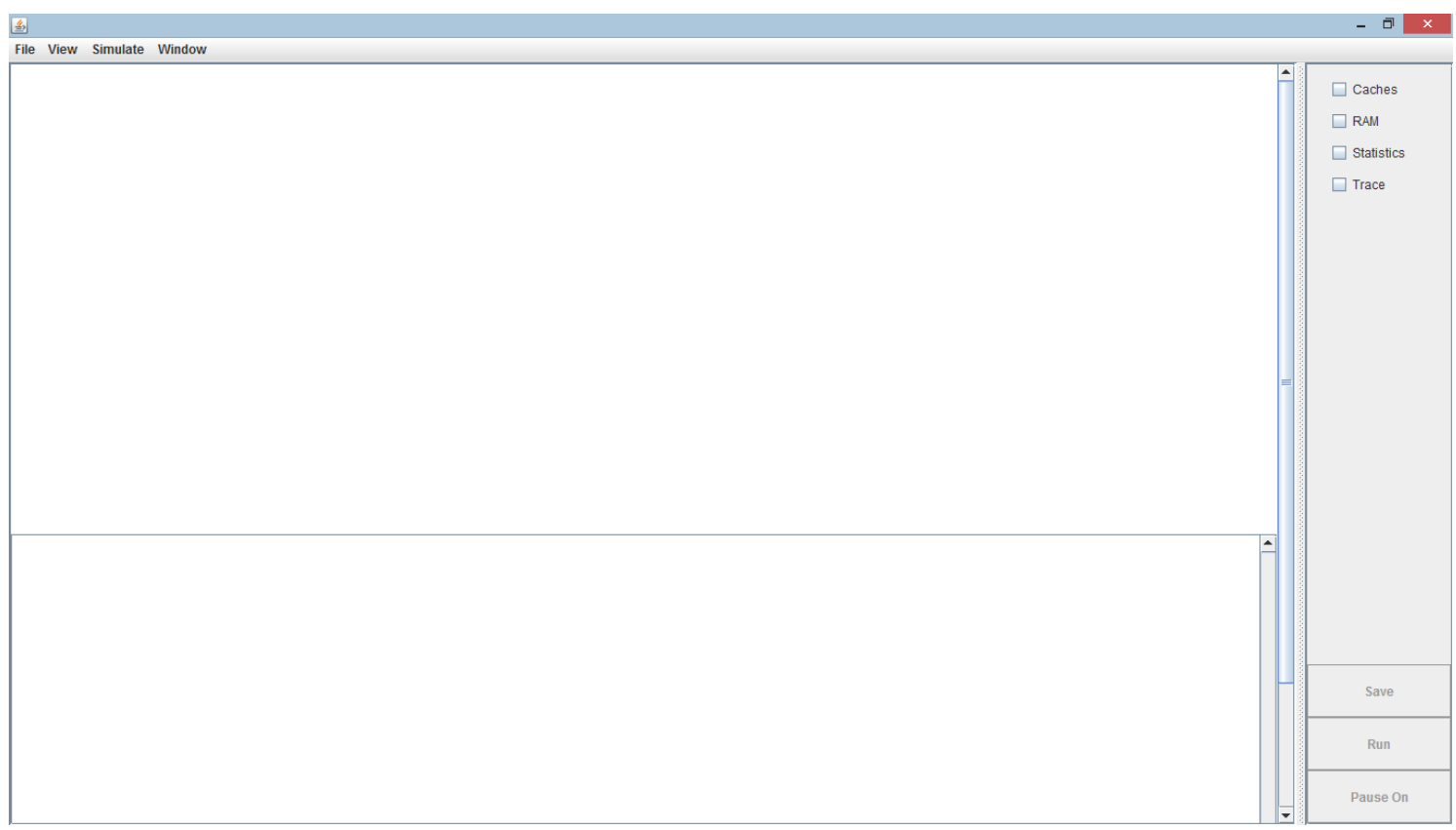

Figura 14 - Interface gráfica da ferramenta Amnesia

A Figura 15 mostra a interface gráfica dividida em 4 áreas. Na área A localiza-se a barra de ferramentas, local que permite o carregamento de uma arquitetura previamente configurada,

${ }^{13}$ Java ARchive (JAR): é um arquivo compactado usado para distribuir um conjunto de classes Java, constituindo um aplicativo Java. 
carregamento de programas representados pelos seus arquivos de rastro, execuções de simulações e o arranjo das janelas internas conforme a necessidade do usuário. $\mathrm{Na}$ área $\mathrm{B}$, em seu canto superior, localizam-se as caixas de seleção de cada componente utilizado durante uma simulação: Caches, RAM, Statistics e Trace. Já no canto inferior da área B, localizam-se os botões Run, Pause e Save. O botão Run é utilizado para realizar a execução direta de um programa. No entanto, se o botão Pause é acionado, o botão Run é modificado para Next Step e a partir deste momento a execução é feita passo a passo. Após o término da execução direta ou passo a passo, o usuário pode acionar o botão Save para salvar um $\log$ contendo as informações da arquitetura utilizada, arquivo de rastro executado, espalhamento dos bits de cada endereço de memória requisitado e as estatísticas de acesso às memórias cache e principal.

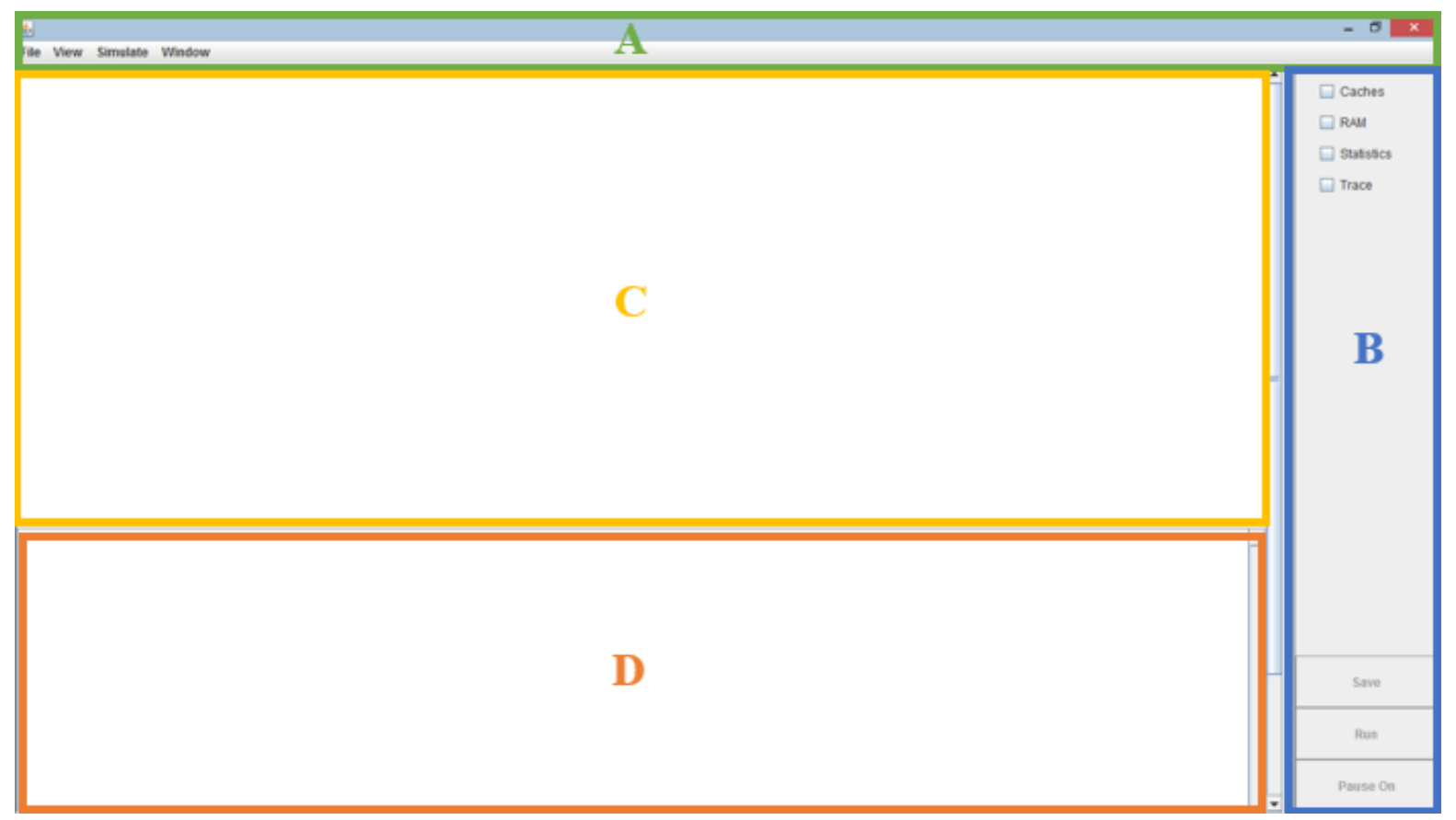

Figura 15 - Áreas da ferramenta Amnesia

Quando a caixa de seleção referente a um componente é ativada, o respectivo componente é exibido no campo de visualização, na área $C$ da Figura 15. Cada componente pode ser movimentado e redimensionado pelo usuário de forma livre ou de forma automática através do menu Window. Na área $\mathrm{D}$, localiza-se o terminal de saída, onde são apresentadas informações relacionadas ao carregamento de arquivo de arquitetura e arquivo de rastro, além dos detalhes da simulação como: acessos à memória cache, espalhamento de bits, informações de acertos ou falhas a cada passo executado.

Para carregar um arquivo de arquitetura, é necessário acessar o menu File > Load Architecture localizado na área A. Neste momento, uma caixa de diálogo será exibida para permitir a seleção de um arquivo $x m l$, como mostra a Figura 16. 


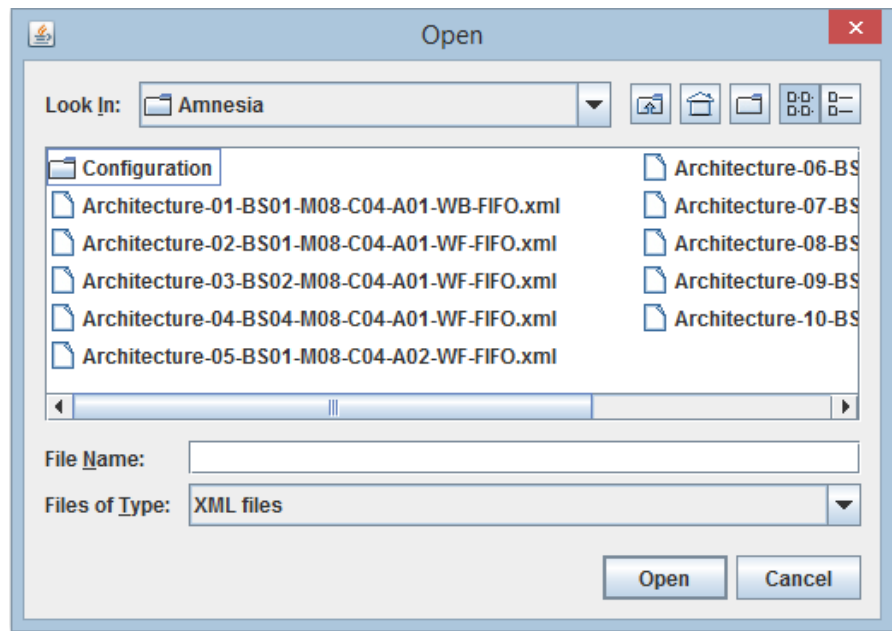

Figura 16 - Caixa de seleção de um arquivo de arquitetura

Em seguida, um arquivo de rastro (trace) pode ser carregado através do menu File > Load Trace, localizado na área A. Este arquivo contém os acessos realizados por um programa à memória principal, sejam eles de leitura, escrita ou busca de instruções. Nesse momento, será exibida uma caixa de diálogo como mostra a Figura 17.

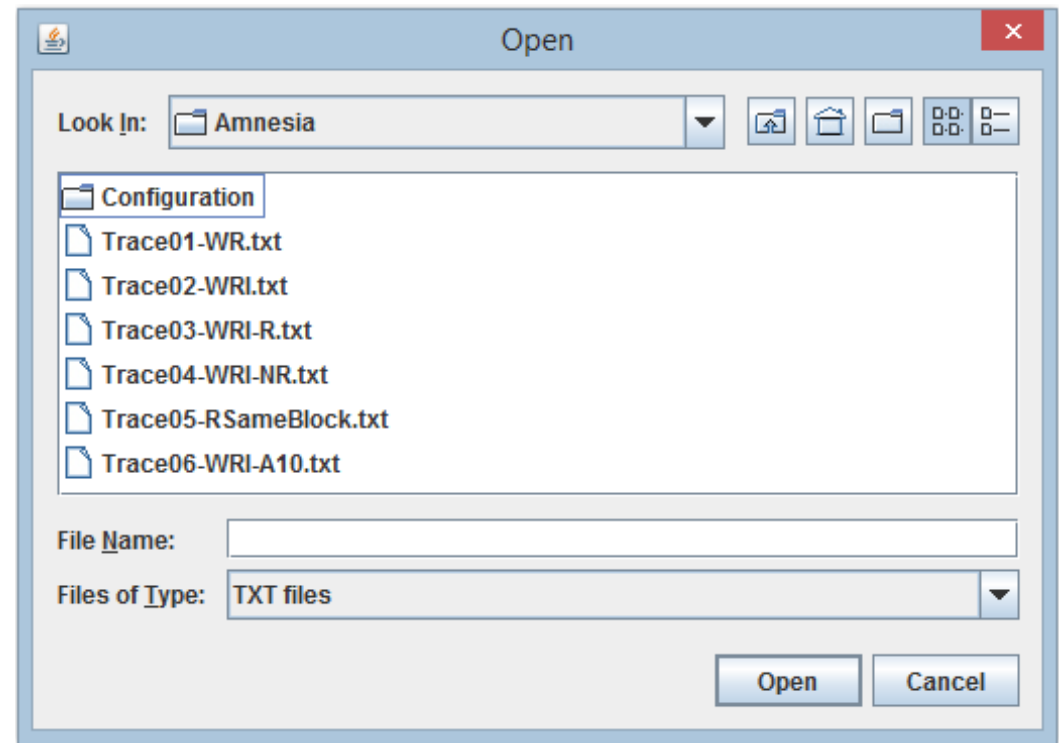

Figura 17 - Caixa de seleção de um arquivo de rastro (trace)

A Figura 18 mostra que após o carregamento da arquitetura e do trace com sucesso, conforme as mensagens visualizadas no terminal de saída localizado na área $\mathrm{D}$, os componentes podem ser visualizados na área $\mathrm{C}$ através da ativação de suas respectivas caixas de seleções, localizadas na área $\mathrm{B}$. Além disso, os botões Run e Pause On também são ativados na área B. 


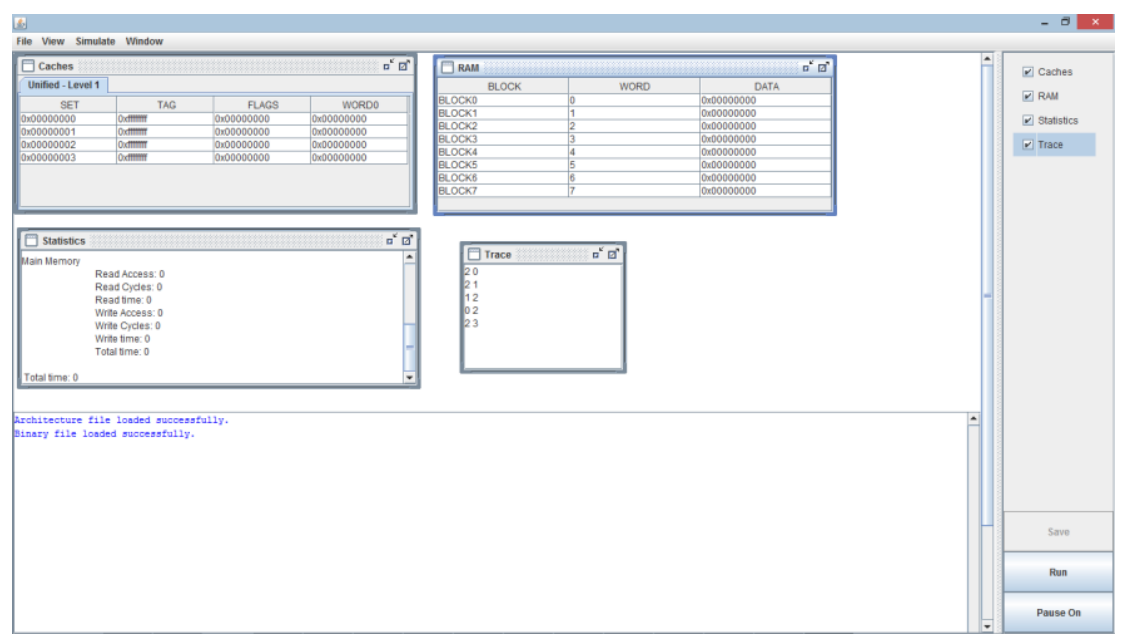

Figura 18 - Apresentação dos componentes

Caso deseje-se realizar uma execução direta, o botão Run deve ser acionado e desta forma todos os passos do trace serão executados de uma só vez. Após a execução, os botões Run e Pause On serão desativados e botão Save será ativado, permitindo que o log detalhado da simulação seja gravado, como pode ser observado na Figura 19. Ainda analisando-se a Figura 19, é possível observar que as estatísticas de execução do programa, representado pelo seu arquivo de rastro (trace), são exibidas no componente Statistics e os componentes Caches e RAM são visualizados em seu estado final de execução na área C.

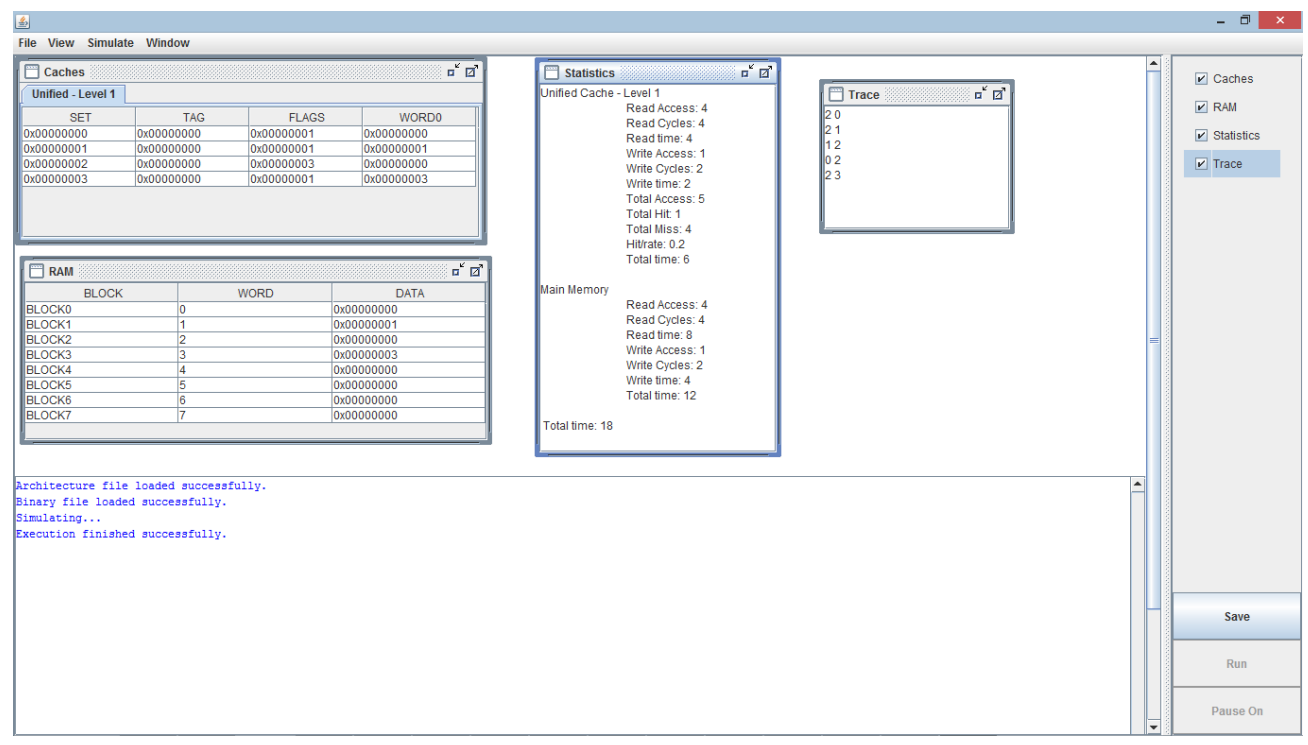

Figura 19 - Execução direta da simulação

Além da execução direta, é possível realizar a execução passo a passo de um programa a partir de seu arquivo de rastro (trace), que provê um log detalhado e em tempo real da alocação das informações da memória principal na memória cache, possibilitando visualizar o espalhamento dos bits de um endereço requisitado e a determinação do byte-offset, word-offset, set e tag a cada instrução executada, localizado na área D. Acionando-se o botão Pause On, os botões Run e Pause On passarão à apresentar as novas funcionalidades Next Step e Pause Off respectivamente, como pode ser observado na Figura 20. 


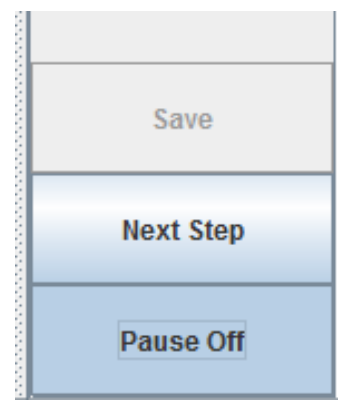

Figura 20 - Alteração do botão Run para Next Step

Conforme a execução de cada passo do arquivo de rastro (trace) através do botão Next Step, o log detalhado da execução pode ser acompanhado, em tempo real, no terminal de saída localizado na área D, como mostra a Figura 21.

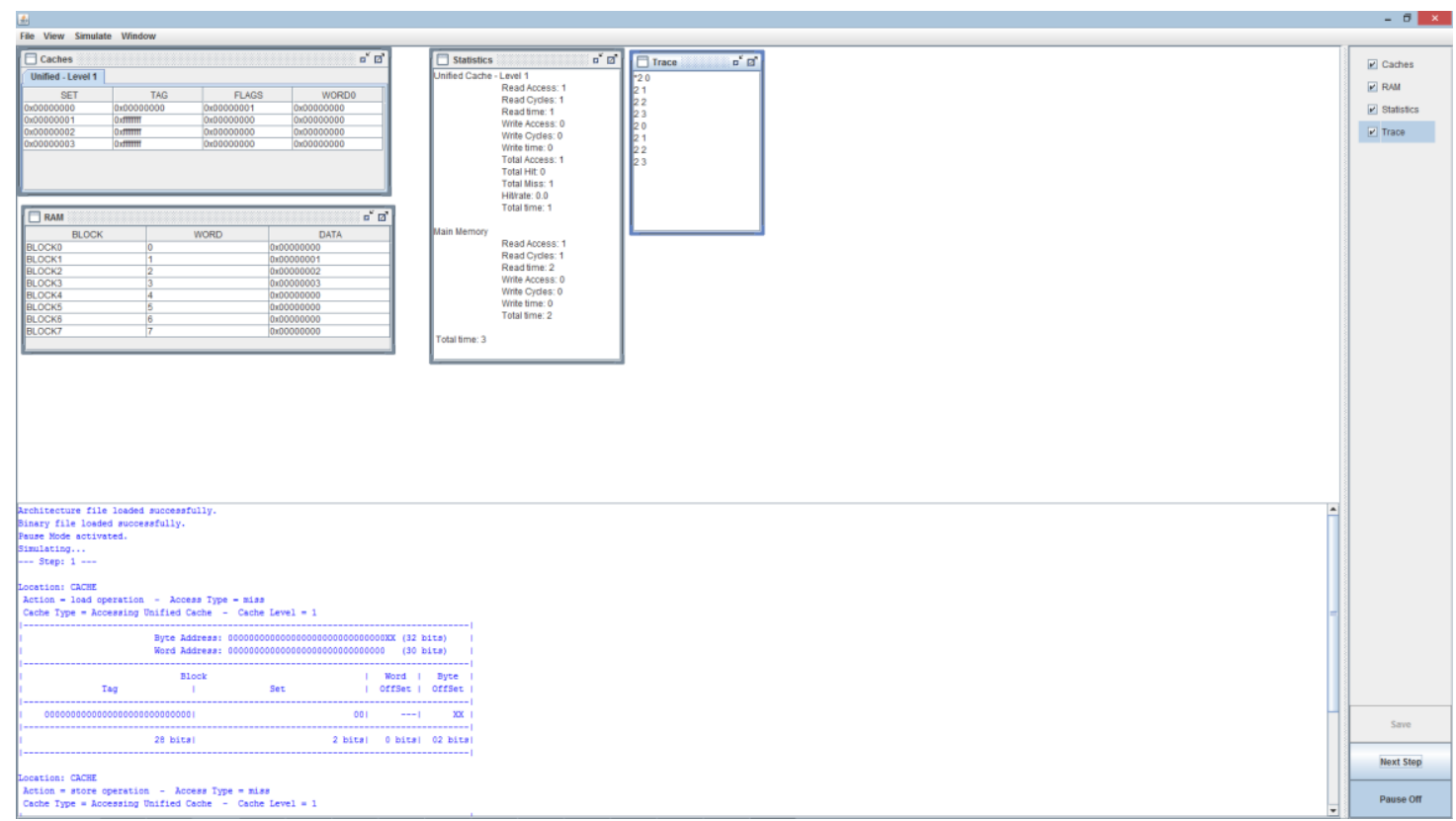

Figura 21 - Execução passo a passo de uma simulação e seu log detalhado

Após o término da simulação, o log detalhado do terminal de saída também pode ser gravado, contendo as informações da arquitetura utilizada, código binário ou arquivo de rastro executado, espalhamento dos bits de cada endereço de memória requisitado e as estatísticas de acesso às memórias cache e principal, através do botão Save, localizado no canto inferior da área B, como mostra a Figura 21.

Para a execução de uma nova simulação, é necessário carregar um novo arquivo de rastro ou um novo arquivo de arquitetura e repetir todos os procedimentos descritos anteriormente. 


\subsection{Outras ferramentas para simulação de memória}

Existem diversos simuladores que visam facilitar o aprendizado do tema hierarquia de memória, com diferentes níveis de complexidade e funcionalidades.

Alguns simuladores de hierarquia de memória, mais especificamente memória cache devido ao foco deste projeto de mestrado, foram comparados (Rodrigues, 2012): KSH (Ribeiro, 2003), Multilevel and Split Cache Simulator (MSCSim) (Coutinho, 2006), Didactic Cache Memory Simulator (DCMSim) (Cordeiro et al, 2003), Dinero IV (Hill, 2015), CacheSim (Prete, 1994), LBGCache (Moreira K., 2005) e SMPCache (Vega, 2000).

Dentre os simuladores citados, destacam-se o KSH, DCMSim, LBGCache e o MSCSim por possuírem uma interface gráfica e didática, diferenciando dos demais simuladores que apresentam somente uma interface textual e por este motivo foram comparados com a ferramenta Amnesia.

A Figura 22 mostra o KSH, um simulador de memória cache que pode ser executado em uma interface gráfica e em modo texto. Desenvolvido na Pontifícia Universidade Católica (PUC) de Minas Gerais, permite a simulação utilizando algoritmos de mapeamento direto, associativo e associativo por conjunto, além das políticas de substituição FIFO e LRU e das políticas de escrita write-through e writeback. Apesar de permitir a simulação de acessos paralelos à memória, não permite a configuração de caches separadas, multiníveis e arquivos de rastro (Ribeiro, 2003).

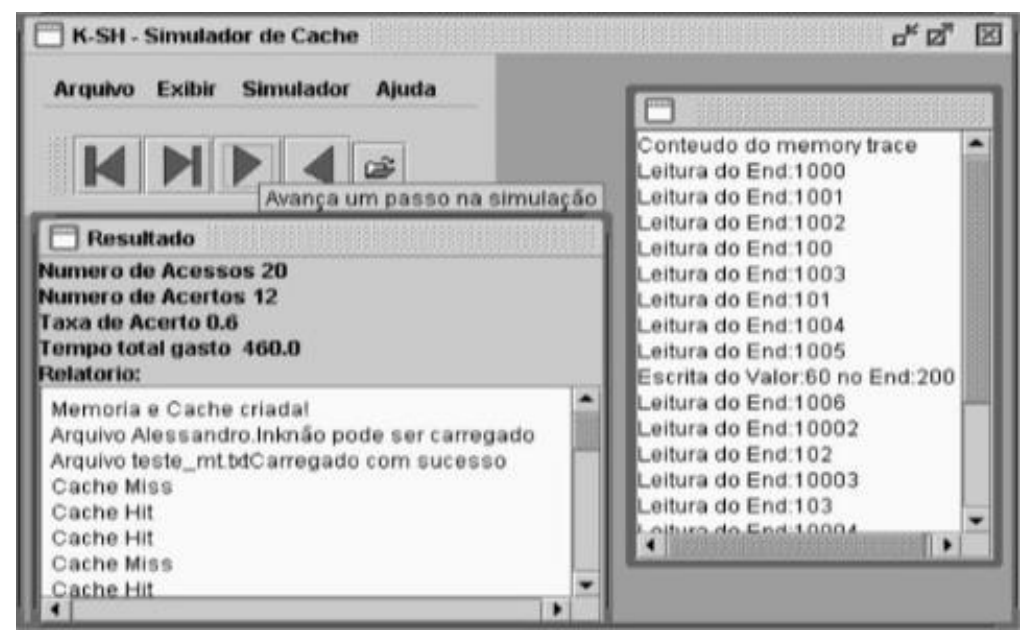

Figura 22 - Simulador de memória cache KSH (Rodrigues, 2012)

O Didatic Cache Memory Simulator, mais conhecido como DCMSim, também possui uma interface gráfica para a simulação de memória cache, como pode ser visualizado na Figura 23. Desenvolvido pelo Grupo de Sistemas Digitais e Computacionais (GSDC) da PUC, permite a simulação utilizando algoritmos de mapeamento direto, associativo e associativo por conjunto, políticas de substituição FIFO e LRU e políticas de escrita write-through e write-back, ajuste do tipo da memória cache em unificado ou separado, geração de arquivos de rastro e um log detalhado que armazena os dados das simulações. Esta ferramenta também dispõe de alguns planos de aulas para o direcionamento de atividades nela realizadas (Cordeiro et al, 2003). 


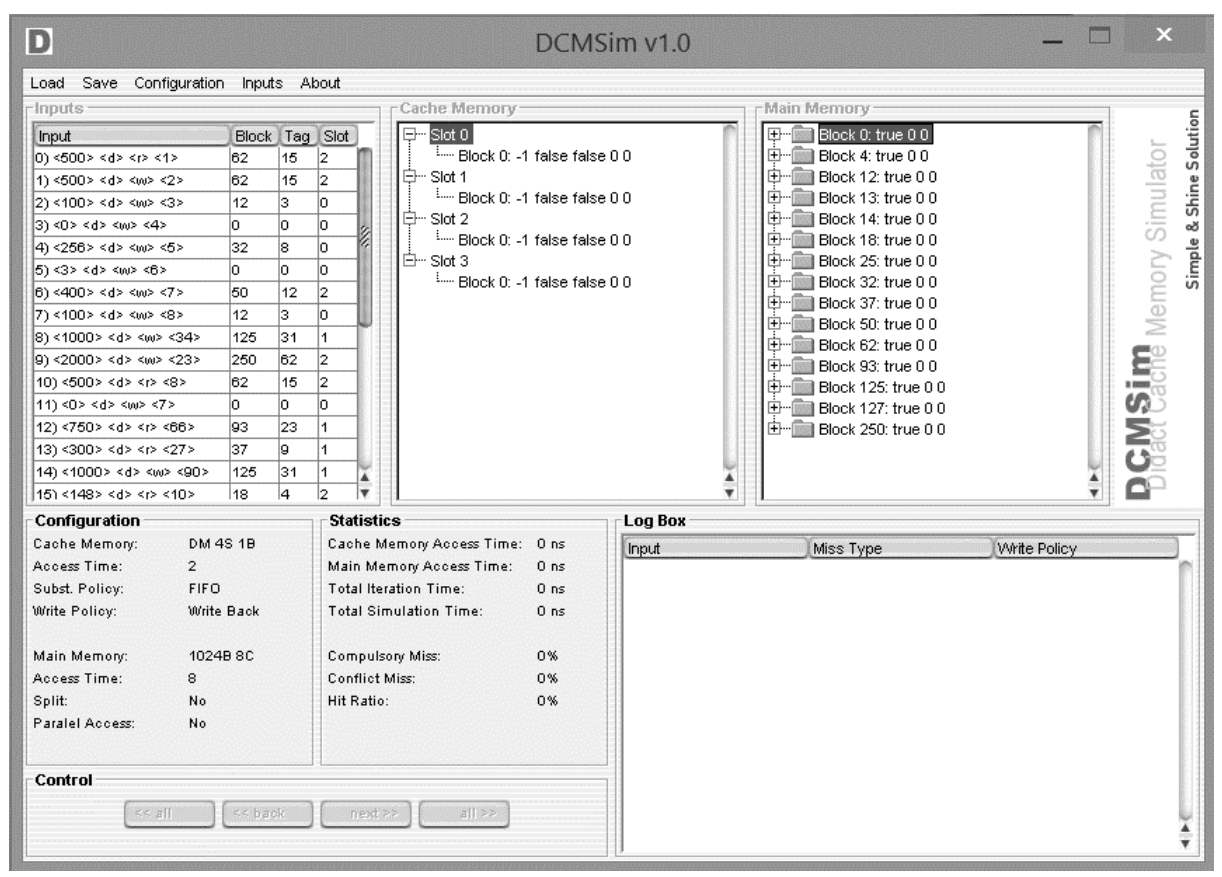

Figura 23 - Simulador de memória cache DCMSim

O LBGCache é um simulador de memória cache desenvolvido no Centro Federal de Educação Tecnológica do Rio Grande do Norte (CEFET-RN). Através de sua interface gráfica visualizada na Figura 24, permite a simulação utilizando algoritmos de mapeamento direto, associativo e associativo por conjunto, políticas de substituição FIFO, LRU, LFU e aleatória e políticas de escrita write-through e write-back, configuração da memória cache em unificada ou separada, geração de arquivos de rastro e um log com um resumo do desempenho das caches, caso configure-se mais de uma para a simulação (Moreira K., 2005).

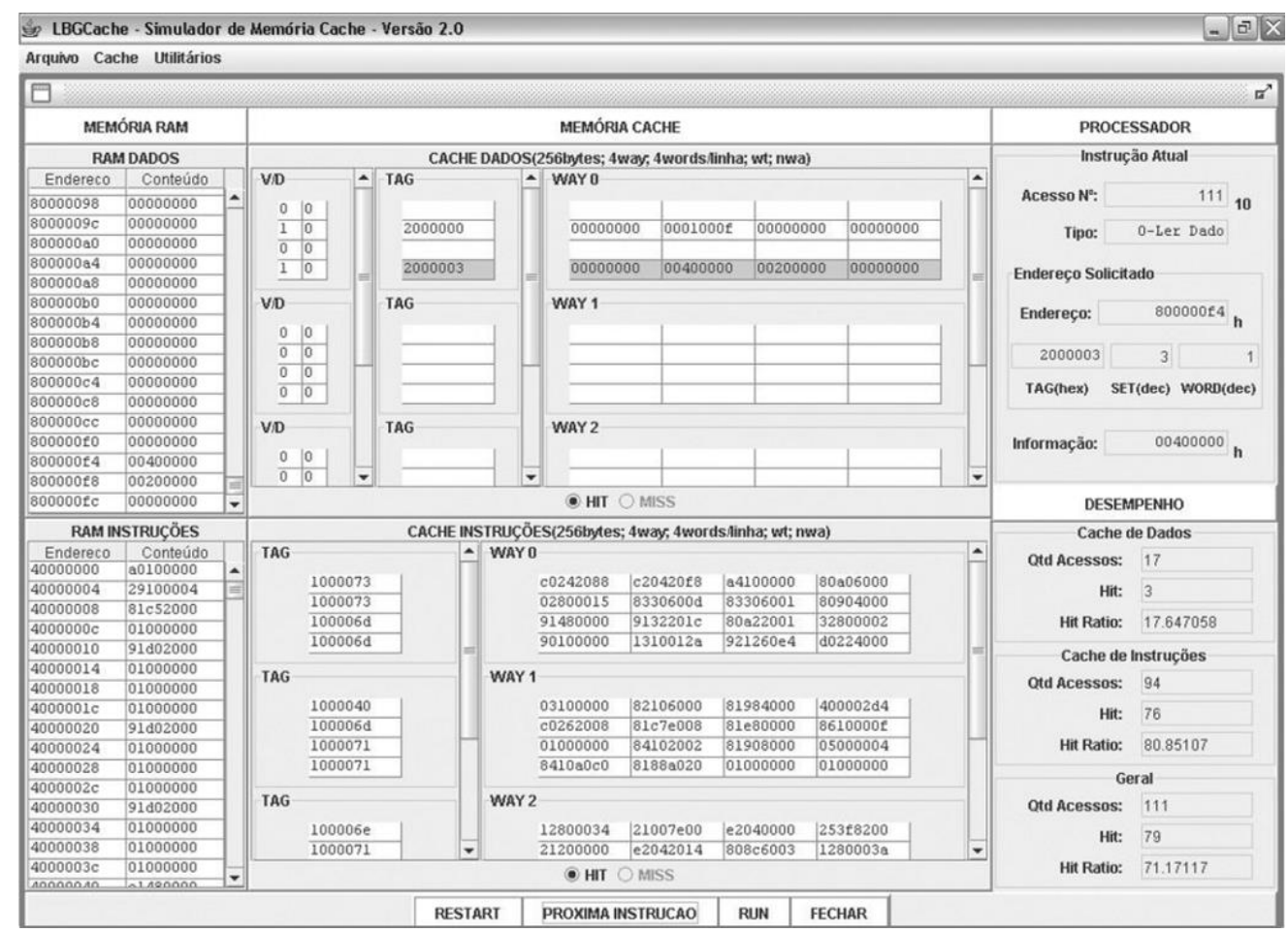

Figura 24 - Simulador de memória cache LBGCache (Netto, 2007) 
A Figura 25 exibe o Multilevel and Split Cache Simulator, mais conhecido como MSCSim, que também simula a memória cache através de sua interface gráfica. Desenvolvido pela PUC de Minas Gerais, permite a simulação utilizando algoritmos de mapeamento direto, associativo e associativo por conjunto, políticas de substituição FIFO e LRU e políticas de escrita write-through e write-back. Também permite a configuração do tipo do acesso à memória em sequencial ou paralelo, além do ajuste do tipo da memória cache em unificado ou separado, geração de arquivos de rastro, $\log$ das operações e configurações de diferentes tipos de arquitetura (Coutinho, 2006).

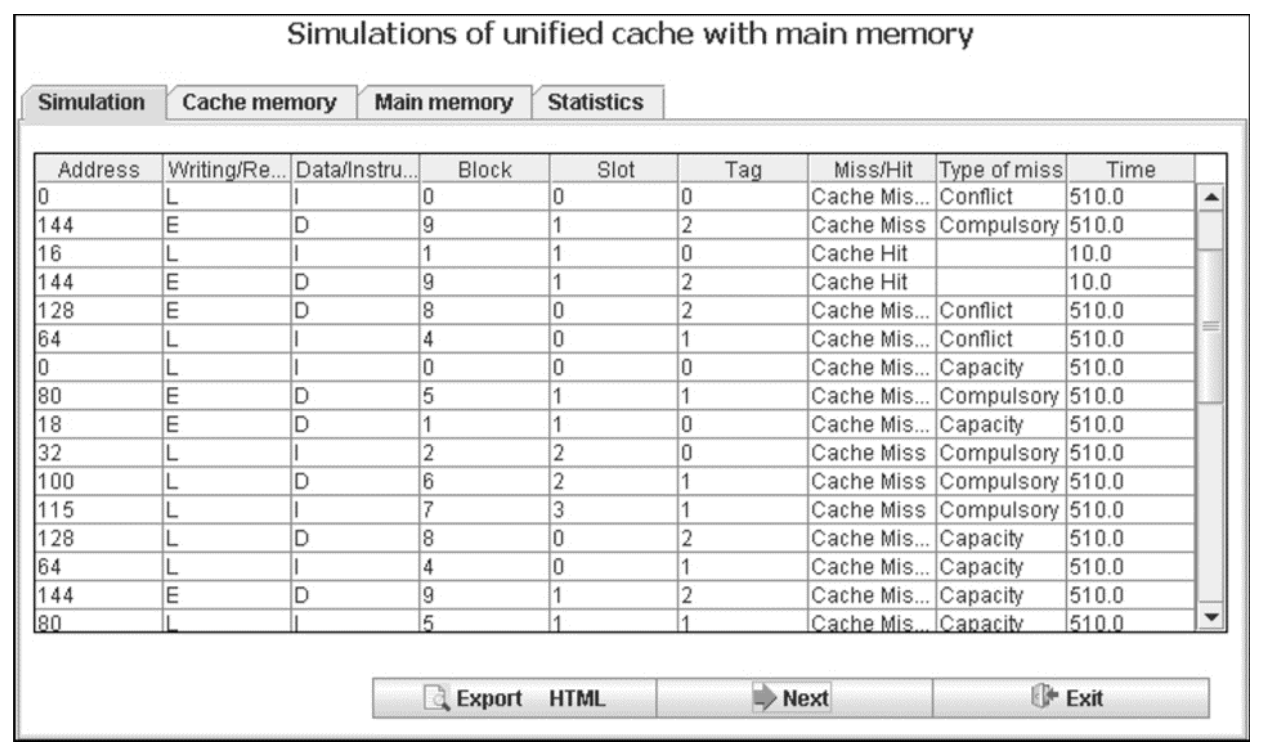

Figura 25 - Simulador de memória cache MSCSim (Coutinho, 2006)

Apesar de não possuir interface gráfica e não permitir a simulação de caches separadas, o CacheSim é um simulador conhecido na área acadêmica e por isso faz-se necessário a sua apresentação. Desenvolvido a partir da linguagem C no Departamento de Engenharia da Informação da Faculdade de Engenharia da Universidade de Pisa em 1994, permite a simulação utilizando algoritmos de mapeamento direto, associativo e associativo por conjunto, políticas de substituição FIFO, LRU e aleatória e políticas de escrita write-through e write-back, além de possibilitar a configuração do tamanho do bloco e grau de associatividade (Rodrigues, 2012). Sua interface de utilização, em modo texto, pode ser visualizada pela Figura 26.

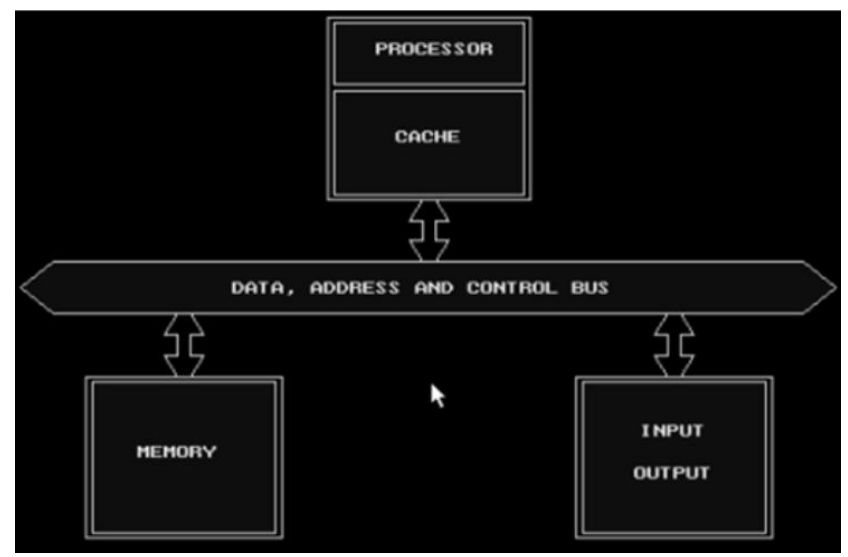

Figura 26 - Simulador de memória cache CacheSim (Rodrigues, 2012) 
A Tabela 1 apresenta as características utilizadas para comparar os simuladores: Split indica se é possível ou não simular caches que armazenam dados e instruções de forma separada; caches multiníveis define se o simulador é capaz de trabalhar com diferentes níveis de cache; acesso paralelo determina se o simulador executa acessos paralelos à memória cache, além de acessos sequenciais; tempo de acesso define se o simulador exibe os tempos dos acessos realizados na memória cache; associatividade indica se diferentes níveis de associatividade (número de blocos por conjunto) podem ser considerados; trace aponta se o simulador é capaz de gerar novos traços de memória a cada nova execução; estatísticas indicam se há métricas que mostram o desempenho observado durante à execução; Graphical User Interface (GUI) determina se o simulador possui uma interface gráfica e não apenas uma interface de texto e, por fim, download indica se o simulador está disponível para download em um repositório de objetos de aprendizagem (Rodrigues, 2012).

Tabela 1 - Tabela de características dos simuladores

\begin{tabular}{lccccc}
\hline \multicolumn{1}{c}{ Características } & KSH & DCM Sim & LBG Cache & MSC Sim & Amnesia \\
\hline Split (Caches separadas) & & $\mathrm{X}$ & $\mathrm{X}$ & $\mathrm{X}$ & $\mathrm{X}$ \\
Caches multiníveis & & & & $\mathrm{X}$ & $\mathrm{X}$ \\
Acesso paralelo & $\mathrm{X}$ & & & $\mathrm{X}$ & \\
Tempo de acesso & $\mathrm{X}$ & $\mathrm{X}$ & $\mathrm{X}$ & $\mathrm{X}$ & $\mathrm{X}$ \\
Associatividade & & $\mathrm{X}$ & & $\mathrm{X}$ & $\mathrm{X}$ \\
Trace & & $\mathrm{X}$ & $\mathrm{X}$ & $\mathrm{X}$ & $\mathrm{X}$ \\
Estatísticas & $\mathrm{X}$ & $\mathrm{X}$ & $\mathrm{X}$ & $\mathrm{X}$ & $\mathrm{X}$ \\
GUI & $\mathrm{X}$ & $\mathrm{X}$ & & & $\mathrm{X}$ \\
Planos de aula & & & & & $\mathrm{X}$ \\
Tutoriais & & & & & $\mathrm{X}$ \\
Download & & & &
\end{tabular}

Analisando a Tabela 1, pode-se observar que o MSCSim é o que mais se aproxima das funcionalidades existentes na ferramenta Amnesia. No entanto, ele não possui planos de aula e tutoriais que podem guiar e facilitar o aprendizado de um aluno. Sua localização e aquisição também é um pouco difícil, pois não está armazenado em um repositório de objetos de aprendizagem.

Conforme descrito na Seção 4.3, a ferramenta Amnesia possui uma interface textual e também uma interface gráfica que possibilitam a simulação de um programa em um ambiente previamente configurado, possibilitando a visualização em tempo real das informações contidas na memória principal e sua alocação detalhada na memória cache exibindo o espalhamento dos bits de cada endereço requisitado e a determinação do byte-offset, word-offset, set e tag. Além disso, ela foi armazenada no repositório de objetos de aprendizagem MERLOT, com o objetivo de disponibilizá-la de forma segura e confiável através de uma plataforma distribuída para facilitar sua utilização.

\subsection{Considerações finais}

A ferramenta Amnesia, como as demais ferramentas analisadas, visam auxiliar o ensino da hierarquia de memória, simulando o uso de recursos como registradores, caches e memória. No entanto, a 
ferramenta Amnesia tem um escopo abrangente, profundo e flexível, considerando aspectos funcionais, estruturais e de desempenho, desde registradores até memória secundária, diferenciando-a das demais ferramentas.

Outro diferencial, baseia-se no seu objetivo de ser um objeto de aprendizagem, associado a planos de aula e tutoriais utilizados para aprimorar o nível de aprendizado dos alunos, possibilitando que construção do conhecimento sobre um determinado conteúdo seja obtida de uma forma mais prática e colaborativa, facilitando a assimilação dos tópicos abordados na teoria.

O próximo capítulo descreve como o módulo de memória cache foi totalmente revisado e validado junto com o desenvolvimento de novas funcionalidades que foram incorporadas para facilitar e melhorar seu funcionamento, transformando-o em um objeto de aprendizagem. 


\section{Transformação da ferramenta}

\section{Amnesia em um objeto de aprendizagem}

\subsection{Considerações iniciais}

Conforme observado no capítulo anterior, existem várias ferramentas que visam auxiliar o ensino de hierarquia de memória e a ferramenta Amnesia é uma delas. No entanto, identificou-se no módulo de memória cache da ferramenta Amnesia uma oportunidade de se construir um objeto de aprendizagem, associado a planos de aula e tutoriais utilizados para aprimorar o nível de aprendizado dos alunos.

Como um objeto de aprendizagem pode ser comparado a um átomo, onde um pequeno objeto pode ser combinado com outros formando um maior (Wiley, 2000b), após a análise da ferramenta Amnesia, concluiu-se que cada um de seus três módulos processador, cache e memória virtual poderia ser tratado como um objeto de aprendizagem. Através da combinação destes três objetos de aprendizagem, um objeto maior seria formado: o objeto de aprendizagem Amnesia.

O objetivo deste projeto de mestrado foi transformar o módulo de memória cache da ferramenta Amnesia em um objeto de aprendizagem. Para atingi-lo, funcionalidades existentes foram readequadas e novas funcionalidades foram desenvolvidas, testadas e implementadas. Foram concebidos, validados e implementados planos de aula e questionários de avaliação e usabilidade. Um tutorial que descreve o funcionamento do objeto foi elaborado e metadados, no padrão LOM, foram catalogados com o intuito de melhorar sua visibilidade no repositório de objetos de aprendizagem MERLOT, onde o objeto de aprendizagem foi cadastrado.

Ressalta-se que o módulo de memória virtual também vem sendo transformado em um objeto de aprendizagem através do projeto de mestrado intitulado "Aplicando objetos de aprendizagem para melhorar a qualidade do ensino de memória virtual" de autoria do aluno de mestrado Carlos Emilio de Andrade Cacho, sob orientação do Prof. Paulo Sérgio Lopes de Souza (Cacho, 2014).

Assim, este capítulo proporcionará o conhecimento e o entendimento de cada uma das ações realizadas no processo de transformação do módulo de memória cache da ferramenta Amnesia em um objeto de aprendizagem.

\subsection{Desenvolvimento de planos de aula e questionários de avaliação $e$ usabilidade}

Visando diminuir a distância entre teoria e prática com o objetivo de facilitar e melhorar o aprendizado na disciplina de Organização e Arquitetura de Computadores, este projeto de mestrado baseou-se na afirmação de que um objeto de aprendizagem deve ser bem estruturado e dividido em três partes bem definidas (Singh, 2001).

A primeira delas são os objetivos, que possibilitam demonstrar ao aprendiz o que ele poderá aprender a partir da utilização desse objeto, ressaltando ou não uma lista de conhecimentos prévios necessários para um bom aproveitamento de todo o conteúdo disponível. 
A segunda refere-se ao conteúdo instrucional, responsável por apresentar todo o material didático necessário para que, após o término da atividade, o aluno possa atingir os objetivos citados.

Por fim, a prática e o feedback evidenciam que ao final de cada atividade com o objeto, julga-se necessário que o aprendiz verifique se o seu desempenho atingiu ou não as expectativas. Caso não tenha atingido, este aprendiz deve ter a liberdade para voltar a utilizar-se do objeto quantas vezes necessário.

Para demonstrar ao aluno o que ele poderia aprender através da utilização do objeto de aprendizagem no apoio ao ensino, foi desenvolvido um plano de aula que pode ser visualizado no Apêndice A. Com o objetivo de reforçar, na prática, o conteúdo teórico de memória cache ministrado na disciplina de Organização de Computadores Digitais I (SSC0112) do ICMC/USP, o plano de aula abordou os seguintes assuntos: motivação e conceitos, funções de mapeamento, políticas de substituição e de atualização, aspectos de desempenho, caches multiníveis e caches unificadas e separadas.

Em todas as atividades do plano de aula foram definidos claramente a motivação, objetivo, detalhamento e resultados esperados, para evitar uma abordagem superficial ou ausência de contextualização que dificultasse o entendimento e a fixação dos conceitos abordados pelo objeto. Durante a prática de cada atividade, acompanhada de um monitor, o aluno poderia avaliar se os resultados esperados foram atingidos e, se necessário, poderia realizar a atividade novamente quantas vezes julgasse necessário, mantendo-se completamente inserido no contexto do aprendizado e participando da construção do seu próprio conhecimento.

A primeira atividade abordava a execução de um programa sobre uma arquitetura sem memória cache, para demonstrar aos alunos que o tempo de acesso aos dados e instruções na memória principal é alto. Já a segunda, introduzia os benefícios obtidos com o uso de uma memória cache, executando um programa sobre uma arquitetura com memória cache para demostrar que sua utilização pode diminuir os acessos à memória principal através do princípio da localidade temporal e consequentemente diminuir o tempo de execução de um programa, visto que o tempo de acesso à memória cache é vinte vezes menor do que à memória principal (Patterson e Hennessy, 2010).

A terceira atividade permitia a execução de um programa sobre uma arquitetura com memória cache com um bloco por conjunto, demonstrando o mapeamento direto, a transferência e a ordem de leitura dos dados do processador até a memória principal, o espalhamento de bits em byte-offset, wordoffset, set, tag de um endereço de memória requisitado, a validação do bloco procurado pelo processador e se ele estava ou não na memória cache, a determinação do local que o bloco da memória principal ocupava na memória cache e, por fim, a verificação do resultado do acesso à memória cache, ou seja, se resultou em um acerto (hit) ou uma falha (miss).

A quarta atividade mostrava a execução de um programa sobre uma arquitetura com uma memória cache com mais de uma palavra por bloco, para demonstrar o princípio da localidade espacial e ressaltar a utilidade do campo word-offset no espalhamento de bits. A quinta abordava a execução de um programa sobre uma arquitetura com uma memória cache com mais de um bloco por conjunto para demonstrar o mapeamento associativo por conjunto. Já a sexta, permitia a execução de um programa sobre uma arquitetura com uma memória cache com todos os blocos em um único conjunto, para demonstrar o mapeamento totalmente associativo.

A sétima atividade permitia a execução de um programa sobre uma arquitetura com uma memória cache que resultasse em uma alta taxa de substituição, para compreender como funcionavam as políticas de substituição FIFO e LRU. 
A oitava atividade tratava das operações de escrita, pois mostrava a execução de um programa com a função de escrever na memória cache, ressaltando a importância de se existir dados na posição onde a escrita será realizada, caso contrário, além da operação de escrita, uma operação de carregamento deve ser executada. A nona, também mostrava a execução de um programa de escrita na memória cache, para compreender como funcionavam as políticas de escrita write-through e write-back que têm a função de manter os dados da memória cache consistentes com os dados da memória principal.

A décima atividade possibilitava a execução de um programa sobre uma arquitetura com uma memória cache com mais de um nível, para demonstrar o funcionamento de caches multiníveis e o conceito da penalidade por falta.

Finalmente, a décima primeira, permitiu a execução de um programa sobre uma arquitetura com uma memória cache separada, para demonstrar o funcionamento da cache separada em relação a cache unificada quanto à busca de instruções e dados.

Em todas as atividades foram coletadas estatísticas com objetivo de analisar e comparar os aspectos de desempenho, como taxas de acerto e falha e tempo total de execução, para que o aluno compreendesse e reafirmasse, na prática, o conceito visto na teoria em sala de aula. Desta forma, o plano de aula também poderia ser ajustado manualmente para diferentes turmas ou até mesmo para diferentes alunos, considerando o grau de aprendizado de cada um.

Ressalta-se que todo o plano de aula, bem como o exemplo de um arquivo de arquitetura com configurações de memória cache e o programa executado, representado pelo seu arquivo de rastro (trace), podem ser observados nos Apêndices A, B e C respectivamente.

Com o objetivo de se avaliar o feedback de cada aluno em relação ao objeto de aprendizagem, visando diminuir a distância entre a promessa e a realidade, dois questionários foram adaptados com base nos estudos realizados por Gama (2007) e Santos et al (2012) e introduzidos no processo de aprendizagem. O primeiro, de expectativa de uso, antes da utilização do objeto e o segundo, logo após sua utilização, tratava da reação ao uso. Os dois questionários podem ser visualizados nos Apêndices D e E, respectivamente.

Através do questionário de expectativa de uso, os alunos poderiam expressar se estavam ou não em dúvida quanto à utilização de um objeto de aprendizagem e também determinar o grau do seu conhecimento sobre o conteúdo que seria abordado no objeto.

Através do questionário de reação ao uso, poderia observar-se o percentual de alunos que utilizariam o objeto novamente, o percentual de alunos que se sentiram seguros quanto aos resultados nele obtidos e o percentual de alunos que declararam saber mais sobre o conteúdo abordado pelo objeto. Aliado a isso, seria possível contabilizar o percentual de alunos que consideraram que o conteúdo abordado na teoria em sala de aula tornou-se mais interessante com a utilização do objeto de aprendizagem e a motivação em utilizar outros objetos para auxiliar na aprendizagem. 


\subsection{Implementações e readequações de funcionalidades}

Outro ponto crítico, devidamente analisado e discutido durante a transformação da ferramenta em um objeto de aprendizagem, foi a aparência (design) do objeto. Observando-se as Figuras 27 e 28, pode-se notar diversas modificações realizadas entre a tela da ferramenta Amnesia, representada pela Figura 27 e a tela do objeto de aprendizagem de memória cache, representada pela Figura 28.

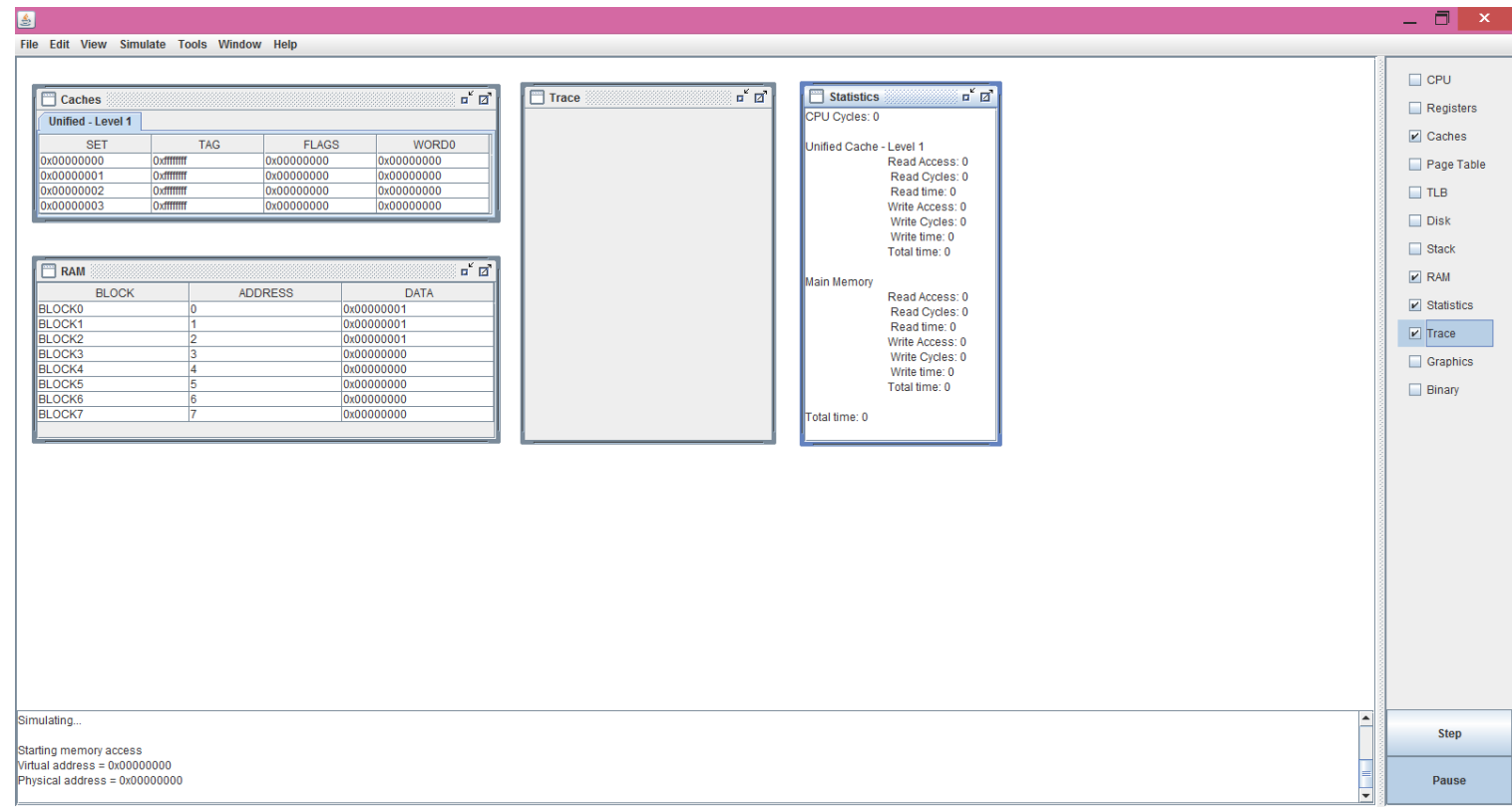

Figura 27 - Ferramenta Amnesia (antes do processo de transformação)

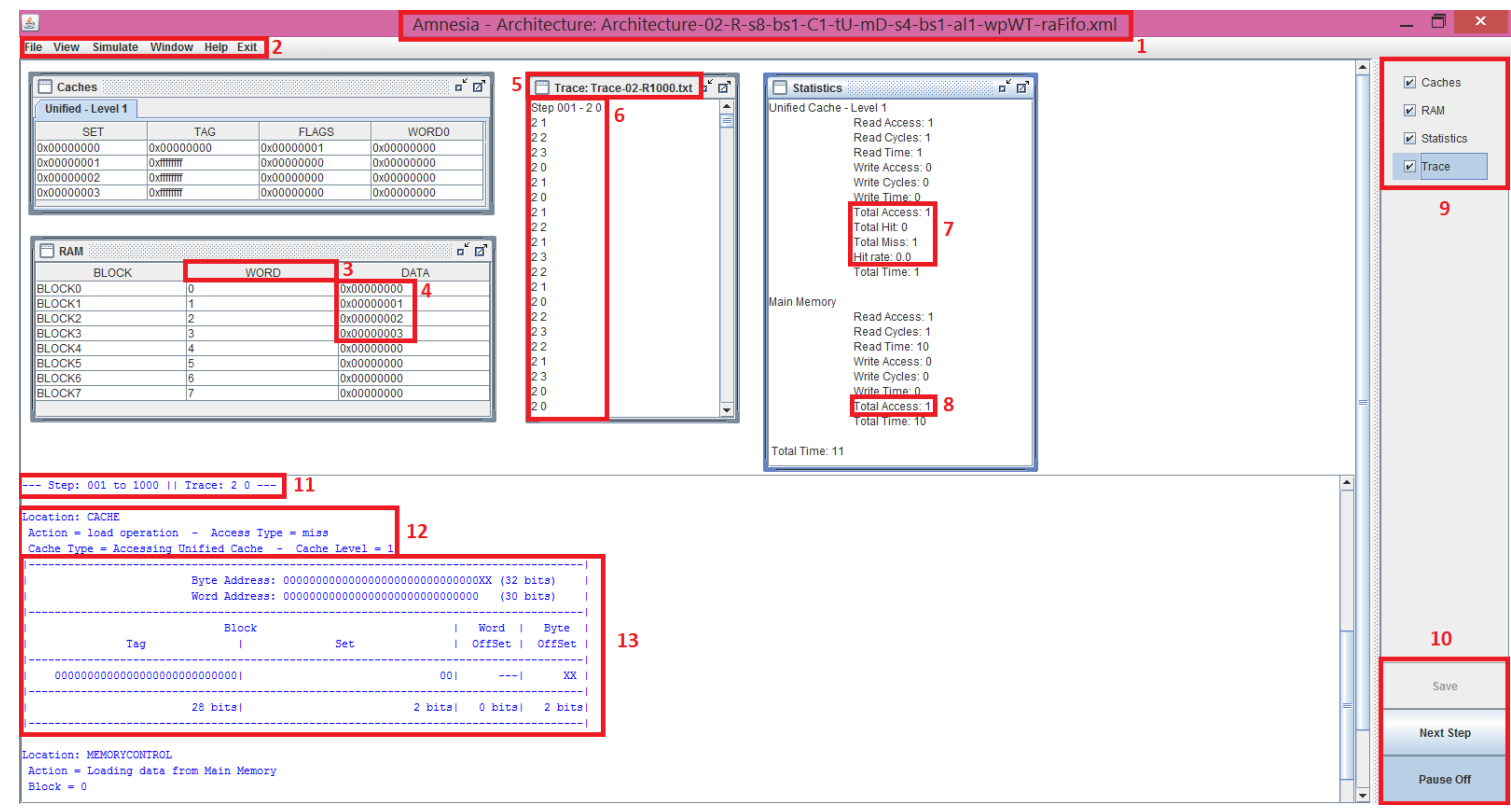

Figura 28 - Objeto de aprendizagem de memória cache (depois do processo de transformação)

Todas as modificações foram enumeradas e serão detalhadamente explicadas a seguir:

1) Inserção do nome do arquivo referente à arquitetura utilizada pela simulação em execução na barra título do objeto de aprendizagem, facilitando a identificação deste arquivo pelo usuário do objeto; 
2) Retirada dos menus principais Edit e Tools da barra de ferramentas. O menu Edit permitia a configuração de uma arquitetura através de uma interface, mas apresentava problemas no momento de salvar o arquivo $\mathrm{xml}$ com os valores parametrizados pelo usuário, além de permitir configurações de parâmetros inválidos. Assim, concluiu-se que ele deveria ser retirado e todas as configurações de arquitetura deveriam ser previamente configuradas junto com a elaboração do plano de aula para atingir um determinado objetivo. Já o menu Tools, possibilitava o acesso ao conversor de código binário para código Assembly MIPS e vice-versa, mas concluiu-se que este conversor seria tratado como um novo objeto de aprendizagem em outro momento, visto que em todas as atividades do objeto de aprendizagem de memória cache foram utilizados arquivos de rastro (trace) e não arquivos binários;

3) Alteração do rótulo que mantém o endereço de armazenamento na memória RAM, onde a palavra Address foi alterada para Word, pois como a memória RAM tem seu endereço baseado na palavra, concluiu-se que a terminologia mais correta para este rótulo seria Word;

4) Modificação do conteúdo inicial armazenado em cada palavra da memória RAM. Na ferramenta Amnesia, o conteúdo era previamente carregado com o valor "1" em todas as palavras contidas na memória RAM e no objeto de aprendizagem concluiu-se que o conteúdo previamente carregado deveria ser de acordo com a palavra correspondente, ou seja, para a palavra 0 o conteúdo seria 0 , para a palavra 1 o conteúdo 1 e assim sucessivamente, tornando o processo mais didático;

5) Inserção do nome do arquivo referente ao programa utilizado pela simulação em execução na barra de título do componente Trace;

6) Identificação de cada passo do Trace, executado em tempo real pela simulação;

7) Inclusão do total de acessos, número de acertos e falhas, bem como o hit hate da memória cache no componente Statistics, possibilitando o acompanhamento dessas informações passo a passo durante uma simulação;

8) Inclusão do total de acessos à memória RAM no componente Statistics, possibilitando o acompanhamento dessa informação passo a passo durante uma simulação;

9) Redefinição das caixas de seleção dos componentes que podem ser visualizados durante uma simulação. Como o objeto de aprendizagem abordou a simulação de uma memória cache através da execução de um programa representado pelo seu arquivo de rastro (trace), apenas os componentes Caches, RAM, Statistics e Trace permaneceram visíveis. Os demais componentes: CPU, Registers, Page Table, TLB, Disk, Stack, Graphics e Binary serão tratados em outros objetos de aprendizagem;

10) Alteração dos nomes dos botões de ação do objeto, onde os botões Step e Pause foram renomeados para Next Step e Pause On ou Pase Off respectivamente, facilitando a ação do usuário durante uma simulação. O botão de ação Save também foi incluído e permitiu salvar o $\log$ de uma simulação em um arquivo texto, com o objetivo de proporcionar seu estudo offline, ou seja, sem o funcionamento do simulador;

11) Inclusão do passo atual e do total de passos da simulação no terminal de saída;

12) Identificação de qual componente do objeto é afetado pelo passo atual da simulação, além de fornecer maiores detalhes das operações realizadas nesse passo; 
13) Demonstração do espalhamento dos bits de um endereço de memória requisitado e a determinação do byte-offset, word-offset, set e tag a cada instrução executada. Assim, tornouse possível compreender qual local da memória cache é utilizado para armazenar (store) ou recuperar (load) uma informação em um determinado momento.

Ressalta-se que para readequar o terminal de saída e implementar as novas funcionalidades através das modificações 11, 12 e 13, todo o sistema de log do objeto foi reestruturado, tornando-o mais didático e facilitando sua leitura pelo usuário final. Na ferramenta Amnesia, para se obter uma determinada ação que não fosse a última executada na simulação, deveria ser realizada uma pesquisa textual no terminal de saída que continha todas as ações realizadas. No entanto, isto causava lentidão no simulador e em diversas vezes até o seu travamento, desestimulando sua utilização.

Após as alterações, o log do simulador passou a ser tratado como uma pilha de informações, permitindo o armazenamento de todas as ações executadas além de facilitar e agilizar a busca de qualquer ação no processo de simulação.

Analisando a Figura 29, é possível notar que o log passou a armazenar a descrição e categoria da ação executada durante a simulação. Essa categorização permitiu que $\log s$ de diferentes módulos da ferramenta, sejam eles processador, cache ou memória virtual passassem a ser tratados de forma centralizada, porém especializados para cada tipo de categoria, como pode ser observado na Figura 30, que mostra o procedimento responsável pela impressão do log no terminal de saída.

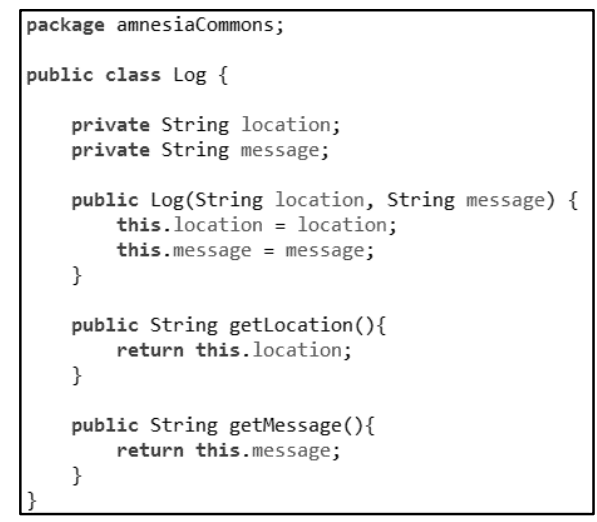

Figura 29 - Classe $\log$

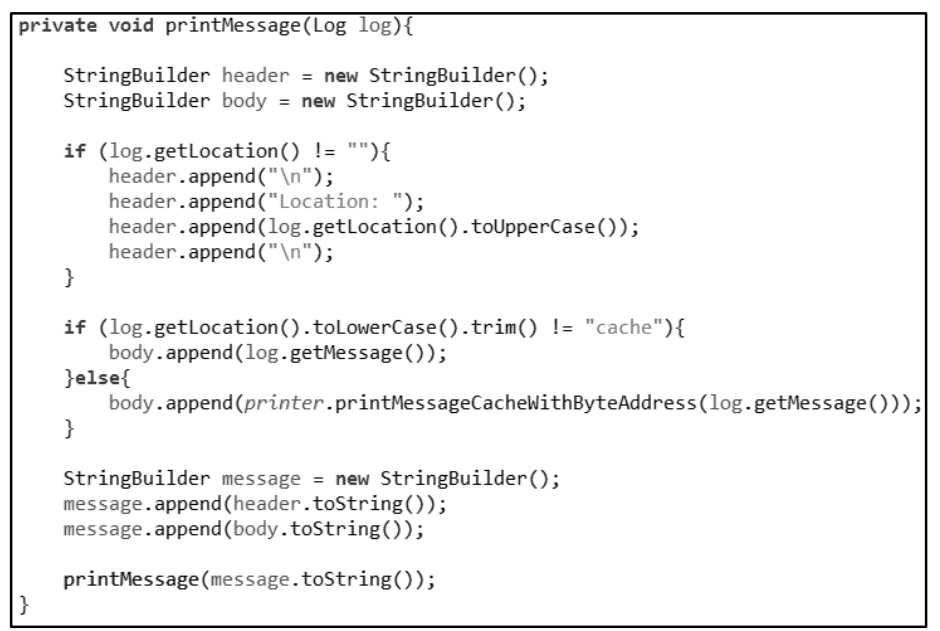

Figura 30 - Procedimento responsável pela impressão do log no terminal de saída 
Além das modificações no design do objeto, também foram realizadas modificações em funcionalidades que não são visíveis pelo usuário final, mas poderiam interromper o funcionamento de uma simulação e até travar a ferramenta. Dentre essas modificações ressaltam-se duas: alteração do processo de carregamento dos arquivos de arquitetura e rastro e a correção na contabilização das estatísticas geradas por uma simulação.

$\mathrm{Na}$ ferramenta Amnesia, era possível carregar um arquivo de arquitetura ou de rastro durante a execução de uma simulação, ocasionando o travamento desta simulação e consequentemente o travamento da ferramenta. Para realizar uma nova simulação, a única solução possível era reiniciar todo o processo, impactando negativamente na experiência do usuário. Já no objeto de aprendizagem, o processo de carregamento de uma arquitetura ou arquivo de rastro foi totalmente reescrito e seu funcionamento foi liberado somente antes da execução de uma nova simulação. Assim, após o início de uma simulação os menus File > Load Architecture e File > Load Trace foram bloqueados e, somente após sua finalização, liberados.

Outro erro grave, mas quase imperceptível, ocorria na execução de uma simulação: a contabilização incorreta de estatísticas. Alguns comandos, como o Step, eram identificados pela letra inicial de seu nome no núcleo do sistema. No entanto, o comando Statistics, que também tem a letra "S" no início de seu nome, era interpretado como se fosse o comando Step em alguns momentos. Assim, ao invés de se coletar as estatísticas, a ferramenta interpretava o comando para direcionar a simulação para o próximo passo, invalidando todo o processo, visto que as estatísticas de um passo da simulação não eram devidamente contabilizadas. Já no objeto de aprendizagem, todos os comandos foram revistos e sua interpretação passou a ser pelo seu nome completo, facilitando o entendimento do código fonte do núcleo do sistema por parte do programador, bem como certificando que cada ação da simulação seria devidamente executada.

Finalmente, foi desenvolvido um tutorial de funcionamento do objeto de aprendizagem de memória cache com o objetivo de facilitar sua utilização pelo usuário final. Este tutorial abrange todas etapas e ações que podem ser executadas em uma nova simulação, conforme descrito na Seção 4.4 do Capítulo 4.

\subsection{Armazenamento em um repositório de objeto de aprendizagem}

Como os Repositórios de Objetos de Aprendizagem (ROA) caracterizam-se por fornecerem uma interface formal através da qual os objetos podem ser cadastrados, armazenados e acessados de forma segura e confiável através de uma plataforma distribuída para a manutenção e preservação do acervo digital, o objeto de aprendizagem de memória cache produzido neste projeto de mestrado foi cadastrado no MERLOT, como mostra Figura 31. O perfil de metadados utilizado por este repositório é composto por 15 elementos no padrão LOM, exibidos na Tabela 2. 


\section{Aminesia - Cache Simulator}

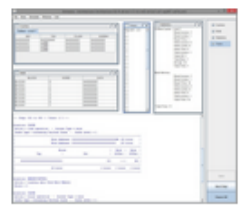

Amnesia is a memory hierarchy simulator in von Neumann architecture (Patterson, 2005). Its function is to demonstrate how registers (based on the MIPS processor), caches, main memory and virtual memory work together in a hierarchical view. Amnesia aims to facilitate and improve learning in Computer Organization and Architecture courses

Go to material

\section{Discuss this Material}

Material Type: Simulation

Technical Format: $\mathrm{HTML} / \mathrm{Text}$

Date Added to MERLOT: Janeiro 27, 2015

Date Modified in MERLOT: Janeiro 27, 2015

Authors:

Fernando Tiosso

Sarita Mazzini Bruschi

ICMC/USP

Paulo Sergio Lopes de Souza

ICMC/USP

Carlos Emilio de Andrade Cacho

ICMC/USP

Submitter: Fernando Tiosso

Keywords: Computer Architecture, Cache Memory, Simulation in Lab Environments, Education, Learning Objects, Amnesia

\section{[Report Broken Link] [Report as Inappropriate]}

\section{About}

Primary Audience: Graduate School

Mobile Compatibility: Not specified at this time

Technical Requirements:

JAVA 6.5 or higher installed in computer.

Language: English

Material Version: 1.0

Cost Involved: unsure

Source Code Available: no

Accessiblity Information Available: yes

Copyright: yes

Creative Commons: no

\section{Browse in CATEgories}

\section{DetaILs}

Editor Review (not reviewed) User Rating (not rated)

Comments (none)

Learning Exercises (none)

Bookmark Collections (none)

Course ePortfolios (none)

Accessibility Info (none)

Rate this material

Create a learning exercise

Add accessibility information

Bookmark this material

Connections

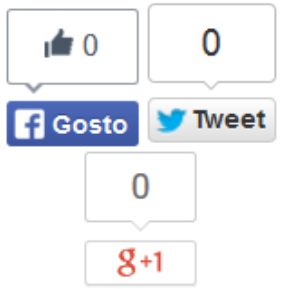

Pinit in $\oplus$ I

- $\underline{\text { Science and Technology / Computer Science / Computer Simulation }}$

Discussion

Discussion for Amnesia - Cache Simulator

$\underline{L}$ og in to participate in the discussions or Register if you are not already a MERLOT member.

Return to Top of Page

Figura 31 - Tela de cadastro do objeto de aprendizagem no MERLOT 
Tabela 2 - Tabela de metadados cadastros no padrão LOM para o repositório MERLOT

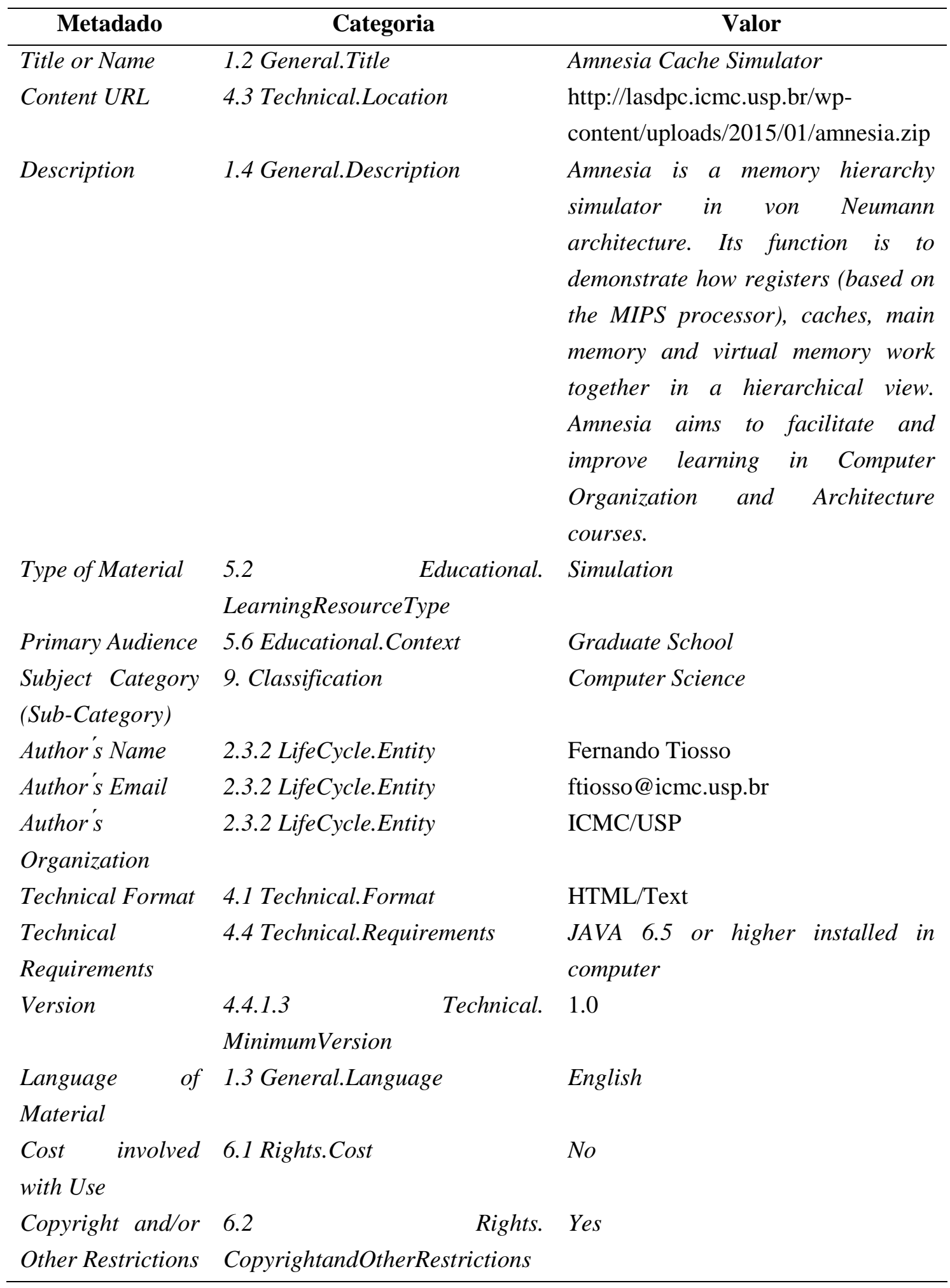

Assim, o objeto de aprendizagem de memória cache encontra-se disponível em uma comunidade virtual, onde professores e alunos podem encontrá-lo e utilizá-lo durante seus trabalhos. 


\subsection{Considerações finais}

Através da readequação de funcionalidades existentes, desenvolvimento, testes e implementação de novas funcionalidades, concepção de planos de aula e questionários de avaliação e usabilidade e desenvolvimento de um tutorial que compreende o funcionamento de todo processo de simulação, foi possível transformar o módulo de memória cache da ferramenta Amnesia em um objeto de aprendizagem.

Com o objetivo de disponibilizá-lo de forma fácil, eficiente e segura para a comunidade, o objeto de aprendizagem também foi armazenado no repositório de objetos de aprendizagem MERLOT.

Para demonstrar ao aluno o que ele poderia aprender através da utilização do objeto de aprendizagem no apoio ao ensino, reforçando na prática, o conteúdo teórico de memória cache ministrado em sala de aula, experimentos foram realizados e analisados. As conclusões resultantes da análise desses experimentos podem ser visualizadas no próximo capítulo. 


\section{Avaliação do objeto de aprendizagem}

\subsection{Considerações iniciais}

Objetivando verificar a eficiência do objeto de aprendizagem desenvolvido a partir do módulo memória cache da ferramenta Amnesia, dois experimentos foram realizados com os seguintes objetivos: (1) analisar se o objeto de aprendizagem melhorou, de fato, a aprendizagem dos alunos no assunto memória cache e (2) verificar a opinião dos alunos em relação a sua utilização.

O primeiro experimento contou com a participação de alunos do curso de graduação em computação, especificamente da disciplina Organização de Computadores Digitais I (SSC0112), a qual faz parte da grade curricular dos alunos do curso de Bacharelado em Ciências de Computação do ICMC/USP. O segundo experimento teve a participação de alunos do programa de pós-graduação de Ciências de Computação e Matemática Computacional do ICMC/USP, os quais estavam afastados há algum tempo dos conceitos relacionados à memória cache.

Assim, neste capítulo, serão descritos detalhadamente os dois experimentos realizados, bem como os resultados obtidos em cada um e suas conclusões.

\subsection{Experimentos realizados}

Os dois experimentos realizados visavam analisar se o objeto de aprendizagem contribuiria de forma positiva na aprendizagem dos alunos e verificar as opiniões de cada um em relação a sua utilização.

Com o objetivo de avaliar a efetividade de aprendizagem, em ambos experimentos foram aplicados dois testes distintos: um antes, chamado de pré-teste, e outro depois da utilização do objeto de aprendizagem, chamado de pós-teste. O pré-teste e o pós-teste podem ser visualizados nos Apêndices $\mathrm{F}$ e $\mathrm{G}$ respectivamente. Os dois testes foram elaborados com níveis semelhantes de dificuldade, contendo dois grupos diferentes de 15 questões cada um e abordando todo o conteúdo teórico de memória cache ministrado em sala de aula na disciplina de Organização de Computadores Digitais I.

Para os alunos da graduação, o pré-teste foi aplicado para todos os alunos da turma logo após o professor responsável pela disciplina ter ministrado o conteúdo teórico de memória cache. Para isso, o professor disponibilizou 15 minutos de uma de suas aulas. Para os alunos da pós-graduação, o pré-teste foi aplicado em um dia específico, sem que estes tivessem estudado o assunto antes. Depois da aula prática com o apoio do objeto de aprendizagem, detalhada a seguir, os alunos também responderam às questões do pós-teste em aproximadamente 15 minutos. Tanto para os alunos da graduação quanto para os alunos da pós-graduação, o pós-teste não foi aplicado imediatamente após a aula prática, deixandose um intervalo de alguns dias. Esse intervalo teve o objetivo de não favorecer possíveis resultados positivos.

A aula prática com o objeto de aprendizagem durou 2 horas para cada turma e abordou os principais assuntos relativos à memória cache. Os assuntos foram trabalhados com os alunos em 11 exercícios práticos, mediante plano de aula já descrito e detalhado na Seção 5.2 do Capítulo 5, considerando aspectos funcionais e estruturais de caches, bem como o impacto no desempenho para o programa em execução. Especificamente, foram abordados os seguintes assuntos: motivação e conceitos 
de caches; princípios de localidade temporal e espacial; mapeamento direto, totalmente associativo e associativo por conjunto; acertos e falhas nos acessos, políticas de substituição (FIFO e LRU) e de escrita (write-through e write-back), acessos de leitura e escrita nas caches, aspectos de desempenho, caches multiníveis e caches unificadas/separadas; espalhamento de bits do endereço requisitado em byte-offset, word-offset, set e tag, caches multiníveis e penalidade por falta vs taxa de faltas.

Em todos os exercícios foram coletadas as informações sobre o desempenho dos acessos com objetivo de analisar e comparar taxas de acerto/falta e tempo total da operação, para que os alunos compreendessem e reafirmassem, na prática, o conceito observado na teoria. A condução dos exercícios foi realizada por cada aluno e acompanhada por um monitor. $\mathrm{O}$ objeto de aprendizagem foi instalado pelo próprio aluno em sua máquina local e todos os exercícios foram executados individualmente, dependendo da total interação deste aluno para sua conclusão, mantendo-o completamente inserido no contexto de aprendizagem e participando da construção do seu próprio conhecimento.

Além da avaliação da efetividade de aprendizagem, nestes experimentos também foi avaliada a utilização do objeto de aprendizagem. No dia da realização da aula prática, foram respondidos dois questionários, um de expectativa (Apêndice D) e outro de reação ao uso (Apêndice E).

\subsection{Avaliação da efetividade de aprendizagem}

No primeiro experimento, envolvendo os alunos de graduação em computação que cursavam a disciplina Organização de Computadores Digitais I (SSC0112), a aplicação do pré-teste contou com a participação de 102 alunos, do pós-teste com 93 alunos e a aula prática com 32 alunos. Dentre todos os cenários obtidos neste experimento, destacam-se dois:

- Cenário 1: composto por 23 alunos que participaram dos dois testes e da aula prática;

- Cenário 2: composto por 52 alunos que participaram dos dois testes e não participaram da aula prática.

Para as análises que serão feitas a seguir, foi utilizado como medida o número total de questões de cada cenário, ou seja, o Cenário 1 possui um total de 23 alunos $* 15$ questões por teste $=345$ questões, e o Cenário 2 possui um total de 52 alunos $* 15$ questões por teste $=780$ questões.

O gráfico apresentado na Figura 32 ilustra o número de questões respondidas corretamente em cada um dos cenários. É possível notar um melhor aproveitamento dos alunos que participaram da aula prática, quando comparados os números de questões respondidas corretamente nos dois cenários. Os alunos do Cenário 1 acertaram 165 questões no pré-teste e 205 no pós-teste, demonstrando uma evolução de 24\%. Já os alunos do Cenário 2, acertaram 443 questões no pré-teste e 476 no pós-teste, demonstrando um crescimento significativamente menor, de $7 \%$. 


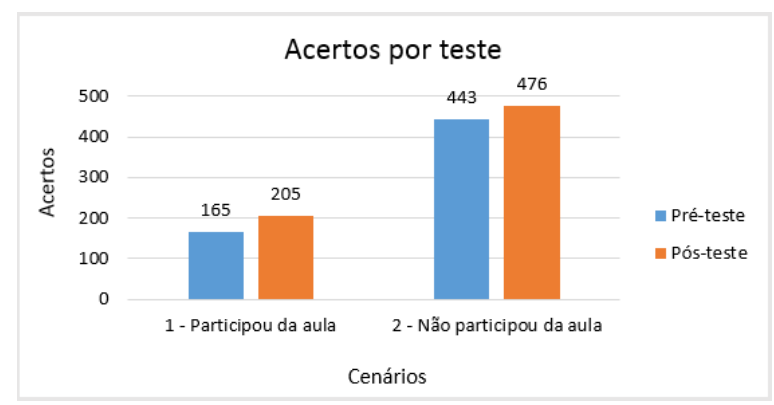

Figura 32 - Acertos por Cenário do Experimento 1

Na Figura 33 pode-se observar, através de gráficos boxplot, uma análise dos dados sob um outro ponto de vista que não o número de acertos totais em cada cenário. No gráfico boxplot é possível observar onde está concentrado $50 \%$ dos valores do conjunto de dados, representados pelas extremidades inferior ( $1^{\circ}$ quartil, ou percentil de $25 \%$ ) e superior ( $3^{\circ}$ quartil, ou percentil de $75 \%$ ), a mediana dos dados (barra central da caixa), os valores mínimo e máximo (os extremos do gráfico) e, caso existam, os outliers.

Assim, a Figura 33a ilustra a evolução do conhecimento obtido no Cenário 1, onde se observa que a mediana no pós-teste foi maior do que no pré-teste, além de uma distribuição maior da quantidade de acertos por aluno no pós-teste, eliminando inclusive o outlier presente no pré-teste. A Figura 33b mostra a evolução do conhecimento obtido pelos alunos no Cenário 2 e se pode observar que a mediana do pré-teste foi quase a mesma que a obtida no pós-teste e os valores ficaram mais concentrados perto da mediana.
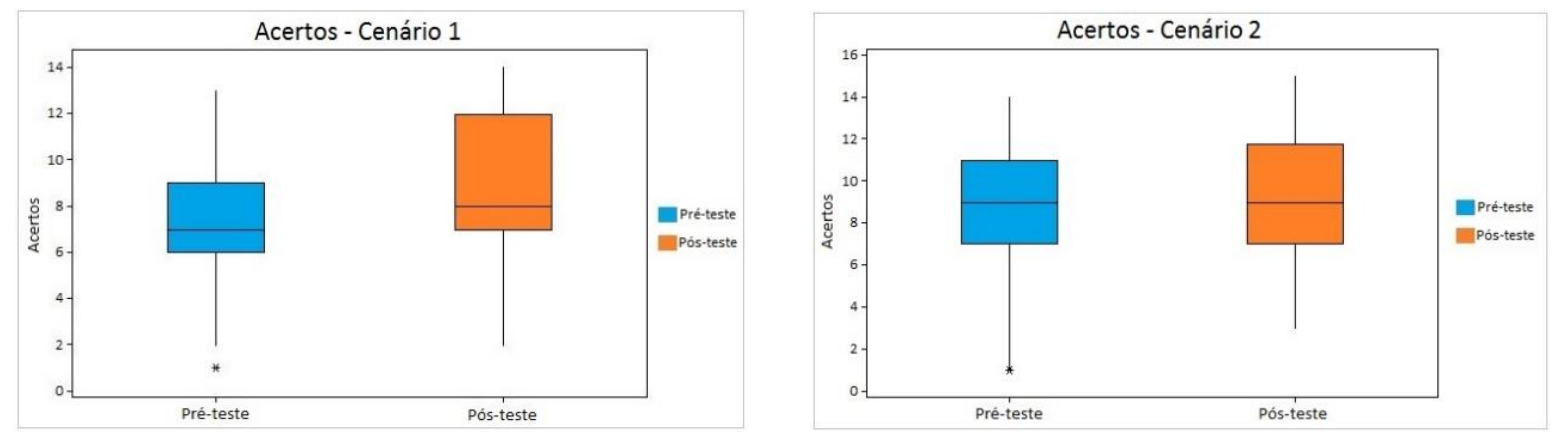

Figura 33 - a) Acertos no Cenário 1 do Experimento 1 - b) Acertos no Cenário 2 do Experimento 1

Desta forma, comprova-se que a utilização do objeto de aprendizagem, neste experimento, influenciou positivamente na sedimentação do conhecimento obtido pelos alunos.

Com o objetivo de embasar estatisticamente o resulto obtido, também foi calculada a diferença entre as notas dos alunos no pré-teste e pós-teste a fim de observar se eles seguiram uma distribuição normal. $\mathrm{O}$ teste de normalidade foi realizado de forma a embasar a escolha do melhor método estatístico para que o pré-teste e o pós-teste pudessem ser comparados e para que fosse possível provar a influência do objeto no processo de aprendizagem.

O teste de normalidade utilizado foi o teste de Shapiro Wilk (Shapiro, 1965). Para o Cenário 1, concluiu-se que as diferenças não seguiam uma distribuição normal $(\mathrm{p}=0.01613)$ e para o Cenário 2 as diferenças seguiram uma distribuição normal $(\mathrm{p}=0.1595)$.

Como o Cenário 1 não seguiu uma distribuição normal, o teste não-paramétrico de Friedman (Friedman, 1937) foi utilizado para mostrar a diferença entre os dois grupos: pré-teste e pós-teste. Este 
teste compara os métodos de avaliação, considerando amostras dependentes, e neste caso, as amostras dependentes foram os resultados obtidos no pré-teste e pós-teste.

O resultado obtido no Cenário 1 foi um valor-p igual a 0.001063 , levando a uma rejeição na igualdade entre os grupos. Como os acertos do pós-teste foram maiores que os obtidos no pré-teste, pode-se afirmar que a utilização do objeto de aprendizagem melhorou o desempenho do aluno.

Aplicando o teste de Friedman para o Cenário 2, obteve-se um valor-p igual a 0.1011, conduzindo a um valor que não rejeita a igualdade dos grupos. Em outras palavras, os grupos foram estatisticamente iguais, confirmando que o desempenho dos alunos no pós-teste foi semelhante ao obtido no pré-teste.

Outra análise realizada com os dados obtidos no experimento com os alunos da graduação pode ser observada nas Figuras 34 e 35, as quais mostram o número de acertos por assunto nos Cenários 1 e 2 , respectivamente. Para a maioria dos assuntos pode-se notar uma evolução no conhecimento dos alunos do Cenário 1, exceto para funções de mapeamento e políticas de substituição. Quando comparados estes dados com os do Cenário 2, observa-se que dentre os assuntos que apresentaram queda de desempenho, também estão presentes funções de mapeamento e políticas de substituição. Esta informação é importante para que a queda do desempenho nestes assuntos não seja relacionada com a utilização do objeto de aprendizagem. No entanto, ao investigar os possíveis fatores que justificariam essa queda, observou-se que, durante os exercícios realizados neste experimento, faltou dar uma ênfase maior nestes assuntos.

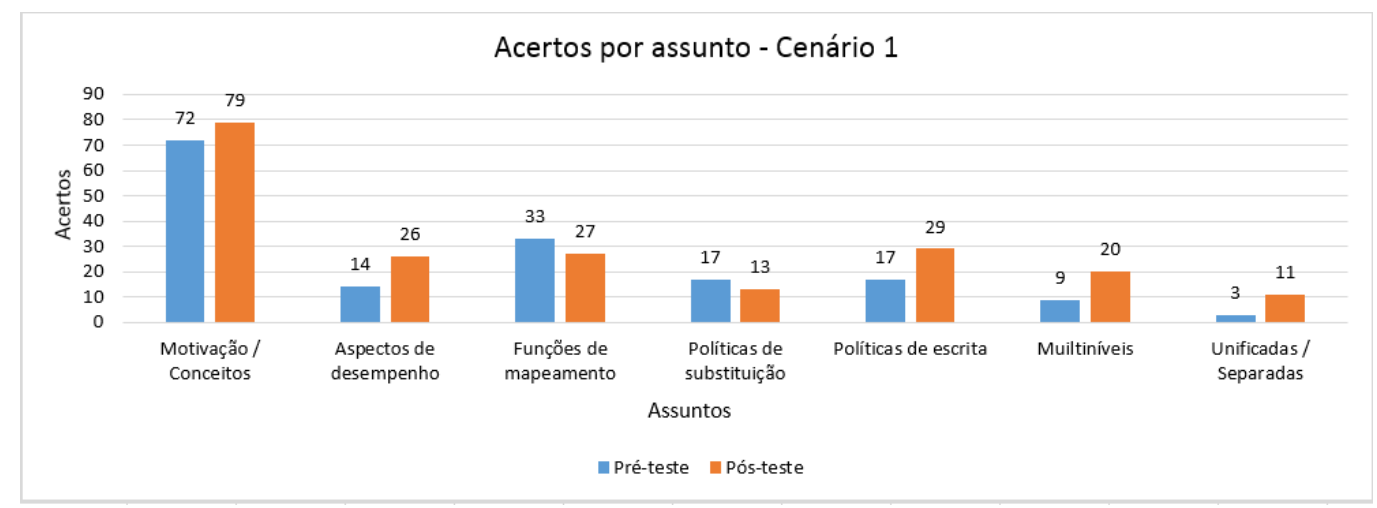

Figura 34 - Acertos por assunto no Cenário 1 do Experimento 1

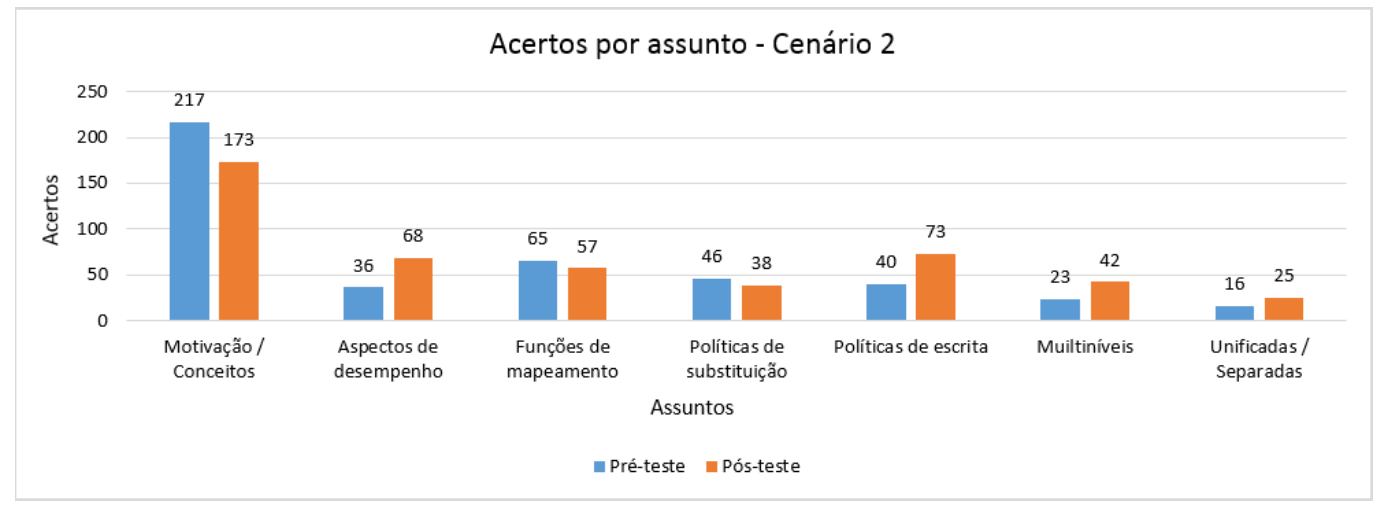

Figura 35 - Acertos por assunto no Cenário 2 do Experimento 1

Ainda comparando os Cenários 1 e 2 a partir das Figuras 34 e 35, observa-se que os alunos que utilizaram o objeto de aprendizagem evoluíram consideravelmente no desempenho das questões referentes à motivação/conceitos, caches multiníveis e unificadas/separadas. Como os alunos 
participaram da construção do seu próprio conhecimento, notou-se uma maior preocupação quanto ao entendimento dos exercícios e os conceitos neles envolvidos, justificando o melhor desempenho em motivação/conceitos. Em relação aos assuntos sobre caches multiníveis e unificadas/separadas, sabe-se que eles demandam uma arquitetura de memória cache complexa para ser explicada na teoria e a utilização do objeto de aprendizagem facilitou a compreensão dos alunos, devido à simulação prática.

No segundo experimento, o qual envolveu os alunos da pós-graduação, a aplicação do pré-teste, do pós-teste e da aula prática contou com a participação de 15 alunos. Nesta aula prática, direcionou-se uma ênfase maior aos assuntos funções de mapeamento e política de substituição em virtude dos resultados obtidos no primeiro experimento.

Analisando a Figura 36, pode-se notar uma considerável evolução no número de acertos no pósteste. No pré-teste, os alunos acertaram 52 questões e no pós-teste 135, comprovando uma melhoria de $160 \%$. Nota-se também que, no pós-teste, a mediana foi maior do que no pré-teste, além de uma distribuição maior da quantidade de acertos por aluno.
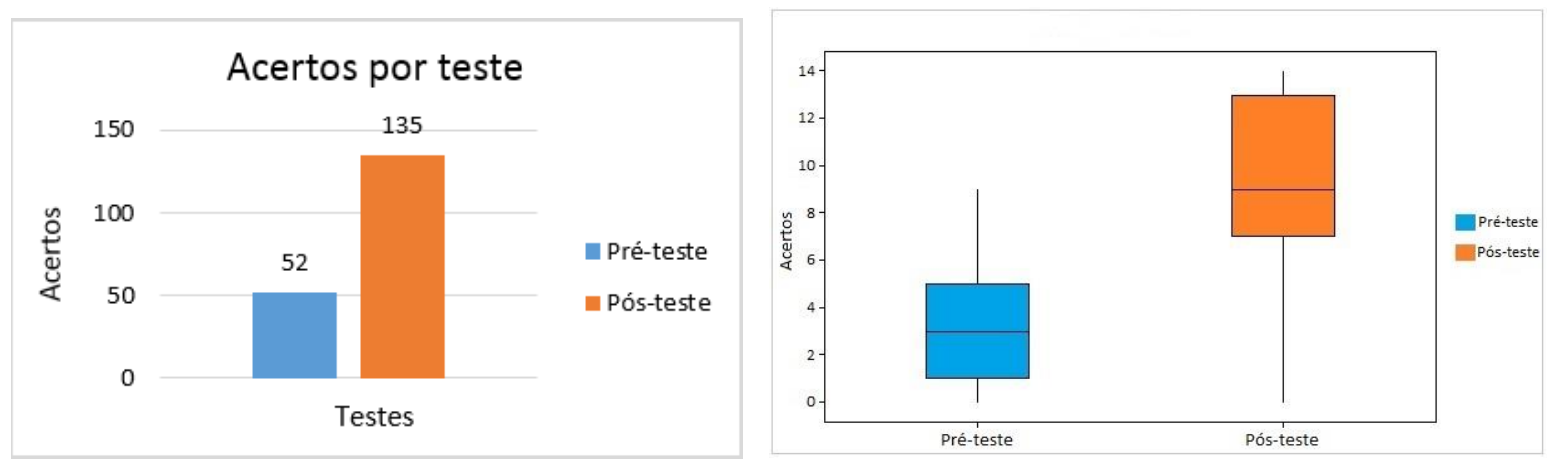

Figura 36 - Acertos no Experimento 2

A Figura 37 mostra o número de acertos por assunto, onde se nota uma evolução no conhecimento em todos os assuntos. Com isso, é possível afirmar que o ajuste realizado entre o Experimento 1 e o Experimento 2, relacionado aos assuntos funções de mapeamento e políticas de substituição, também foi positivo.

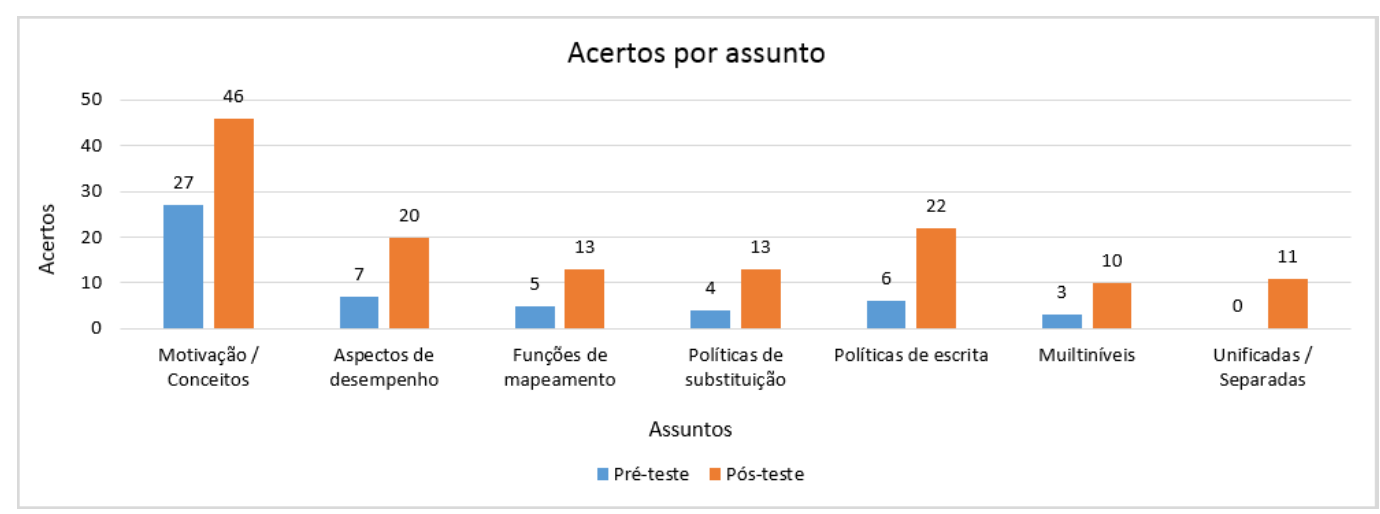

Figura 37 - Acertos por assunto no Experimento 2

Apesar dos alunos participantes deste segundo experimento estarem afastados há algum tempo dos conceitos relacionados à memória cache, o resultado foi extremamente positivo. Observou-se que a aula prática com a utilização do objeto de aprendizagem despertou um maior interesse desses alunos, 
mantendo-os atentos na sequência dos exercícios realizados e proporcionando uma sedimentação maior do conhecimento de cada um, justificando a melhora considerável no aprendizado.

Outro indicador que deve ser ressaltado nos experimentos, foi a instrução fornecida aos alunos antes dos testes para que eles deixassem em branco as questões as quais não sabiam a resposta correta. Com isso, foi possível observar um outro aspecto positivo relacionado aos dois experimentos: o significativo número menor de questões não respondidas no pós-teste pelos alunos que participaram da aula prática.

Analisando a Figura 38, pode-se notar que o número de questões não respondidas pelos alunos do Cenário 1 do Experimento 1 no pré-teste foi 57 enquanto que no pós-teste foi 28, aproximadamente $50 \%$ menos. Os alunos do Experimento 2 não responderam 96 questões no pré-teste e no pós-teste 32 questões, diminuição de 66\%. No entanto, os alunos do Cenário 2 do Experimento 1, que não participaram da aula prática, não responderam 100 questões no pré-teste e 95 no pós-teste, registrando uma diminuição de apenas 5\%. Assim, ressalta-se a importância da aula prática com a utilização do objeto de aprendizagem.

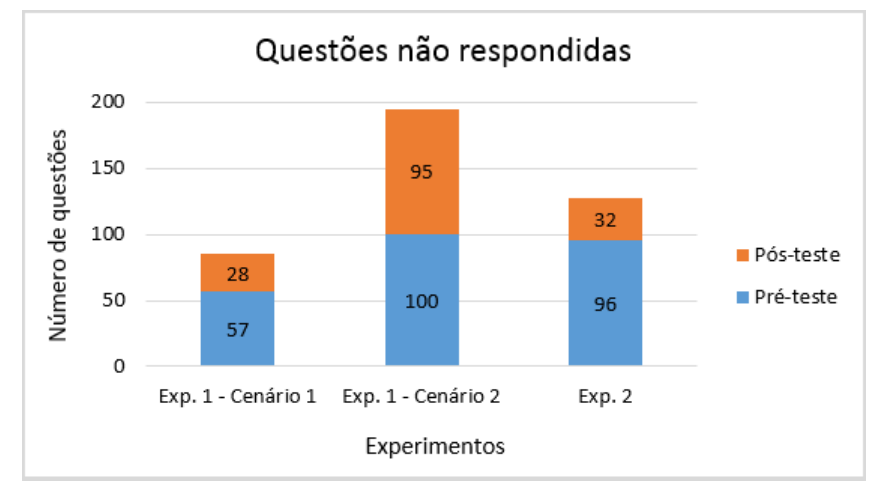

Figura 38 - Número de questões não respondidas

Para enfatizar a relevância de uma aula prática usando um objeto de aprendizagem, foi analisada a relação entre o número de questões que foram deixadas em branco no pré-teste e que foram corretamente respondidas no pós-teste. A Figura 39 mostra essa relação, considerando os dois experimentos realizados e o assunto "Cache Unificada / Separada", pois este assunto possuía apenas uma questão no pré-teste e no pós-teste.

Considerando os 23 participantes no Cenário 1 do Experimento 1, 11 alunos responderam corretamente a questão deste assunto no pós-teste, entre os quais 8 haviam deixado a questão em branco no pré-teste. Para o Cenário 2 do Experimento 1, considerando-se os 52 participantes, 25 alunos responderam corretamente a questão deste assunto no pós-teste, sendo que 13 haviam deixado em branco no pré-teste. Já no Experimento 2, considerando-se 15 participantes, 11 alunos responderam corretamente e 9 deles haviam a deixado em branco no pré-teste.

Em termos percentuais, observa-se que no Cenário 1 do Experimento 1 e no Experimento 2, 73\% e $82 \%$ dos estudantes que estavam envolvidos na aula prática foram capazes de responder corretamente a questão do pós-teste e que foi deixada em branco no pré-teste, respectivamente. Já no Cenário 2 do Experimento 1, esse valor foi de 52\%, ressaltando a importância da aula prática usando o objeto de aprendizagem. 


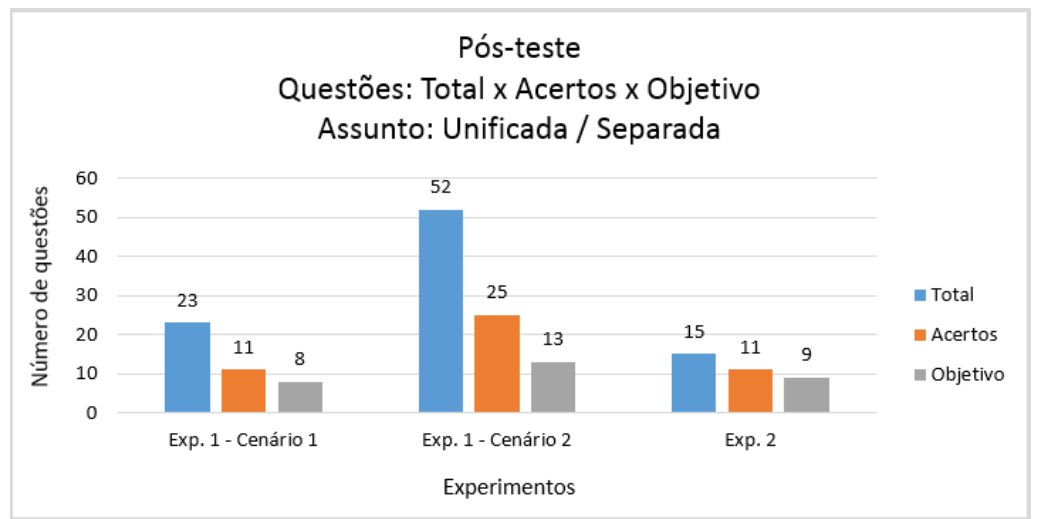

Figura 39 - Número de questões não respondidas no pré-teste e corretamente respondidas no pós-teste (Objetivo) no assunto caches Unificadas / Separadas

\subsection{Avaliação da utilização}

Como já descrito na Seção 5.2 do Capítulo 5, outra preocupação em relação à avaliação do objeto de aprendizagem foi verificar a experiência de utilização deste pelos alunos.

No primeiro experimento, o qual envolveu os alunos da graduação, a avaliação da utilização do objeto contou com a participação de 32 alunos. Já no segundo experimento envolvendo os alunos da pós graduação, a avaliação da utilização do objeto contou com a participação de 14 alunos. Cada aluno respondeu 7 questões referentes à expectativa de uso (Apêndice D) e 15 questões referentes à reação ao uso (Apêndice E) do objeto de aprendizagem.

A Tabela 3 mostra os percentuais relacionados a cada resposta obtida nas questões referentes à expectativa de uso do objeto de aprendizagem no primeiro e no segundo experimentos, exceto a última questão que solicitava uma resposta de forma dissertativa. Já a Tabela 4, mostra os percentuais relacionados a cada resposta obtida nas questões referentes à reação ao uso do objeto de aprendizagem, exceto a última questão que também solicitava uma resposta de forma dissertativa.

Tabela 3 - Tabela com as respostas obtidas nos questionários de expectativa de uso

\begin{tabular}{l|r|r}
\hline 1) O que você acha da ideia de ter a disposição um software ou objeto de aprendizagem em qualquer lugar e hora \\
para poder resolver algum problema ligado a disciplina? \\
\hline Muito Bom & Experimento 1 (\%) & Experimento 2 (\%) \\
Bom & 90,63 & 71,43 \\
Indiferente & 9,37 & 21,42 \\
Ruim & 0 & 0 \\
Péssimo & 0 & 0 \\
Não responderam & 0 & 0 \\
\hline 2) Quanto ao uso do objeto para auxiliar na aprendizagem, pode ser considerada? & 0 \\
\hline \multicolumn{3}{|c|}{ Experimento 1 (\%) } \\
Vai melhorar o seu conhecimento & 93,75 & Experimento 2 (\%) \\
Vai se manter na mesma & 0 & 85,72 \\
Vai saber pouca coisa a mais & 6,25 & 0 \\
Não vai fazer diferença & 0 & 7,14 \\
Não responderam & 0 & 0 \\
& & 7,14
\end{tabular}




\begin{tabular}{|c|c|c|}
\hline & Experimento 1 (\%) & Experimento $2(\%)$ \\
\hline Sim & 53,13 & 42,86 \\
\hline Parcialmente & 31,25 & 35,71 \\
\hline Não & 6,25 & 0 \\
\hline Não se aplica ou não sabe & 9,37 & 14,29 \\
\hline Não responderam & 0 & 7,14 \\
\hline \multicolumn{3}{|c|}{ 4) Na expectativa de uso do objeto, você se sente? } \\
\hline & Experimento 1 (\%) & Experimento $2(\%)$ \\
\hline Temeroso & 0 & 0 \\
\hline Indiferente & 3,12 & 14,28 \\
\hline Motivado & 53,13 & 71,43 \\
\hline Confiante & 43,75 & 7,14 \\
\hline Não responderam & 0 & 7,14 \\
\hline \multicolumn{3}{|c|}{ 5) Na sua opinião, o objeto vai permitir o desenvolvimento de um conteúdo novo? } \\
\hline & Experimento $1(\%)$ & Experimento $2(\%)$ \\
\hline Sim & 34,38 & 42,86 \\
\hline Parcialmente & 43,75 & 21,43 \\
\hline Não & 3,12 & 0 \\
\hline Não se aplica ou não sabe & 18,75 & 28,57 \\
\hline Não responderam & 0 & 7,14 \\
\hline \multicolumn{3}{|c|}{ 6) Na expectativa para o uso do objeto, você pretende usar várias vezes em experiências futuras? } \\
\hline & Experimento $1(\%)$ & Experimento 2(\%) \\
\hline Sim & 50,00 & 21,43 \\
\hline Parcialmente & 37,50 & 14,29 \\
\hline Não & 3,12 & 0 \\
\hline Não se aplica ou não sabe & 9,38 & 57,14 \\
\hline Não responderam & 0 & 7,14 \\
\hline
\end{tabular}

Tabela 4 - Tabela com as respostas obtidas nos questionários de reação ao uso

\begin{tabular}{|c|c|c|}
\hline \multicolumn{3}{|c|}{ 1) O seu conhecimento sobre o conteúdo antes de utilizar o objeto era? } \\
\hline & Experimento $1(\%)$ & Experimento $2(\%)$ \\
\hline Muito bom & 0 & 0 \\
\hline Bom & 35,29 & 0 \\
\hline Regular & 38,24 & 57,14 \\
\hline Ruim & 14,71 & 28,57 \\
\hline Péssimo & 8,82 & 14,28 \\
\hline Não responderam & 2,94 & 0 \\
\hline \multicolumn{3}{|c|}{ 2) O objeto é compreensível e de fácil manuseio? } \\
\hline & Experimento $1(\%)$ & Experimento $2(\%)$ \\
\hline Sim & 79,41 & 64,29 \\
\hline Parcialmente & 20,59 & 35,71 \\
\hline Não & 0 & 0 \\
\hline Não se aplica ou não sabe & 0 & 0 \\
\hline Não responderam & 0 & 0 \\
\hline \multicolumn{3}{|c|}{ 3) Você considera, em relação ao grau de conhecimento adquirido com o uso do objeto, que saiu? } \\
\hline & Experimento $1(\%)$ & Experimento $2(\%)$ \\
\hline Sabendo menos do que antes & 0 & 0 \\
\hline Sabendo a mesma coisa que antes & 11,77 & 0 \\
\hline Sabendo pouca coisa a mais & 58,82 & 7,14 \\
\hline Sabendo muito mais do que antes & 29,41 & 92,86 \\
\hline Não responderam & 0 & 0 \\
\hline \multicolumn{3}{|c|}{ 4) Em relação a motivação de utilizar objetos para auxiliar na aprendizagem ela pode ser considerada? } \\
\hline & Experimento $1(\%)$ & Experimento $2(\%)$ \\
\hline A mesma antes de conhecer o objeto & 14,71 & 7,14 \\
\hline Diminuiu & 0,00 & 0 \\
\hline Aumentou & 73,53 & 78,57 \\
\hline Sofreu momentos de altos e baixos & 8,82 & 14,28 \\
\hline Não responderam & 2,94 & 0 \\
\hline
\end{tabular}




\begin{tabular}{|c|c|c|}
\hline & Experimento $1(\%)$ & Experimento $2(\%)$ \\
\hline Sim & 55,88 & 64,29 \\
\hline Parcialmente & 35,30 & 35,71 \\
\hline Não & 2,94 & 0 \\
\hline Não se aplica ou não sabe & 2,94 & 0 \\
\hline Não responderam & 2,94 & 0 \\
\hline \multicolumn{3}{|c|}{ 6) A aula se tornou mais interessante com o uso do objeto? } \\
\hline & Experimento $1(\%)$ & Experimento $2(\%)$ \\
\hline Sim & 85,30 & 100,00 \\
\hline Parcialmente & 5,88 & 0 \\
\hline Não & 5,88 & 0 \\
\hline Não se aplica ou não sabe & 0 & 0 \\
\hline Não responderam & 2,94 & 0 \\
\hline \multicolumn{3}{|c|}{ 7) A atividade é apropriada e o uso do objeto facilitou a sua compreensão sobre o conteúdo? } \\
\hline & Experimento $1(\%)$ & Experimento $2(\%)$ \\
\hline Sim & 76,47 & 100,00 \\
\hline Parcialmente & 23,53 & 0 \\
\hline Não & 0 & 0 \\
\hline Não se aplica ou não sabe & 0 & 0 \\
\hline Não responderam & 0 & 0 \\
\hline \multicolumn{3}{|c|}{ 8) As respostas de todas as operações realizadas no objeto estavam de acordo com suas expectativas? } \\
\hline & Experimento $1(\%)$ & Experimento $2(\%)$ \\
\hline Sim & 50,00 & 64,29 \\
\hline Parcialmente & 41,18 & 35,71 \\
\hline Não & 8,82 & 0 \\
\hline Não se aplica ou não sabe & 0 & 0 \\
\hline Não responderam & 0 & 0 \\
\hline \multicolumn{3}{|c|}{ 9) Você se sente seguro quanto aos resultados obtidos no objeto? } \\
\hline & Experimento $1(\%)$ & Experimento $2(\%)$ \\
\hline Sim & 88,24 & 71,43 \\
\hline Parcialmente & 5,88 & 28,57 \\
\hline Não & 5,88 & 0 \\
\hline Não se aplica ou não sabe & 0 & 0 \\
\hline Não responderam & 0 & 0 \\
\hline \multicolumn{3}{|c|}{ 10) Quando se deparou com algum erro teve suporte técnico que lhe ajudou a resolver o problema? } \\
\hline & Experimento $1(\%)$ & Experimento $2(\%)$ \\
\hline Sim & 17,65 & 35,71 \\
\hline Parcialmente & 17,65 & 0 \\
\hline Não & 23,53 & 0 \\
\hline Não se aplica ou não sabe & 41,17 & 64,29 \\
\hline Não responderam & 0 & 0 \\
\hline \multicolumn{3}{|c|}{ 11) Está confiante e saberá usar o conhecimento adquirido pelo objeto em uma futura prática? } \\
\hline & Experimento 1 (\%) & Experimento $2(\%)$ \\
\hline Sim & 76,47 & 71,43 \\
\hline Parcialmente & 23,53 & 28,57 \\
\hline Não & 0 & 0 \\
\hline Não se aplica ou não sabe & 0 & 0 \\
\hline Não responderam & 0 & 0 \\
\hline \multicolumn{3}{|c|}{ 12) O uso do objeto aumentou o nível de seu conhecimento? } \\
\hline & Experimento $1(\%)$ & Experimento $2(\%)$ \\
\hline Sim & 61,77 & 92,86 \\
\hline Parcialmente & 32,35 & 7,14 \\
\hline Não & 5,88 & 0 \\
\hline Não se aplica ou não sabe & 0 & 0 \\
\hline Não responderam & 0 & 0 \\
\hline \multicolumn{3}{|c|}{ 13-a) Qual a sua opinião sobre o objeto, quanto a relevância? } \\
\hline & Experimento 1 (\%) & Experimento $2(\%)$ \\
\hline Muito importante & 44,12 & 50,00 \\
\hline Importante & 52,94 & 50,00 \\
\hline Não se aplica & 2,94 & 0 \\
\hline Não responderam & 0 & 0 \\
\hline
\end{tabular}




\begin{tabular}{l|r|r}
\hline 13-b) Qual a sua opinião sobre o objeto, quanto à adequação, sequência? & \\
\hline Boa & Experimento 1 (\%) & Experimento 2 (\%) \\
Regular & 85,29 & 92,86 \\
Ruim & 14,71 & 7,14 \\
Não responderam & 0 & 0 \\
\hline 13-c) Qual a sua opinião sobre o objeto, quanto à compreenão? & 0 & 0 \\
\hline & Experimento 1 (\%) & Experimento 2 (\%) \\
Fácil & 94,12 & 85,72 \\
Difícil & 2,94 & 7,14 \\
Não responderam & 2,94 & 7,14 \\
\hline 14) Você usaria o objeto novamente? & Experimento 1 (\%) & Experimento 2 (\%) \\
\hline & 97,06 & 100,00 \\
Sim & 0 & 0 \\
Parcialmente & 2,94 & 0 \\
Não & 0 & 0 \\
Não se aplica ou não sabe & 0 & 0 \\
Não responderam & & \\
\hline
\end{tabular}

Analisando os dados do primeiro experimento nas Tabelas 3 e 4, observa-se que 37,5\% dos alunos estavam em dúvida com relação a utilizar o objeto futuramente e $38,24 \%$ possuíam um conhecimento regular sobre o conteúdo abordado antes da atividade prática. Após a utilização do objeto, 97,06\% responderam que o utilizariam novamente, $88,24 \%$ sentiram-se seguros quanto aos resultados nele obtidos, $58,82 \%$ declararam saber o conteúdo um pouco mais do que antes e $29,41 \%$ saber muito mais. Aliados a estes dados, $85,30 \%$ dos alunos consideraram que o conteúdo abordado na teoria em sala de aula tornou-se mais interessante com a utilização do objeto de aprendizagem, 76,47\% relataram que o uso do objeto facilitou a sua compreensão sobre o conteúdo teórico e 73,53\% consideraram que a motivação em utilizar outros objetos para auxiliar na aprendizagem aumentou.

$\mathrm{Na}$ análise dos dados das Tabelas 3 e 4 para o segundo experimento, observa-se que 57,14\% possuíam um conhecimento regular sobre o conteúdo abordado antes de utilizar o objeto e 92,86\% declararam saber o conteúdo muito mais após a utilização. Após a utilização do objeto, 71,43\% sentiramse seguros em relação aos resultados por ele apresentados, $100 \%$ declararam que o utilizariam novamente e também que o uso do objeto facilitou a sua compreensão sobre o conteúdo, enquanto que $78,57 \%$ consideraram que a motivação em utilizar outros objetos para auxiliar na aprendizagem aumentou.

Com relação às questões dissertativas inseridas nos questionários de expectativa e reação ao uso do objeto de aprendizagem, ressalta-se: a primeira, inserida no questionário de expectativa, solicitava que o participante descrevesse sua expectativa em relação ao uso do objeto de aprendizagem; a segunda, no questionário de reação, solicitava que o participante descrevesse sua opinião após à utilização do objeto.

Analisando todas as respostas obtidas, pequenos problemas detectados no funcionamento do objeto puderam ser corrigidos e novas implementações foram realizadas para melhorar a experiência do usuário, conforme descrito na Seção 5.3 do Capítulo 5. No entanto, algumas recomendações também originaram novas características que serão tratadas como trabalhos futuros. 


\subsection{Considerações finais}

Um dos principais objetivos do objeto de aprendizagem proposto foi tentar diminuir a distância entre teoria e prática, motivando o aluno a participar ativamente da construção do seu conhecimento. Como o objeto de aprendizagem estimulou a interação dos alunos, foi possível mantê-los inseridos no contexto do aprendizado e participativos na construção do seu próprio conhecimento, despertando uma maior preocupação quanto ao entendimento dos exercícios, bem como dos conceitos envolvidos.

De modo geral, foi possível observar que a simulação prática dos conceitos teóricos relativos à memória cache apresentados em sala de aula, aprimoraram o nível de aprendizagem. Analisando a Tabela 4 que detalha as respostas de reação ao uso do objeto, nota-se que a sua utilização aumentou o nível de conhecimento dos alunos, conforme as respostas da questão 12. Para 61,77\% dos alunos do Experimento 1 e $92,86 \%$ dos alunos do Experimento 2, o uso do objeto de aprendizagem proporcionou um aumento no nível de conhecimento. Além disso, a utilização do objeto influenciou positivamente na motivação em utilizar o próprio objeto novamente, bem como outros objetos para auxiliar na aprendizagem, conforme as respostas das questões 14 e 4, respectivamente.

O considerável interesse em utilizar o objeto de aprendizagem novamente, bem como outros objetos de aprendizagem, ressalta a importância da construção do conhecimento sobre um conteúdo ser obtido de uma forma mais prática. 


\section{Conclusão}

\subsection{Conclusão Geral}

A desmotivação dos alunos que ingressam na Universidade ocorre, entre outros fatores, também pela falta de conexão entre teoria e prática. Visando tornar o aprendizado mais prático e didático, objetos de aprendizagem vêm sendo utilizados para melhorar as formas de aprendizagem nas disciplinas dos cursos de tecnologia.

A utilização de objetos de aprendizagem procura resolver problemas referentes à qualidade de conteúdo, abordagem superficial, ausência de contextualização e a falta de utilização de exemplos. Assim, este projeto de mestrado propôs a análise da ferramenta Amnesia, responsável por simular uma hierarquia de memória, transformando-a em um objeto de aprendizagem para ser utilizado como apoio ao ensino.

Inicialmente, o funcionamento de cada módulo da ferramenta bem como seu funcionamento global foi minunciosamente certificado e, em seguida, analisou-se a sua aplicabilidade como um objeto de aprendizagem visando melhorar a qualidade do ensino de hierarquia de memória, mais especificamente do módulo de memória cache.

Além disso, realizou-se um levantamento bibliográfico com o objetivo de se conhecer alguns simuladores de memória cache com diferentes níveis de complexidade e funcionalidade. Foram comparados com a ferramenta Amnesia os seguintes simuladores: KSH, MSCSim, DCMSim, Dinero IV, CacheSim, LBGCache e SMPCache.

Para a transformação do módulo de memória cache da ferramenta Amnesia em um objeto de aprendizagem, funcionalidades existentes foram readequadas e novas funcionalidades desenvolvidas, testadas e implementadas. Foram concebidos, validados e implementados planos de aula e questionários de avaliação e usabilidade. Um tutorial que descreve o funcionamento do objeto também foi elaborado e metadados, no padrão LOM, foram catalogados com o intuito de melhorar sua visibilidade no repositório de objetos de aprendizagem MERLOT, onde o objeto de aprendizagem foi cadastrado com o objetivo de armazená-lo de forma segura e confiável.

De modo geral, foi possível observar que a simulação dos conceitos teóricos relativos à memória cache apresentados em sala de aula em conjunto com a participação ativa do aluno, aprimoraram o nível de aprendizagem, conforme discutido na avaliação de aprendizagem descrita na Seção 6.3 do Capítulo 6.

Como o objeto de aprendizagem estimulou a interação do aluno, foi possível mantê-lo completamente inserido no contexto do aprendizado e participativo na construção do seu próprio conhecimento, despertando uma maior preocupação quanto ao entendimento dos exercícios, bem como os conceitos envolvidos. Essa conclusão justifica-se pela melhoria do conhecimento em $24 \%$ dos alunos do Experimento 1 que utilizaram o Amnesia, em relação aos 7\% dos alunos que não o utilizaram, e também pela considerável melhoria no conhecimento de $160 \%$ apresentada pelos alunos do Experimento 2.

Além disso, a partir da avaliação do uso do objeto de aprendizagem, descrita na Seção 6.4 do Capítulo 6, pode-se perceber que a motivação dos alunos em utilizar o próprio objeto novamente, bem 
como outros objetos para auxiliar na aprendizagem aumentou, ressaltando a importância da construção do conhecimento sobre um conteúdo ser construído de forma prática.

É importante ressaltar que o objeto de aprendizagem desenvolvido não substitui o professor. Muito pelo contrário, ele foi utilizado como um apoio à aprendizagem visando tornar a participação do aluno mais efetiva na disciplina.

\subsection{Contribuições}

A principal contribuição deste projeto de mestrado foi o desenvolvimento de um objeto de aprendizagem para apoio no ensino de hierarquia de memória e sua implantação na disciplina Organização de Computadores Digitais I (SSC0112) do ICMC/USP, despertando maior interesse dos alunos e proporcionando melhorias no processo de aprendizagem.

O processo de transformação da ferramenta Amnesia em um objeto de aprendizagem, permitiu a difusão dos conceitos de objeto de aprendizagem para o grupo do LASDPC do ICMC/USP. Tutoriais e planos de aulas foram desenvolvidos com o objetivo de facilitar a compreensão do objeto e abordar na prática toda a teoria vista em sala de aula.

Assim, novos projetos vêm sendo desenvolvidos utilizando objetos de aprendizagem, como por exemplo, o projeto de mestrado do aluno de mestrado Carlos Emilio de Andrade Cacho intitulado "Aplicando objetos de aprendizagem para melhorar a qualidade do ensino de memória virtual", sob orientação do Prof. Paulo Sérgio Lopes de Souza (Cacho, 2014).

\subsection{Produção Cientifica}

Este projeto de mestrado permitiu a produção do artigo "Amnesia: um Objeto de Aprendizagem para o Ensino de Hierarquia de Memória" que foi publicado no $25^{\circ}$ Simpósio Brasileiro de Informática na Educação (SBIE 2014).

TIOSSO, F. ; BRUSCHI, S. M. ; SOUZA, P. S. L. ; BARBOSA, E. F. . Amnesia: um Objeto de Aprendizagem para o Ensino de Hierarquia de Memória. Anais do $25^{\circ}$ Simpósio Brasileiro de Informática na Educação, 2014, Dourados, Mato Grosso do Sul, Brasil.

Outra submissão foi realizada para o Frontiers in Education 2015 (FIE). No entanto, as comunicações sobre o aceite ainda não foram divulgadas.

\subsection{Trabalhos Futuros}

Apesar das contribuições deste projeto de mestrado serem significativas, novos estudos serão realizados com o objetivo de melhorar e aperfeiçoar os métodos de avaliação, de utilização do objeto de aprendizagem no apoio ao ensino e sua transformação em um Recurso Educacional Aberto.

Assim, ressalta-se a pesquisa que vem sendo desenvolvida para transformar o módulo de memória virtual da ferramenta Amnesia em um objeto de aprendizagem, através do projeto de mestrado intitulado "Aplicando objetos de aprendizagem para melhorar a qualidade do ensino de memória virtual" de autoria do aluno de mestrado Carlos Emilio de Andrade Cacho, sob orientação do Prof. Paulo Sérgio Lopes de Souza (Cacho, 2014). 
Além disso, o módulo processador e o conversor de código binário para código Assembly MIPS também poderão ser transformados em objetos de aprendizagem. Por fim, todos os módulos formarão o objeto de aprendizagem Amnesia.

Durante a transformação do módulo processador em um objeto de aprendizagem, será possível avaliar o esforço necessário para inclusão de processadores multinúcleos que possibilitará acessos paralelos na hierarquia de memória.

No objeto de aprendizagem Amnesia ainda não é possível mensurar o quanto uma atividade agregou no conhecimento individual do usuário, pois exercícios são desenvolvidos para reforçar e sedimentar o conhecimento como um todo.

Desta forma, identificou-se a possibilidade de uma nova pesquisa utilizando o objeto de aprendizagem Amnesia: sua adaptação para cada usuário que o utiliza, transformando-o em um Sistema Tutor Inteligente (STI).

Através da inclusão de Sistemas Multiagentes (SMA) e da análise de diferentes necessidades e estilos de aprendizagem dos usuários, o conhecimento obtido será mensurado pelo objeto de aprendizagem em cada atividade realizada, transformando-o em um objeto inteligente de aprendizagem.

Assim, o objeto proporcionará novos conhecimentos através de novas atividades ou permitirá que o conhecimento adquirido seja reforçado através de atividades que se preocupem com alguma deficiência apresentada no processo de aprendizagem do usuário. 


\section{Referências bibliográficas}

(ADL, 2015) SCORM. Disponível em <http://www.adlnet.org/>. Acesso em 20 de fevereiro de 2015.

(Almeida, 2010) Almeida, R. R. Elaboração de um catálogo de objetos de aprendizagem digitais para o ensino do sistema digestório com ênfase no seu potencial como ferramenta de ensino e aprendizagem. 2010. 86f. Dissertação (Mestrado em Ensino de Ciências e Matemática) - Pontifícia Universidade Católica de Minas Gerais, Minas Gerais. 2010.

(Barker, 2005) Barker, P. What is IEEE Learning Object Metadata / IMS Learning Resource Metadata? Centre For Educational Technology Interoperability Standards (CETIS), p.1-5, 2005.

(Baker, 2006) Baker, K. D. Learning objects and process interoperability. International Journal on ELearning, v.5, p.167-172, 2006.

(Battistella, 2009) Battistella, P. E.; Neto, A. C. R.; Campos, R. L. R.; Inácio, A. S.; Junior, D. I. R.; Silveira, R. A.; Wangenheim, A. V. Classificação de Objetos de Aprendizagem e análise de Ferramentas de Autoria. Anais do XX Simpósio Brasileiro de Informática na Educação, 2009.

(BRASSCOM, 2015) Procuram-se profissionais de TI. Disponível em: $<$ http://www.brasscom.org.br/brasscom/Portugues/detNoticia.php?codArea=2\&codCategoria=26\&cod Noticia $=400>$. Acesso em 23 de fevereiro de 2015.

(Cacho, 2014) Cacho, C. E. A. Aplicando objetos de aprendizagem para melhorar a qualidade do ensino de memória virtual. Monografia apresentada ao Instituto de Ciências Matemáticas e de Computação - ICMC-USP para o Exame de Qualificação, 2014.

(Campos e Rocha, 1993) Campos, G. H. B; Rocha, A. R. C. Avaliação da Qualidade de Software Educacional. v. 12, n. 57, p. 32-45, Brasília, 1993.

(Churchill, 2007) Churchill, D. Toward a userful classification of learning objects. Educational Technology Research and Development. v. 55, n. 5, p. 479-497, 2007.

(Colom, 2004) Colom, A.J. A (des)construção do conhecimento pedagógico: novas perspectivas para a educação. Porto Alegre: Artmed, 2004.

(Cordeiro et al, 2003) Cordeiro, E.S.; Stefani, I.G.A.; Soares, T.C.A.P.; Martins, C.A.P.S. DCMSim: Didatic Cache Memory Simulator. IEEE Computer Society, v.2, p. F1C 14-19, 2003.

(Coutinho, 2006) Coutinho, L. M. MSCSim - Multilevel and Split Cache Simulator. 36th Annual Frontiers in Education Conference, p. 7-12, San Diego, 2006.

(Dutra e Tarouco, 2006) Dutra, R.L.S.; Tarouco, L.M.R. Objetos de Aprendizagem: Uma comparação entre SCORM e IMS Learning Desing. CINTED (Centro Interdisciplinar de Novas Tecnologias da Educação), v. 4, n. 1, 2006.

(Fabre et al, 2013) Fabre, M.J.M.; Tarouco, L.M.R.; Tamusiunas F.R. SCORM. Disponível em <http://www.cinted.ufrgs.br/files/tutoriais/scorm/scorm.htm>. Acesso em 05 de janeiro de 2014. 
(Filatro e Piconez, 2008) Filatro, A.; Piconez, S.C.B. Contribuições do learning design para o design instrucional. Faculdade da Educação, 2008.

(Friedman, 1937) Friedman, M. The use of ranks to avoid the assumption of normality implicit in the analysis of variance. In: Journal of the American Statistical Association (American Statistical Association), p. 675-701, 1937.

(Friesen, 2005) Friesen, N. Interoperability and Learning Objects: An overview of e-learning Standardization. In: Interdisciplinarity Journal of Knowledge and Learning Objects, v. 1, p. 23-31, 2005.

(Gama e Scheer, 2007) Gama, C.L.G.; Scheer, S. Contribuições a um modelo de requisitos para objetos educacionais: Características e Critérios de construção e avaliação. In: Anais do XXXV Congresso Brasileiro de Educação Em Engenharia (COBENGE), 2007, Curitiba.

(Gama, 2007) Gama, C.L.G. Método de construção de objetos de aprendizagem com aplicação em métodos numéricos. Tese (Doutorado em Métodos Numéricos em Engenharia) - Universidade Federal do Paraná, Curitiba, 2007.

(Hill, 2015) Hill, M. Dinero - cache simulator, version III. Disponível em <http://www.ece.cmu.edu/ ece548/tools/dinero/man/dinero.htm>. Acesso em 02 de fevereiro de 2015.

(IMS, 2003) IMS Learning Design Information Model, Version 1.0 Final Specification. Copyright 2003 IMS Global Learning Consortium, Inc. Disponível em <http://www.imsglobal.org/learningdesign/ldv1p0/imsld_infov1p0.html>. Acesso em 01 de fevereiro de 2013.

(Johnson, 2003) Johnson, L.F. Elusive Vison: Challenges Impeding the Learning Objects Economy. Disponível em: <http://www.nmc.org/pdf/Elusive_Vision.pdf>. Acesso em 15 de dezembro de 2012.

(Koper e Manderveld, 2004) Koper, R., Manderveld, J. Educational modelling language: modelling reusable, interoperable, rich and personalized units of learning. In: British Journal of Educational Technology, p. 537-551, 2004.

(Koper, 2005) Koper, R. Current Research in Learning Design. In: International Forum of Educational Technology \& Society (IFETS), v.9, p. 13-22, 2005.

(Koren, 2015) Koren, I. Multitask Cache Simulator. Disponível em <http://www.ecs.umass.edu/ece/koren/architecture/CacheTr/cacheSim.html>. Acesso em 12 de janeiro de 2015.

(Longmire, 2000) Longmire, W., A Primer on Learning Objects. ASTD Learning Circuits, 2000.

(LTSC, 2013) IEEE LTSC. WG12: Learning Object Metadata. Disponível em: <http://standards.ieee.org/findstds/standard/1484.12.1-2002.html>. Acesso em 07 de janeiro de 2015.

(Macedo, 2010) Macedo, C.M.S. Diretrizes para criação de objetos de aprendizagem acessíveis. 2010. Tese (Doutorado em Engenharia e Gestão do Conhecimento) - Universidade Federal de Santa Catarina, Florianópolis, 2010. 
(MacRae, 1992) MacRae, N. John Von Neumann: The Scientific Genius Who Pioneered the Modern Computer, Game Theory, Nuclear Deterrence, and Much More. New York: Pantheon Books, 1992.

(Mano, 1998) Mano, R. Unidade Central de Processamento. Disponível em <http://wwwusers.rdc.puc-rio.br/rmano/comp8ucp.html>. Acesso em 20 de dezembro de 2014.

(Moreira, 2005) Moreira K., P. B. LBGCache V2.0: Simulador Didático para Análise do Comportamento e Funcionamento Estrutural de Memórias Caches. In: Anais do III Congresso de Iniciação Científica do CEFETRN, p. 17-20, Natal, 2005.

(Nascimento, 2007) Nascimento, A.C.A. Objetos de aprendizagem: A distância entre a promessa e a realidade. MEC, SEED, p.135-145, Brasília, 2007.

(Nesbit et al, 2004) Nesbit, J.C., Belfer, K., Leacock T.L. LORI 1.5: Learning Object Review Instrument, 2004.

(Netto, 2007) Netto, E. B. W. Ensino de Arquitetura de Computadores para Cursos de Tecnologia com Enfase em Software. In: Anais Workshop sobre Educação em Arquitetura de Computadores (WEAC), Rio Grande do Norte, Natal, 2007.

(Oliveira et al, 2008) Oliveira, B. H.; Santos, J. H.; Souza, P. S. L.; Bruschi, S. M.; Souza, S. R. S., Amnesia: Um simulador de Hierarquia de Memória. In: International Symposium on Computer Architecture And High Performance Computing (SBAC-PAD) / Workshop sobre Educação em Arquitetura de Computadores, 2008, Campo Grande. Anais do III Workshop sobre Educação em Arquitetura de Computadores, p. 13-16, 2008.

(Oliveira et al, 2008b) Oliveira, B.H.; Souza, P.S.L.; Souza, S.R.S. Explorando objetos de aprendizado no ensino de memória cache. ICMC/USP, 2008.

(Patterson e Hennessy, 2010) Patterson, D. A., Hennessy, J. L., Organização e projeto de computadores: a interface hardware/software. Rio de Janeiro: Elsevier, 2010.

(Polsani, 2003) Polsani, P.R. Use and Abuse of Reausable Learning Objects. In: Journal of Digital Information, v.3, n.4, p. 1-10, 2003.

(Prete, 1994) Prete, C. A. Cachesim: A Graphical Software Environment to Support the Teaching of Computer Systems with Cache Memories. In: 7th SEI CSEE Conference on Software Engineering Education, p. 317-327, London, 1994.

(REA, 2015) Recursos Educacionais Abertos. Disponível em <http://www.rea.net.br/site/faq/>. Acesso em 10 de abril de 2015.

(Ribeiro, 2003) Ribeiro, A. S. KSH: Simulador de Memória Cache com Carregamento Dinâmico de Módulos e Execução de Script de Configuração. In: Anais do IV Workshop em Sistemas Computacionais de Alto Desempenho (WSCAD), p. 160-163, São Paulo, 2003.

(Rodrigues, 2012) Rodrigues, J. C. Simuladores de Memória Cache: Um Estudo Comparativo e Sua Aplicabilidade na Educação. In: International Journal of Computer Architecture Education, p. 30$38,2012$. 
(Romero et al, 2009) Romero, R.L.; Andrade, R.; Pietrocola, M. Parâmetros para análise de roteiros de Objetos de Aprendizagem. In: Anais do Simpósio Nacional do Ensino de Física, 18, Vitória, Es, 2009.

(Sá et al, 2007) Sá, E. J. V.; Teixeira, J. S. F.; Fernandes, C. T. Design de Atividades de Aprendizagem que usam Jogos como princípio para Cooperação. In: Anais do XVIII Simpósio Brasileiro de Informática na Educação - SBIE, 2007.

(Santos et al, 2012) Santos, N.S.R.S.; Lima, J.V.; Wives, L.K. Integração de recursos para acesso aos Objetos de Aprendizagem Multimodais. Cinted (Centro Interdisciplinar de Novas Tecnologias da Educação), v. 10, n. 3, 2012.

(Shapiro, 1965) Shapiro, S. W. An Analysis of Variance Test for Normality (Complete Samples). Biometrika, p. 591-611, 1965.

(Singh, 2001) Singh, H. Introduction to Learning Objects. Apresentação realizada em Julho de 2001 no fórum Washington eLearning Forum. Disponível em: http://www.elearningforum.com/meetings/2001/july/Singh.pdf . Acesso em 20 de agosto de 2014.

(Souza et al, 2007) Souza, M.F.C et al. Redes de Petri Coloridas na Produção de Objetos de Aprendizagem. In: Revista Brasileira de Informática na Educação. v. 15, n. 3, p. 39-42, 2007.

(Souza, 2005) Souza, A.C.S. Objetos de aprendizagem colaborativos. Disponível em: <http://www.abed.org.br/congresso2005/por/pdf/024tcc4.pdf >. Acesso em: 05 de fevereiro de 201.

(Stallings, 2009) Stallings, W. Arquitetura e organização de computadores. 8. Ed. São Paulo: Pearson Practice Hall, 2009.

(UNESCO, 2011) UNESCO. Guidelines for Open Educational Resources (OER) in Higher Education. Disponível em: 〈http://www.col.org/PublicationDocuments/Guidelines_OER_HE.pdf >. Acesso em 15 de dezembro de 2014.

(Vega, 2000) Vega, M. A. SMPCache: Simulador de Sistemas de Memoria Caché en Multiprocesadores Simétricos. In: Actas de las Xi Jornadas de Paralelismo, p. 3-8, Granada, 2000.

(Tanenbaum, 2006) Tanenbaum A.S., Structured computer organization, Pearson Practice Hall, 2006.

(Vieira, 1999) Vieira, F.M.S. Avaliação de Software Educativo: reflexões para uma análise criteriosa. EDUTECNET, 1999.

(Wiley, 2000a) Wiley, D. A. Learning object design and sequencing theory. Tese (Doutorado em filosofia) - Brigham Young University, 2000.

(Wiley, 2000b) Wiley, D. A. Connecting Learning Objects to Instructional Design Theory - a definition, a methaphor and a taxonomy. WILEY, D. A. The Instructional Use of Learning Objects. Utah: [s.n.], 2000. 


\section{Apêndice A - Plano de aula utilizado nas aulas práticas}

Importante salientar que para todas as arquiteturas, as configurações dos parâmetros ciclesPerAccessRead, ciclesPerAccessWrite e timeCicle serão constantes conforme a seguir:

\begin{tabular}{|c|c|c|c|}
\hline Memória / Configuração & ciclesPerAccessRead & ciclesPerAccessWrite & timeCicle \\
\hline Cache & 1 & 2 & $\mathbf{1}$ \\
\hline Principal & 1 & 2 & 10 \\
\hline
\end{tabular}

1) Ausência de memória cache entre processador e memória principal.

Motivação: Demonstrar aos alunos que o tempo de acesso aos dados e instruções na memória principal é alto. Introduzir os benefícios obtidos com o uso de uma memória cache.

Objetivo: Destacar o tempo total de execução de uma aplicação (através do seu trace) sem o uso da cache.

Detalhamento: Utilizar um arquivo de arquitetura sem memória cache e executar um arquivo de trace que realiza o carregamento das mesmas instruções na memória por diversas vezes consecutivas (ênfase no princípio da localidade temporal).

Arquitetura: Architecture-01-R-s8-bs1-Cno.xml

Trace: Trace01-R50.txt

Tipo da execução: Direta

Resultados que serão enfatizados:

Acessos: 50

Tempo total: 500

2) Incluir memória cache entre o processador e memória principal.

Motivação: Mostrar aos alunos que o uso de cache pode diminuir os acessos à memória principal e consequentemente o tempo total de execução de um determinado programa.

Objetivo: Reduzir o tempo total de execução de um determinado programa com o uso de uma cache. 
Detalhamento: Utilizar um arquivo de arquitetura com uma memória cache pequena e com nível de associatividade igual a um (mapeamento direto). Executar o arquivo de trace do experimento anterior que realiza o carregamento das mesmas instruções na memória diversas vezes consecutivas (princípio da localidade temporal).

Arquitetura: Architecture-02-R-s8-bs1-C1-tU-mD-s4-bs1-al1-wpWT-raFifo.xml Trace: Trace01-R50.txt

Tipo da execução: Direta

Resultados que serão enfatizados:

\begin{tabular}{|c|c|c|c|c|}
\hline $\begin{array}{c}\text { Memória / } \\
\text { Taxas }\end{array}$ & Acessos & $\begin{array}{c}\text { Total de } \\
\text { acertos }(\text { hits })\end{array}$ & $\begin{array}{c}\text { Total de falhas } \\
(\text { misses })\end{array}$ & $\begin{array}{c}\text { Tempo } \\
\text { total }\end{array}$ \\
\hline Cache & 50 & 46 & 4 & $\mathbf{5 0}$ \\
\hline Principal & 4 & & & $\mathbf{4 0}$ \\
\hline & & & & $\mathbf{9 0}$ \\
\hline
\end{tabular}

Razão: $90 / 500=0,18(18 \%$ do tempo total sem a memória $)$

Variações que podem ser realizadas:

- Inserir mais instruções no arquivo de trace e observar a vantagem da memória cache:

- Executar o arquivo de trace Trace-02-R1000.txt

- Realiza o carregamento das mesmas instruções na memória, só que por 1000 vezes consecutivas;

- Destacar o tempo total, que será menor do que o tempo total do experimento um (próximo da metade) só que para um número bem maior de instruções. Além disso, enfatizar que o tempo total é bem próximo do tempo total da memória cache.

\begin{tabular}{|c|c|c|c|c|}
\hline $\begin{array}{c}\text { Memória / } \\
\text { Taxas }\end{array}$ & Acessos & $\begin{array}{c}\text { Total de acertos } \\
(\text { hits })\end{array}$ & $\begin{array}{c}\text { Total de falhas } \\
(\text { misses })\end{array}$ & $\begin{array}{c}\text { Tempo } \\
\text { total }\end{array}$ \\
\hline Cache & 1000 & 996 & 4 & $\mathbf{1 0 0 0}$ \\
\hline Principal & 4 & & & $\mathbf{4 0}$ \\
\hline & & & & $\mathbf{1 0 4 0}$ \\
\hline
\end{tabular}

Razão: 1040 / 10000: 0,104 (10,4\% do tempo total sem a memória)

3) Algoritmo de mapeamento ou espalhamento - Mapeamento Direto (Associatividade 1).

Motivação: Determinar o local que o bloco da memória principal ocupa na memória cache e como identificar que o bloco procurado pelo processador está ou na memória cache. 
Objetivo: Entender como funciona o algoritmo de mapeamento direto.

Detalhamento: Utilizar um arquivo de arquitetura com uma memória cache pequena e com nível de associatividade igual a um (mapeamento direto) e executar um arquivo de trace pequeno que realiza o carregamento de algumas instruções.

Arquitetura: Architecture-02-R-s8-bs1-C1-tU-mD-s4-bs1-al1-wpWT-raFifo.xml

Trace: Trace03-R.txt

Tipo da execução: Passo a passo

Resultados que serão enfatizados:

\begin{tabular}{|c|c|c|c|c|}
\hline $\begin{array}{c}\text { Memória / } \\
\text { Taxas }\end{array}$ & Acessos & $\begin{array}{c}\text { Total de } \\
\text { acertos }(\text { hits })\end{array}$ & $\begin{array}{c}\text { Total de } \\
\text { falhas } \\
\text { (misses })\end{array}$ & $\begin{array}{c}\text { Tempo } \\
\text { total }\end{array}$ \\
\hline Cache & 10 & 2 & $\mathbf{8}$ & $\mathbf{1 0}$ \\
\hline Principal & 8 & & & $\mathbf{8 0}$ \\
\hline & & & & $\mathbf{9 0}$ \\
\hline
\end{tabular}

- Enfatizar que a concorrência na memória cache é alta para este padrão de acesso, devido à falta de localidade espacial. Assim, a taxa de falhas é elevada, aumentando o tempo total de execução, pois muitos acessos à memória principal são realizados.

Conceitos que serão enfatizados:

- Unidade de transferência de dados entre os níveis da hierarquia de memória é bloco;

- Como é feita a transferência do disco para a memória principal (blocos e palavras que estão dentro do bloco e não blocos ou blocos adjacentes);

- Como é a ordem de leitura dos dados do processador até a memória principal;

- Como identificar se a palavra / bloco procurada pelo processador está ou não na memória cache;

- Taxas de acerto (hit) e falha (miss);

- O número de total de acessos em uma memória cache é a soma dos acertos com as falhas;

- Definições de Tag, Set (conjunto), Word-OffSet (Identificador da palavra) e Byte-Offset e número de bits reservados para cada um;

4) Princípio da localidade espacial.

Motivação: Diminuir a taxa de falhas e tempo total de execução de um programa / trace.

Objetivo: Compreender o princípio da localidade espacial para diminuir a taxa de falhas e tentar reduzir o tempo total de execução do trace. 
Detalhamento: Utilizar um arquivo de arquitetura com uma memória cache pequena, com nível de associatividade igual a um (mapeamento direto) e com duas palavras por bloco. Executar um arquivo de trace pequeno que realiza o carregamento de diferentes instruções que devem ser alocadas, em sua grande maioria, no mesmo bloco da memória cache.

Arquitetura: Architecture-03-R-s8-bs2-C1-tU-mD-s4-bs2-al1-wpWT-raFifo.xml Trace: Trace03-R.txt

Tipo da execução: Passo a passo

Resultados que serão enfatizados:

\begin{tabular}{|c|c|c|c|c|}
\hline $\begin{array}{c}\text { Memória / } \\
\text { Taxas }\end{array}$ & Acessos & $\begin{array}{c}\text { Total de } \\
\text { acertos }(\text { hits })\end{array}$ & $\begin{array}{c}\text { Total de falhas } \\
(\text { misses })\end{array}$ & $\begin{array}{c}\text { Tempo } \\
\text { total }\end{array}$ \\
\hline Cache & 10 & 6 & 4 & $\mathbf{1 0}$ \\
\hline Principal & 4 & & & $\mathbf{4 0}$ \\
\hline & & & & $\mathbf{5 0}$ \\
\hline
\end{tabular}

- Enfatizar a queda do número de falhas e o aumento do número de acertos, proporcionando um tempo total de execução menor do que o obtido no experimento anterior (50 em relação à 90$)$.

Conceitos que serão enfatizados:

- Ressaltar que o campo Word-OffSet foi utilizado com um bit para identificar a palavra acessada no bloco;

Variações que podem ser realizadas:

- Alterar o padrão de acessos do arquivo de trace de forma que gere mais conflitos de blocos. Desta forma, mesmo aumentando o número de palavras por bloco ainda haverá alta taxas de falhas devido à substituição motivada pelo tipo de mapeamento direto.

- Executar o arquivo de trace Trace-04-R.txt de forma direta:

- Destacar o tempo total e a taxa de falhas (miss), que serão bem maiores em relação ao experimento anterior.

\begin{tabular}{|c|c|c|c|c|}
\hline $\begin{array}{c}\text { Memória / } \\
\text { Taxas }\end{array}$ & Acessos & $\begin{array}{c}\text { Total de acertos } \\
(\text { hits })\end{array}$ & $\begin{array}{c}\text { Total de falhas } \\
(\text { misses })\end{array}$ & $\begin{array}{c}\text { Tempo } \\
\text { total }\end{array}$ \\
\hline Cache & 30 & 3 & 27 & $\mathbf{3 0}$ \\
\hline Principal & 27 & & & $\mathbf{2 7 0}$ \\
\hline & & & & $\mathbf{3 0 0}$ \\
\hline
\end{tabular}


5) Demonstrar algoritmo de Mapeamento Associativo por Conjunto (Associatividade 2)

Motivação: Diminuir a taxa de falhas e o tempo total de execução do programa através da diminuição dos conflitos de blocos alocados na memória cache.

Objetivo: Compreender que o aumento no grau de associatividade proporciona um posicionamento de blocos mais flexível.

Detalhamento: Utilizar um arquivo de arquitetura com uma memória cache pequena, com nível de associatividade igual a dois (associativa por conjunto) e com uma palavra por bloco. Executar o arquivo de trace do experimento anterior para validar que a concorrência entre os blocos de cache diminui devido ao aumento da associatividade (localidade espacial).

Arquitetura: Architecture-04-R-s8-bs1-C1-tU-mA-s4-bs1-al2-wpWT-raFifo.xml Trace: Trace04-R.txt

Tipo da execução: Direta

Resultados que serão enfatizados:

\begin{tabular}{|c|c|c|c|c|}
\hline $\begin{array}{c}\text { Memória / } \\
\text { Taxas }\end{array}$ & Acessos & $\begin{array}{c}\text { Total de } \\
\text { acertos }(\text { hits })\end{array}$ & $\begin{array}{c}\text { Total de falhas } \\
\text { (misses })\end{array}$ & $\begin{array}{c}\text { Tempo } \\
\text { total }\end{array}$ \\
\hline Cache & 30 & 21 & 9 & $\mathbf{3 0}$ \\
\hline Principal & 9 & & & $\mathbf{9 0}$ \\
\hline & & & & $\mathbf{1 2 0}$ \\
\hline
\end{tabular}

- Enfatizar a diminuição na taxa de falhas e a diminuição do tempo total com o aumento da associatividade.

Variações que podem ser realizadas:

- Alterar o padrão de acessos do arquivo de trace de forma que utilize os blocos de apenas um conjunto da memória cache, por exemplo o conjunto zero.

- Executar o arquivo de trace Trace-05-R.txt de forma direta:

- Destacar o tempo total e a taxa de falhas (miss), que serão bem maiores em relação ao experimento anterior.

\begin{tabular}{|c|c|c|c|c|}
\hline $\begin{array}{c}\text { Memória / } \\
\text { Taxas }\end{array}$ & Acessos & $\begin{array}{c}\text { Total de acertos } \\
(\text { hits })\end{array}$ & $\begin{array}{c}\text { Total de falhas } \\
(\text { misses })\end{array}$ & $\begin{array}{c}\text { Tempo } \\
\text { total }\end{array}$ \\
\hline Cache & 30 & 4 & 26 & $\mathbf{3 0}$ \\
\hline Principal & 26 & & & $\mathbf{2 6 0}$ \\
\hline & & & & $\mathbf{2 9 0}$ \\
\hline
\end{tabular}


6) Demonstrar algoritmo de Mapeamento Associativo por Conjunto (Associatividade 4) - Neste caso totalmente associativo, apenas um conjunto.

Motivação: Diminuir a taxa de falhas e o tempo total de execução do programa através da diminuição dos conflitos de blocos alocados na memória cache.

Objetivo: Compreender que o aumento no grau de associatividade proporciona um posicionamento de blocos mais flexível.

Detalhamento: Utilizar um arquivo de arquitetura com uma memória cache pequena, com nível de associatividade igual a quatro (neste caso totalmente associativa) e com uma palavra por bloco. Executar o arquivo de trace do experimento anterior para validar que a concorrência entre os blocos de cache diminui devido ao aumento da associatividade (localidade espacial).

Arquitetura: Architecture-05-R-s8-bs1-C1-tU-mA-s4-bs1-al4-wpWT-raFifo.xml Trace: Trace05-R.txt

Tipo da execução: Direta

Resultados que serão enfatizados:

\begin{tabular}{|c|c|c|c|c|}
\hline $\begin{array}{c}\text { Memória / } \\
\text { Taxas }\end{array}$ & Acessos & $\begin{array}{c}\text { Total de } \\
\text { acertos }(\text { hits })\end{array}$ & $\begin{array}{c}\text { Total de falhas } \\
(\text { misses })\end{array}$ & $\begin{array}{c}\text { Tempo } \\
\text { total }\end{array}$ \\
\hline Cache & 30 & 26 & 4 & $\mathbf{3 0}$ \\
\hline Principal & 4 & & & $\mathbf{4 0}$ \\
\hline & & & & $\mathbf{7 0}$ \\
\hline
\end{tabular}

- Enfatizar a diminuição na taxa de falhas e a diminuição do tempo total com o aumento da associatividade.

7) Política de substituição.

Motivação: Determinar qual bloco será substituído quando utiliza-se um posicionamento de blocos mais flexível através do mapeamento associativo por conjunto e totalmente associativo.

Objetivo: Compreender como funcionam as políticas de substituição FIFO (First In First Out) e LRU (LeastRecentlyUsed) para algoritmos de mapeamento associativo por conjunto e totalmente associativo. Ressaltar que para mapeamento direto (associatividade um) não é necessária uma política de substituição, pois cada local da memória principal é mapeado diretamente para um local exato na cache. 
Detalhamento: Utilizar um arquivo de arquitetura com uma memória cache pequena, com nível de associatividade igual a dois e com uma palavra por bloco. Executar o arquivo de trace do experimento anterior para validar qual bloco será substituído quando houver concorrência.

Validar o algoritmo FIFO:

Arquitetura: Architecture-06-R-s8-bs1-C1-tU-mA-s4-bs1-al2-wpWT-raFifo.xml Trace: Trace06-R.txt

Tipo da execução: Passo a passo

Resultados que serão enfatizados:

- Enfatizar o conjunto (set) que é selecionado para alocar o novo bloco;

- Enfatizar a última instrução do arquivo de trace "2 4" que irá determinar a substituição do primeiro bloco alocado no conjunto 0 devido à política de substituição FIFO.

Validar o algoritmo LRU:

Arquitetura: Architecture-07-R-s8-bs1-C1-tU-mA-s4-bs1-al2-wpWT-raLRU.xml Trace: Trace06-R.txt

Tipo da execução: Passo a passo

Resultados que serão enfatizados:

- Enfatizar o conjunto (set) que é selecionado para alocar o novo bloco;

- Enfatizar a última instrução do arquivo de trace "2 4" que irá determinar a substituição do bloco menos utilizado no conjunto 0 devido a política de substituição LRU.

8) Escrita de dados.

Objetivo: Compreender como funcionam as rotinas de escrita na memória cache.

Detalhamento: Utilizar um arquivo de arquitetura com uma memória cache pequena, com nível de associatividade igual a dois e com uma palavra por bloco. Executar um arquivo de trace que realiza carregamento de instruções, escrita e leitura de dados.

Arquitetura: Architecture-07-R-s8-bs1-C1-tU-mA-s4-bs1-al2-wpWT-raLRU.xml Trace: Trace07-RW.txt

Tipo da execução: Passo a passo

Resultados que serão enfatizados:

- Para um bloco ser escrito na memória cache, ele deve estar presente nela. Caso não esteja presente, o bloco deve ser carregado do nível inferior através 
de uma leitura. Somente depois desta operação, a escrita poderá ser realizada na memória cache.

9) Política de atualização

Motivação: Após uma escrita na memória cache, esta ficará com um valor diferente da memória principal. Como deve ser tratada esta inconsistência?

Objetivo: Compreender como funcionam as políticas de escrita write-through e writeback que têm a função de manter os dados da memória cache consistentes com os dados da memória principal.

Detalhamento: Utilizar um arquivo de arquitetura com uma memória cache pequena, com nível de associatividade igual a dois e com uma palavra por bloco. Executar um arquivo de trace que realiza carregamento de instruções, escrita e leitura de dados.

Validar a política Write-Through (WT):

Arquitetura: Architecture-07-R-s8-bs1-C1-tU-mA-s4-bs1-al2-wpWT-raLRU.xml

Trace: Trace07-RW.txt

Tipo da execução: Passo a passo

Acessos de escrita na memória principal: 3

Validar a política Write-Back (WB):

Arquitetura: Architecture-08-R-s8-bs1-C1-tU-mA-s4-bs1-al2-wpWB-raLRU.xml

Trace: Trace07-RW.txt

Tipo da execução: Passo a passo

Acessos de escrita na memória principal: 2

Resultados que serão enfatizados:

- Para um bloco ser escrito na memória cache, ele deve estar presente nela. Caso não esteja presente, o bloco deve ser carregado do nível inferior através de uma leitura. Somente depois desta operação, a escrita poderá ser realizada na memória cache.

- Política WT: sempre atualiza a memória cache atual e o nível inferior, mantendo os dados consistentes nos dois níveis;

- Política WB: atualiza a memória cache atual. No entanto, só atualiza o nível inferior quando o bloco atualizado na memória cache atual necessita ser substituído;

- Destacar o número de escritas que são realizadas na memória principal entre uma política e outra. 
10) Caches Multiníveis

Motivação: Mesmo que ocorra uma falha na memória cache, demonstrar que é possível agilizar o tempo total de execução inserindo uma cache rápida próxima ao processador e um outra cache um pouco maior, mas com uma taxa de acerto razoável.

Objetivo: Demonstrar o funcionamento de caches multiníveis e o conceito da penalidade por falta.

\section{Detalhamento:}

1. Utilizar um arquivo de arquitetura com uma memória cache unificada, pequena e com nível de associatividade igual a um (mapeamento direto). Executar um arquivo de trace que realiza o carregamento de instruções estimulando a concorrência por blocos que serão alocados.

a. Ressaltar o conceito da penalidade por falta que é alta, pois em toda falha é necessário trazer um bloco do nível inferior, neste caso a memória principal que tem um tempo de ciclo muito alto quando comparado com o tempo de ciclo da memória cache.

Arquitetura: Architecture-02-R-s8-bs1-C1-tU-mD-s4-bs1-al1-wpWT-raFifo.xml

Trace: Trace-08-1-R.txt

Tipo da execução: Direta

\begin{tabular}{|c|c|c|c|c|}
\hline $\begin{array}{c}\text { Memória / } \\
\text { Taxas }\end{array}$ & Acessos & $\begin{array}{c}\text { Total de } \\
\text { acertos }(\text { hits })\end{array}$ & $\begin{array}{c}\text { Total de } \\
\text { falhas } \\
\text { (misses })\end{array}$ & $\begin{array}{c}\text { Tempo } \\
\text { total }\end{array}$ \\
\hline Cache & 48 & 0 & $\mathbf{4 8}$ & $\mathbf{4 8}$ \\
\hline Principal & 48 & & & $\mathbf{4 8 0}$ \\
\hline & & & & $\mathbf{5 2 8}$ \\
\hline
\end{tabular}

2. Utilizar um arquivo de arquitetura com uma memória cache em dois níveis, pequenas e com níveis de associatividade igual a um (mapeamento direto). Executar um arquivo de trace que realiza o carregamento de instruções estimulando a concorrência por blocos que serão alocados no primeiro nível da memória cache.

a. Ressaltar o conceito da penalidade por falta que é baixa, pois em toda falha é necessário trazer um bloco do nível inferior, neste caso a memória cache de segundo nível que tem um tempo de ciclo muito baixo quando comparado com o tempo de ciclo da memória principal. Mesmo com uma taxa de falhas alta no primeiro nível de cache, tem-se um bom desempenho do programa devido à baixa penalidade por falta. 
Arquitetura: Architecture-09-R-s8-bs1-C1-tU-mD-s2-bs1-al1-wpWB-raFifoC2-tU-mD-s4-bs1-al1-wpWB-raFifo.xml

Trace: Trace-08-2-R.txt

Tipo da execução: Direta

\begin{tabular}{|c|c|c|c|c|}
\hline $\begin{array}{c}\text { Memória / } \\
\text { Taxas }\end{array}$ & Acessos & $\begin{array}{c}\text { Total de } \\
\text { acertos }(\text { hits })\end{array}$ & $\begin{array}{c}\text { Total de } \\
\text { falhas } \\
\text { (misses })\end{array}$ & $\begin{array}{c}\text { Tempo } \\
\text { total }\end{array}$ \\
\hline Cache L1 & 200 & 0 & $\mathbf{2 0 0}$ & $\mathbf{2 0 0}$ \\
\hline Cache L2 & 200 & 196 & 4 & $\mathbf{2 0 0}$ \\
\hline Principal & 4 & & & $\mathbf{4 0}$ \\
\hline & & & & $\mathbf{4 4 0}$ \\
\hline
\end{tabular}

Conceitos que serão enfatizados:

- Penalidade por falta;

- Caches multiníveis não possuem o objetivo de diminuir o número de falhas e sim diminuir a penalidade por falta;

Resultados que serão enfatizados:

Enfatizar que o desempenho do programa / trace aumentou, mesmo com um número de falhas bem maior no segundo experimento.

11) Caches Separadas

Motivação: Demonstrar que é possível eliminar a disputa entre a busca de dados e instruções em uma memória cache.

Objetivo: Demonstrar o funcionamento da cache separada em relação a cache unificada quanto a busca de instruções e dados.

\section{Detalhamento:}

1. Utilizar um arquivo de arquitetura com uma memória cache unificada, pequena e com nível de associatividade igual a um (mapeamento direto). Executar um arquivo de trace que realiza o carregamento de instruções, escrita e leitura de dados, estimulando a concorrência por blocos que serão alocados para instruções e dados.

Arquitetura: Architecture-02-R-s8-bs1-C1-tU-mD-s4-bs1-al1-wpWT-raFifo.xml Trace: Trace09-RW.txt

Tipo da execução: Direta 


\begin{tabular}{|c|c|c|c|c|}
\hline $\begin{array}{c}\text { Memória / } \\
\text { Taxas }\end{array}$ & Acessos & $\begin{array}{c}\text { Total de } \\
\text { acertos }(\text { hits })\end{array}$ & $\begin{array}{c}\text { Total de } \\
\text { falhas } \\
(\text { misses })\end{array}$ & $\begin{array}{c}\text { Tempo } \\
\text { total }\end{array}$ \\
\hline Cache & 6 & 1 & 5 & $\mathbf{7}$ \\
\hline Principal & 6 & & & $\mathbf{7 0}$ \\
\hline & & & & $\mathbf{7 7}$ \\
\hline
\end{tabular}

2. Utilizar um arquivo de arquitetura com uma memória cache separada, pequena e com nível de associatividade igual a um (mapeamento direto). Executar um arquivo de trace que realiza o carregamento de instruções, escrita e leitura de dados, estimulando a concorrência por blocos que serão alocados para instruções e dados

Arquitetura: Architecture-10-R-s8-bs1-C1-tS-mD-s4-bs1-al1-wpWT-raFifo Trace: Trace09-RW.txt

Tipo da execução: Direta

\begin{tabular}{|c|c|c|c|c|}
\hline Memória / Taxas & Acessos & $\begin{array}{c}\text { Total de } \\
\text { acertos (hits) }\end{array}$ & $\begin{array}{c}\text { Total de } \\
\text { falhas } \\
\text { (mis ses })\end{array}$ & $\begin{array}{c}\text { Tempo } \\
\text { total }\end{array}$ \\
\hline Data Cache & 2 & 1 & 1 & $\mathbf{3}$ \\
\hline $\begin{array}{c}\text { Instruction } \\
\text { Cache }\end{array}$ & 4 & 0 & 4 & $\mathbf{4}$ \\
\hline Principal & 6 & & & $\mathbf{7 0}$ \\
\hline & & & & $\mathbf{7 7}$ \\
\hline
\end{tabular}

Resultados que serão enfatizados:

Enfatizar que não existe mais concorrência entre operações de carregamento, escrita / leitura de dados;

Políticas podem ser aplicadas especificamente à uma determinada cache, pois dados e instruções encontram-se separados. 


\section{Apêndice B - Arquivo de arquitetura com configurações de memória cache}

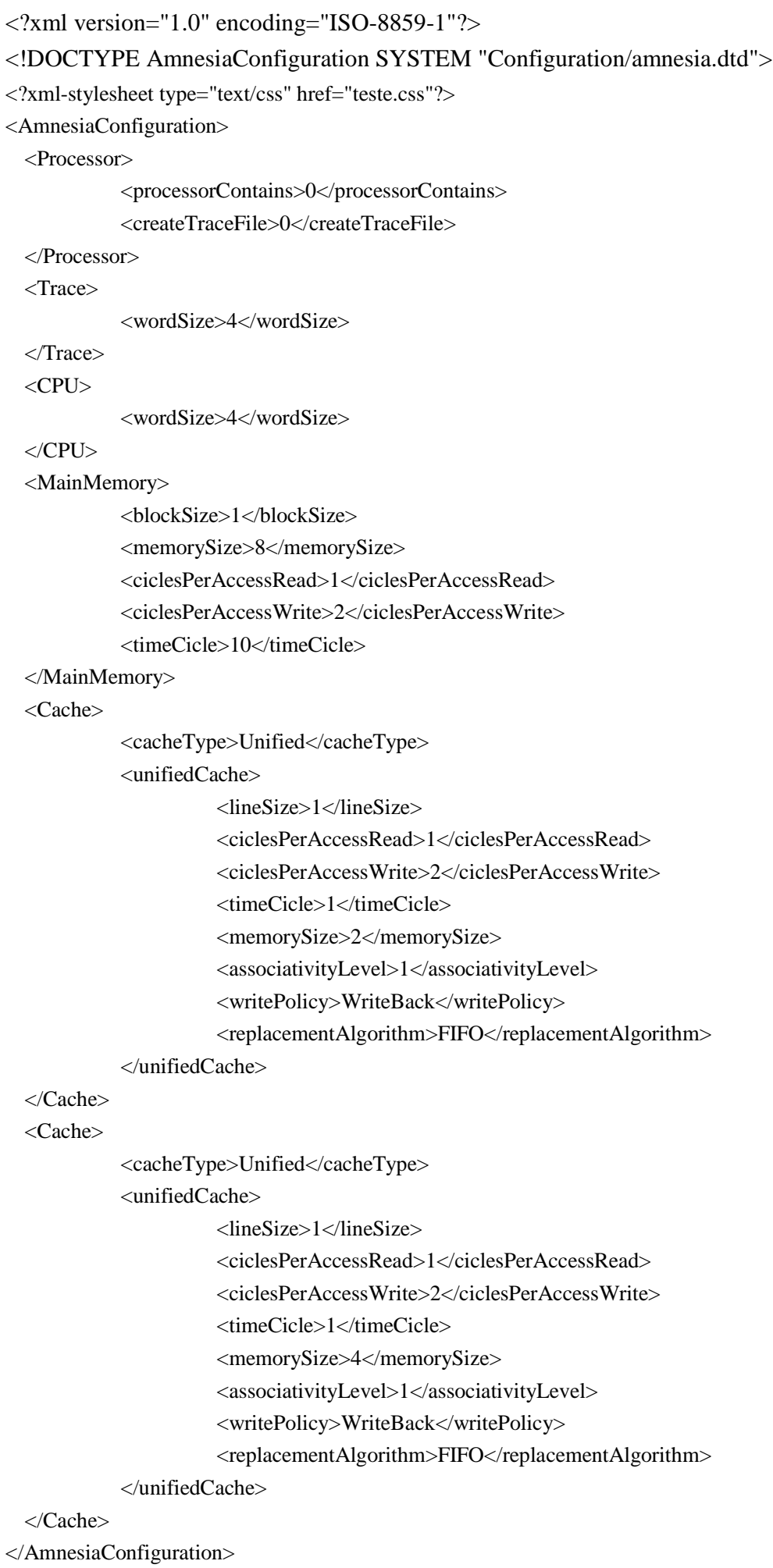




\section{Apêndice C - Programa representado pelo seu arquivo de rastro (trace)}

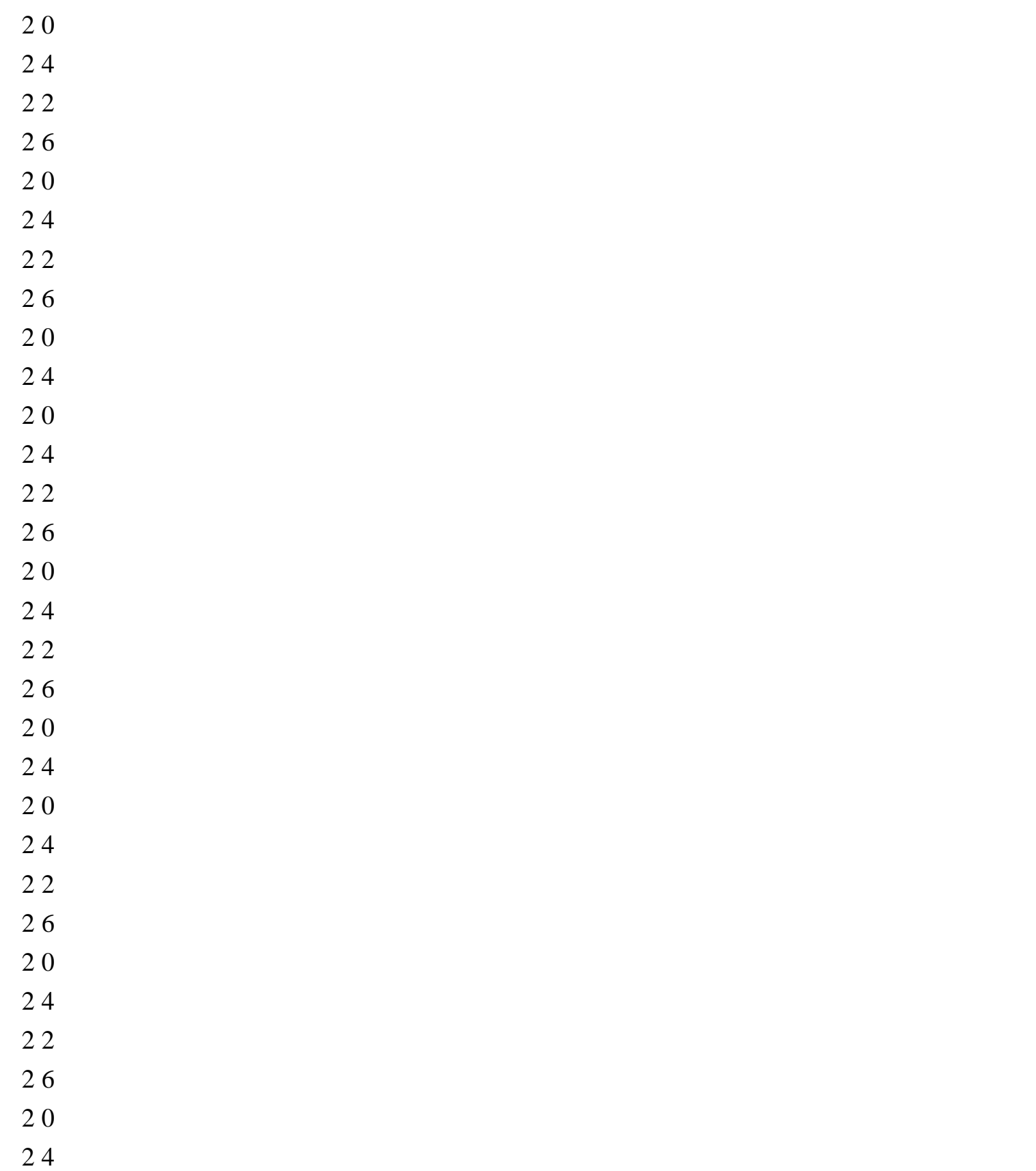




\section{Apêndice D - Questionário de expectativa de uso}

Cod. USP:

1) $\mathrm{O}$ que você acha da ideia de ter a disposição um software ou objeto de aprendizagem em qualquer lugar e hora para poder resolver algum problema ligado a disciplina?

( ) Muito Bom

( ) Bom

( ) Indiferente

( ) Ruim

( ) Péssimo

2) Quanto ao uso do objeto para auxiliar na aprendizagem, pode ser considerada:

( ) Vai melhorar o seu conhecimento

( ) Vai se manter na mesma

( ) Vai saber pouca coisa a mais

( ) Não vai fazer diferença

3) Na sua opinião, o uso deste objeto vai despertar o interesse do usuário sobre o assunto?

( ) Sim ( ) Parcialmente ( ) Não ( ) Não se aplica ou não sabe

4) $\mathrm{Na}$ expectativa de uso do objeto, você se sente:

( ) Temeroso, pois você não se sente à vontade em lidar com objetos de aprendizagem.

( ) Indiferente, para você tanto faz usar ou não um software

( ) Motivado, em poder aprender mais com o uso da tecnologia

( ) Confiante, pois você acredita que o uso vai facilitar a sua aprendizagem

5) Na sua opinião, o objeto vai permitir o desenvolvimento de um conteúdo novo?

( ) Sim ( ) Parcialmente ( ) Não ( ) Não se aplica ou não sabe

6) Na expectativa para o uso do objeto, você pretende usar várias vezes em experiências futuras?

( ) Sim ( ) Parcialmente ( ) Não ( ) Não se aplica ou não sabe

7) Gostaria de fazer algum comentário sobre a expectativa de uso do objeto de aprendizagem? 


\section{Apêndice E - Questionário de reação ao}

USO

Cod. USP:

1) O seu conhecimento sobre o conteúdo antes de utilizar o objeto era:

( ) Muito bom

( ) Bom

( ) Regular

( ) Ruim

( ) Péssimo

2) O objeto é compreensível e de fácil manuseio?

( ) Sim ( ) Parcialmente ( ) Não ( ) Não se aplica

3) Você considera, em relação ao grau de conhecimento adquirido com o uso do objeto, que saiu:

( ) Sabendo menos do que antes

( ) Sabendo a mesma coisa que antes

( ) Sabendo pouca coisa a mais

( ) Sabendo muito mais do que antes

4) Em relação à motivação de utilizar objetos para auxiliar na aprendizagem ela pode ser considerada:

( ) A mesma de quando você não conhecia o objeto (software)

( ) Diminuiu

( ) Aumentou

( ) Sofreu momentos de altos e baixos.

5) Na sua opinião, o uso deste objeto despertou o interesse sobre os conteúdos contidos nele?

( ) Sim ( ) Parcialmente ( ) Não ( ) Não se aplica

6) A aula se tornou mais interessante com o uso do objeto?

( ) Sim ( ) Parcialmente ( ) Não ( ) Não se aplica

7) A atividade é apropriada e o uso do objeto facilitou a sua compreensão sobre o conteúdo?

( ) Sim ( ) Parcialmente ( ) Não ( ) Não se aplica

8) As respostas de todas as operações realizadas no objeto estavam de acordo com suas expectativas?

( ) Sim ( ) Parcialmente ( ) Não ( ) Não se aplica

9) Você se sente seguro quanto aos resultados obtidos no objeto? 
( ) Sim ( ) Parcialmente ( ) Não ( ) Não se aplica

10) Quando se deparou com algum erro teve suporte técnico que lhe ajudou a resolver o problema?

( ) Sim ( ) Parcialmente ( ) Não ( ) Não se aplica

11) Está confiante e saberá usar o conhecimento adquirido pelo objeto em uma futura prática?

( ) Sim ( ) Parcialmente ( ) Não ( ) Não se aplica

12) O uso do objeto aumentou o nível de seu conhecimento?

( ) Sim ( ) Parcialmente ( ) Não ( ) Não se aplica

13) Qual a sua opinião sobre o objeto?

Quanto a relevância: ( ) muito importante ( ) importante ( ) não se aplica

Quanto à adequação: Sequência: ( ) boa ( ) regular ( ) ruim

Compreensão: ( ) fácil ( ) difícil

14) Você usaria o objeto novamente?

( ) Sim ( ) Parcialmente ( ) Não ( ) Não se aplica

15) Gostaria de fazer algum comentário sobre o uso do objeto? 


\title{
Apêndice F - Pré-teste
}

\author{
Instituto de Ciências Matemáticas e de Computação \\ Departamento de Sistemas de Computação
}

N. USP:

1. Por que caches são usadas entre a memória principal e a CPU?

a) Porque caches contêm uma cópia de partes da RAM

b) Porque os acessos às instruções/dados de um programa na memória seguem o princípio de localidade espacial e/ou temporal.

c) Porque cache tem conjuntos e blocos.

d) Porque caches são menores que a RAM.

e) Porque caches podem ter mais níveis para reduzir a penalidade por faltas.

2. No contexto de cache, qual a relação entre os conceitos de conjunto, bloco e palavra?

a) Uma palavra pertence a um conjunto que por sua vez pertence a um bloco

b) Não faz sentido falar desses conceitos sem instanciar onde são inseridos os bytes

c) Um conjunto agrupa diferentes bytes, organizados em blocos de bits que formam palavras intercaladas

d) Um conjunto é formado por blocos que é formado por palavras

e) O número de uma palavra é usado na função de espalhamento para determinar o bloco que receberá os dados na cache

3. A unidade de transferência da memória RAM para a cache é:
a) Bloco
b) Conjunto
c) Nível
d) Palavra
e) Depende da configuração da cache

4. Considerando $x$ a quantidade de acertos na cache, $y$ a quantidade de faltas na cache, então tem-se que:

(I) a taxa de acerto na cache é $x$ / $y$

(II) a taxa de faltas na cache é $y /(x+y)$

(III) a quantidade total de acessos é $(x+y)$
a) (I) e (II) são verdadeiros
b) (I) e (III) são verdadeiros
c) (II) e (III) são verdadeiros
d) Todos são verdadeiros
e) Todos são falsos 
5. Em que momento a função de espalhamento da cache deve ser usada?
a) Quando é necessário trazer uma palavra para a cache
b) Quando é necessário trazer um bloco para a cache
c) Quando é necessário tirar um bloco da cache
d) Quando é necessário tirar uma palavra da cache
e) Quando é necessário trazer e tirar um bloco da cache

6. Os tipos de mapeamentos da memória cache definem sua:
a) Política de substituição
b) Política de leitura e escrita
c) Velocidade
d) Organização
e) Consistência

7. Quando a cache está totalmente ocupada e ocorre uma falta, deve-se:

a) Ir buscar o dado no nível superior e utilizar uma função específica, que depende do tipo de mapeamento, para alocar o novo dado na cache

b) Ir buscar o dado no nível superior e inseri-lo em qualquer lugar da cache

c) Ir buscar o dado no nível inferior e inseri-lo em qualquer lugar da cache

d) Ir buscar o dado no nível inferior e substituir o primeiro bloco da cache

e) Ir buscar o dado no nível inferior e utilizar uma função específica, que depende do tipo de mapeamento, para alocar o novo dado na cache

8. Qual o benefício de se ter um grau de associatividade maior na cache?
a) Potencialmente aumenta-se o número de faltas
b) Potencialmente reduz-se a penalidade por falta
c) Potencialmente reduz-se a latência
d) Aumenta-se o número de blocos para tratamento de colisão
e) Não existe um benefício claro e bem definido

9. Quando caches totalmente associativas são usadas ocorre:
a) A redução do tamanho da cache
b) Uma melhoria no tempo de resposta (redução da latência) da cache
c) Um alto desempenho e baixo custo
d) O aumento da contenção de blocos nos níveis inferiores
e) A substituição de um bloco somente quando ela está totalmente cheia

10. O que ocorre se um bloco tem apenas uma palavra?
a) Não se tem localidade espacial
b) Não se tem localidade temporal
c) Não se tem localidade espacial nem temporal
d) Não tem relação com o princípio de localidade
e) Nenhuma das anteriores 
11. Como determinar se um bloco está presente no conjunto?
a) Verificando campo de LRU e o bit de validade
b) Verificando o campo word-offset
c) Verificando o campo byte-offset
d) Verificando o campo TAG e o bit de validade
e) Todas as anteriores

12. Na essência e obrigatoriamente, o que deve ser considerado quando é necessário tirar um bloco da cache?
a) A frequência com que o bloco foi utilizado
b) A quantidade de vezes que o bloco foi utilizado
c) $O$ bloco que tem menor probabilidade de ser utilizado novamente
d) A política de atualização
e) Nenhuma das anteriores

13. Quando uma escrita é realizada em um bloco na cache, deve-se:
a) Atualizar o bloco no nível inferior imediatamente
b) Atualizar o bloco no nível inferior somente quando ele for retirado do nível onde está alterado
c) Atualizar a memória RAM diretamente para evitar inconsistência
d) As estratégias em (a) e (b) são possíveis
e) Nenhuma das anteriores

14. O objetivo de implementar caches multiníveis é:
a) Diminuir a penalidade por falta
b) Diminuir o número de faltas
c) Aumentar o número de acertos
d) Todas as anteriores
e) Nenhuma das anteriores

15. A implementação de caches divididas (splitted) para instruções e dados é:
a) Normalmente definida no nível mais baixo da hierarquia da cache
b) Normalmente definida no nível mais alto da hierarquia da cache
c) Feita na faixa intermediária da hierarquia da cache
d) Algo que não se deve implementar, pois acarreta vários problemas de gerência sem trazer benefícios práticos
e) Um fator crítico para o uso da pilha e do heap 


\title{
Apêndice G - Pós-teste
}

\author{
Instituto de Ciências Matemáticas e de Computação
}

Departamento de Sistemas de Computação

N. USP:

1. Em relação à memória cache é correto afirmar que:

I. A memória cache contém uma cópia de partes de memória principal. Quando o processador tenta ler uma palavra da memória principal é feita uma verificação para saber se a palavra está ou não na cache. Se estiver, ela é carregada da memória principal e, em seguida, entregue ao processador. Se não, um bloco de memória principal, consistindo em algum número fixo de palavras é lido e fornecido diretamente ao processador.

II. As memórias caches tiram proveito da localidade temporal e espacial.

III. Para atender ao princípio de localidade espacial, ao se ler um bloco de um nível inferior da hierarquia de memória, traz-se também os blocos adjacentes ao lido.
a) (I) e (II) são verdadeiros
b) (I) e (III) são verdadeiros
c) (II) e (III) são verdadeiros
d) Somente a (II) é verdadeira
e) Somente a (I) é verdadeira

2. A informação mínima que deve ser transferida entre dois níveis adjacentes da hierarquia de memória é denominada:
a) Bloco
b) Conjunto
c) Nível
d) Palavra
e) Byte

3. Como o tamanho da memória cache é menor do que o tamanho da memória principal, é necessário haver um algoritmo apto a inserir e posteriormente localizar blocos da memória principal na cache. Qual opção melhor define a função deste algoritmo?
a) Mapeamento ou espalhamento
b) Acesso Direto ou Aleatório
c) Política de substituição
d) Política de atualização
e) Consistência 
4. Em uma memória cache com associatividade de grau 1 e oito conjuntos, quantos bits são utilizados para determinar o conjunto?
a) Oito
b) Quatro
c) Três
d) Sete
e) Nenhum, pois o grau de associatividade é um.

5. Para reduzir as taxas de faltas na cache com um posicionamento de blocos mais flexível, podese:
a) Diminuir o grau de associatividade
b) Aumentar o grau associatividade
c) Diminuir o número de palavras por bloco;
d) Aumentar o número de palavras por bloco;
e) Alterar a política de atualização.

6. Considerando Políticas de Substituição em caches pode-se afirmar que:
a) Elas são aplicadas sobre vários conjuntos;
b) Elas determinam a palavra a ser substituída no bloco;
c) Elas não fazem sentido quando o endereçamento é à palavra e não a byte;
d) Elas determinam quando um conjunto deve ser considerado como inválido;
e) Nenhuma das anteriores.

7. Considerando a divisão em campos do número binário correspondente ao endereço a ser acessado em uma cache, qual campo identifica se o bloco está presente ou não em um determinado conjunto da cache?
a) tag
b) índice
c) word offset
d) byte offset
e) bit de validade

8. Considerando a divisão em campos do número binário correspondente ao endereço a ser acessado em uma cache, qual campo identifica a palavra sendo acessada dentro de um bloco?
a) $\operatorname{tag}$
b) índice
c) word offset
d) byte offset
e) bit de validade 
9. Com relação aos acessos realizados a uma memória cache, é correto afirmar que:

I. Quando o processador encontra a informação na memória cache, não necessitando um acesso a memória principal, ocorre um hit.

II. Quando o processador não encontra a informação na memória cache, ocorre um miss, devendo buscar a informação no nível inferior.

III. O número total de acessos a uma memória cache se dá pela soma dos acertos (hits) e falhas (misses).
a) (I) e (II) são verdadeiros
b) (I) e (III) são verdadeiros
c) (II) e (III) são verdadeiros
d) Todos são verdadeiros
e) Todos são falsos

10. Considerando uma escrita na cache deve-se:

a) Lembrar que a unidade de leitura na cache é bloco; mas a de escrita é palavra;

b) Garantir que a escrita atualize todos os blocos de um conjunto;

c) Garantir que o bloco a ser escrito na cache já esteja presente nela. Caso o bloco não esteja, faz-se necessária uma leitura prévia do bloco nos níveis inferiores da hierarquia de memória, a fim de trazer o mesmo para a cache.

d) Verificar se a estrutura da cache possui um campo determinado "M - Modificado", pois sem ele não se pode atualizar um dado na cache;

e) Garantir que a memória cache seja totalmente associativa, pois sem isso a cache não terá como garantir o funcionamento da função de espalhamento;

11. Após uma escrita na memória cache, a memória principal poderá ter um valor diferente do valor da cache, ou seja, os valores inconsistentes. Para tratar tal inconsistência são utilizadas políticas de atualização/escrita. Considerando a descrição das políticas descritas abaixo em I e II, estas correspondem respectivamente a:

I. Uma escrita sempre atualiza a cache atual e o nível inferior da hierarquia de memória, garantindo que o dado atualizado esteja sempre consistente, em ambos os níveis.

II. Uma escrita atualiza apenas o dado na cache atual e, depois, quando o bloco que contém o dado na cache atual atualizado estiver para ser substituído, o bloco inteiro é atualizado no nível inferior.
a) LRU e write-through
b) write- back e LFU
c) write-back e write-through
d) write-through e FIFO
e) write-through e write-back 
12. Uma vez que o conjunto da memória cache estiver totalmente ocupado, e um novo bloco for mapeado para este conjunto, um dos blocos existentes precisa ser substituído. É correto afirmar que:

a) Para caches associativas por conjunto não é necessário escolher uma política de substituição;

b) Para caches totalmente associativas e associativas por conjunto é necessário escolher uma política de substituição;

c) Para caches com mapeamento direto a política de substituição só pode ser a LRU;

d) Para caches com mapeamento direto, totalmente associativas e associativas por conjunto é necessário escolher uma política de substituição;

e) Caches totalmente associativas com mapeamento direto são exceções e devem ser tratadas da mesma maneira em relação à política de substituição.

13. Como é conhecido o tempo necessário para trazer um bloco do nível inferior da hierarquia de memória e, depois disso, substituir o bloco no nível atual de cache enquanto encaminha ao nível superior o bloco correspondente?
a) Tempo de acerto
b) Latência de memória
c) Tempo de ciclo
d) Penalidade por falta
e) Taxa de falta

14. A estratégia de se ter uma cache pequena e muita rápida junto ao processador e uma outra cache que possui maior capacidade mas não é tão rápida, mas com uma taxa de acerto boa para reduzir o tempo perdido quando houver uma falta na primeira cache, denomina-se:
a) Caches divididas (splitted);
b) Caches agrupadas;
c) Caches associativas;
d) Caches reais;
e) Caches multiníveis.

15. Uma forma de organização muito comum nas caches dos processadores modernos é o uso de memória cache separada para dados e instruções. Dentre as vantagens deste tipo de organização pode-se afirmar que:

a) Ela possui um custo de implementação menor;

b) A política de escrita só precisa ser aplicada à cache de dados;

c) A taxa de faltas fica inalterada;

d) A taxa de acerto diminui;

e) A penalidade por faltas aumenta. 